\title{
A MIGRAÇÃO COMO ESTRATÉGIA ADAPTATIVA EM POPULAÇÕES HUMANAS RURAIS DE NOVO CRUZEIRO, MG PARA PIRACICABA, SP
}

\author{
ana Paula branco do nascimento
}

Dissertação apresentada à Escola Superior de Agricultura "Luiz de Queiroz", Universidade de São Paulo, para obtenção do título de Mestre em Ecologia de Agroecossistemas.

P IR A C I C A B A

Estado de São Paulo - Brasil

Dezembro - 2003 


\section{A MIGRAÇÃO COMO ESTRATÉGIA ADAPTATIVA EM POPULAÇÕES HUMANAS RURAIS DE NOVO CRUZEIRO, MG PARA PIRACICABA, SP.}

\section{ana Paula branco do nascimento}

Bióloga

Orientadora: Profa. Dra. SILVIA MARIA GUERRA MOLINA

Dissertação apresentada à Escola Superior de Agricultura "Luiz de Queiroz", Universidade de São Paulo, para obtenção do título de Mestre em Ecologia de Agroecossistemas.

P I R A C I C A B A

Estado de São Paulo - Brasil

Dezembro - 2003 
Dados Internacionais de Catalogação na Publicação (CIP) DIVISÃO DE BIBLIOTECA E DOCUMENTAÇÃO - ESALQ/ USP

\author{
Nascimento, Ana Paula do \\ A migração como estratégia adaptativa em populações humanas rurais de Novo Cruzeiro, MG \\ para Piracicaba, SP. / Ana Paula do Nascimento. - - Piracicaba, 2004. \\ 89 p. : il. \\ Dissertação (mestrado) - - Escola Superior de Agricultura Luiz de Queiroz, 2003. \\ Bibliografia. \\ 1. Crianças em idade préescolar 2. Desnutrição 3. Ecologia humana 4. Habitação 5. Migração \\ Nutrição da criança 7. Renda familiar I. Título \\ CDD 301.35
}

"Permitida a cópia total ou parcial deste documento, desde que citada a fonte - $\mathrm{O}$ autor" 
Dedico ete trabalho a Deus e ì pessoes mais importantes emminhavida:

a meróxia do meu pai Maralio, por tudb queme ensinou entodos os numentos

a minha nãe Hortenda, por tudb que enfrentau, semprebuscandbo om thor paraseusfilhos

aos neus imãos Patricia eflávio por exstireme serentão espediais 
Migrante, retirante, itinerante

São marcas quefazemumpásmaior

Na ânsia deencontrar o eddorado,

Déxa partedesuavida

E sasdesencontros paratrás.

Norevés deummodło econâmico

Enfrenta merópdes efavdas,

Desorava satões eflorestas,

Sãotantasidas evindas

Na proara deumlugar.

Seu destinoétão incerto

Mesrosemsaber luta comalegia,

Na certezadeumempresp,

Na segurança deumcanto

E nodescanso deu mcaminho.

DeoriceMariaCastanhaLovato 


\section{AGRADECIMENTOS}

À Profa. Dra. Sil via Maria Guera Mdina pda crientação, amizadeeapoio contínuoemtodas as etapes destetrabalho, epdos menetos quefa mais queuma crientadora.

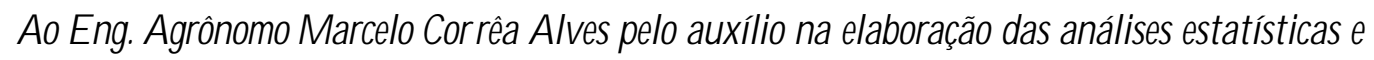
pła disposição emesdarecer mirhes dúvidas comrdação ao program $\mathrm{SAS}$.

À Prớa. Dra Maria Rita Marques deOlivera pda atenção esugestões entodos os numentos emquea prou ré para sanar minhes dúvidas comrelação a avdiação nutricional.

Ao Departamento deGenética pło espaço concedidb durantea realização destetrabalho, conø tambéma todos us coleges do Labortónio de Ecogenética de Rex́duos Agrandustriais eEcologia Humana, emespeid aJ ulia eLígia, por sempreetarempor peto eofereceremauxílio

À Pisgui, amiga quemeincentivau a vir para Piracicaba, pda anizadeeapoio, particilamente nos primerros numetos emquenão conheóanos ninguénaqi emPira.

Aos amigos de tockas as horas Andersão e Raqud por dividirem comigo tocas as alegias e angústias, comererandb au buscandb sduções Vocês deramsentidb espeial a mirha vica

A todbs os amigos da Moradia Estudantil, minha família aqui emPira, pło carinhoeamizade emtodos os merentos de nossa convivênia Emespeja: Rosângda, Katia, Danuska, Márcia, Milena, HerniqueeElia Anrovocês'

As autres amiges que conhej emPira, eque admiro mita. Kathia, Cáudia e Magali que compartilharamperíodos de dostáaul os comotanhémdedescontraçãa. 
À minha imã Pati, a qual tenho mito orgulho eque aléndedenenstrar mito incentivo e carinho emtocha a minha caminhada, cdaborcu coma digtação dos meus dadbs Obrigada!

Às amiges distantes e ao monto tão prestes, Camila, Dani2, Melianee Tiane, exemplo de milheres lindas ebatal hadoras, quemeapaiaramemdiversos momentos

À Angä, Simone, Fabi e Bianca amigessimãs que partilharam sorhos, confidências e

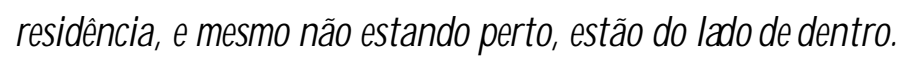

À turma Bidogos sp que apesar de diregões geogáficas dferentes continuama apaiar e denenstrar mito carinho por cada umcla turma. Emespeial a amigaj ú, queorganizau o egups

A tock a mirha fańlia, pdos momentos emque não pudenos passar juntas À minha nãe Hath por todbs os mementos queligue dizendb que estava sofrendb e da me "tranquilizau", como tanbémo carinho eapaio das minhas tias J ad eDiná À Luzia Piffer, minha mãepor qpããa, que mernomito longenunca déxau demeliger qu escrever meincentivando entodos os momentos

À UNI NGÁFaaul dadel ngá, pło incentivo a pósgraduaçãoe pda qparturicadedetrabal har comprofissionais tão competettes conro as Prfas. Intia eShèla, ecomo amigp etérico Fenandb, que me nostrau entodos os mumentos quea realização é consequêndia de trabalho e deedicação, exemplodepessar queara oquefaz.

AoCdégjo São Dimas pda cportunidadedetrabalho, ea todbs os professcres emparticular a J vevice, etambémaos alunos, quemensemsaberemmederamforças para cantinuar.

À CAPES pło apaio financero nos útinos nove res, semo qual este trabalho não teia tanta dkedicação.

Enfim a todosqueeu não terha mencionadb equeetiveramjuntos nessa minha caminhada, o meu mito darigada 


\section{SUMÁRIO}

Página

LISTA DE TABELAS $\quad$............................................................................... vii

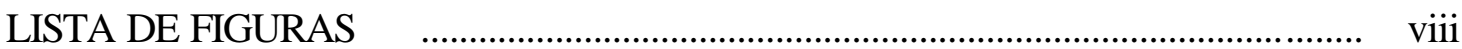

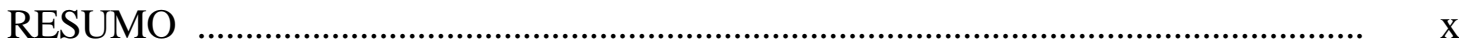

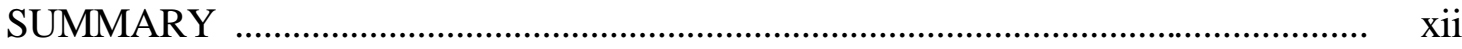

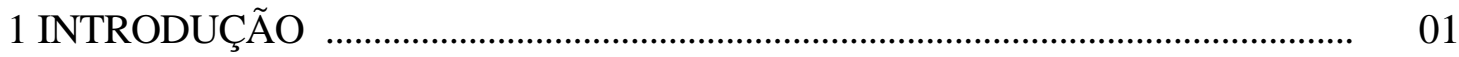

$1.1 \mathrm{O}$ problema e sua importância $\quad$ …................................................................................... 01

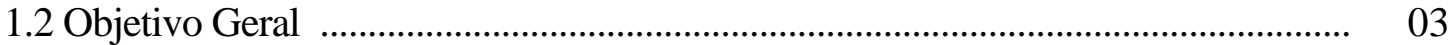

1.3 Objetivos Específicos ......................................................................................... 03

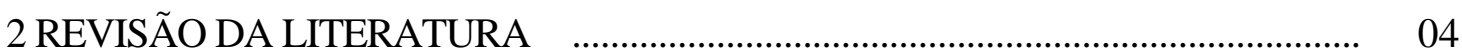

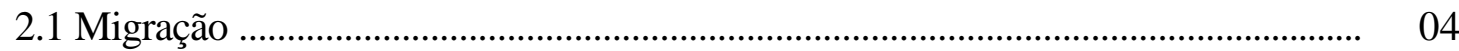

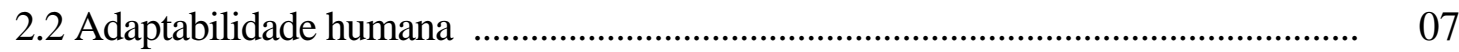

2.3 Desenvolvimento físico de crianças ............................................................................ 11

2.4 Estado nutricional ...................................................................................... 14

2.4.1 Desnutrição e Obesidade ................................................................................. 16

2.5 Quintais Domésticos ............................................................................................. 18

2.6 Antropologia Nutricional ..................................................................................... 21

2.6.1 Antropometria ….................................................................................... 23

2.6.1.1 Índices Antropométricos .................................................................. 25 


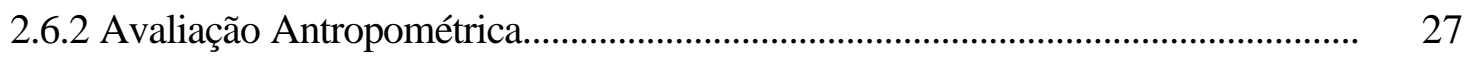

2.7 Breve histórico de Novo Cruzeiro, MG ................................................................... 29

2.8 Breve histórico de Piracicaba, SP …........................................................................ $\quad 30$

3 CASUÍSTICA E MÉTODOS ......................................................................... 34

3.1 Municípios estudados ........................................................................................ 34

3.2 Constituição das amostras ................................................................................... 34

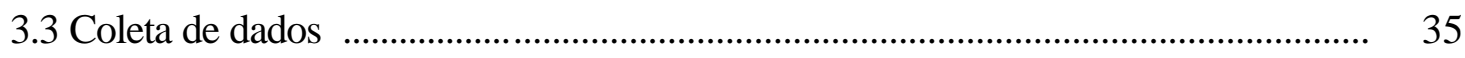

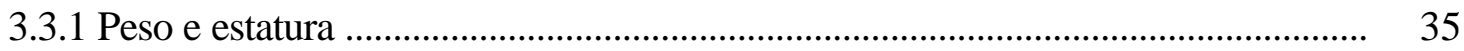

3.4 Relato do cotidiano das crianças nas E.M.E.I. ......................................................... 36

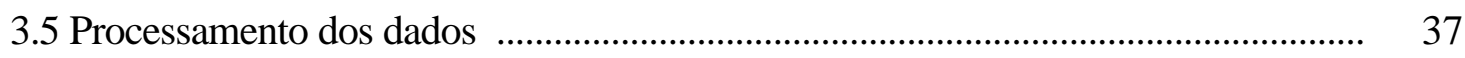

3.5.1 Estratos populacionais .................................................................................. 37

3.5.2 Seleção das variáveis ..................................................................................... 38

3.5.3 Descrição das variáveis estudadas ....................................................................... 39

3.5.3.1 Indicadores do desenvolvimento físico ............................................................. 39

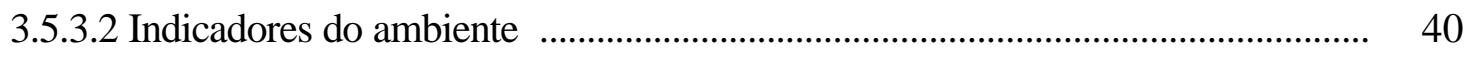

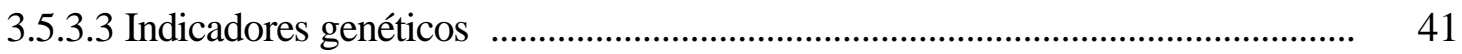

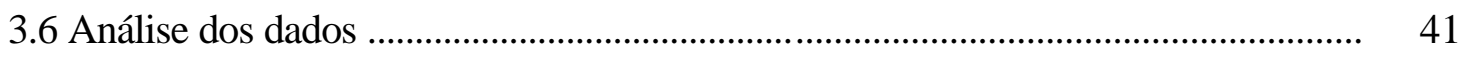

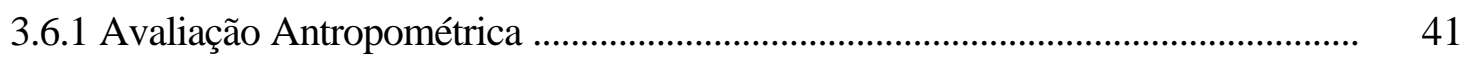

3.6.2 Análise estatística .............................................................................................. 42

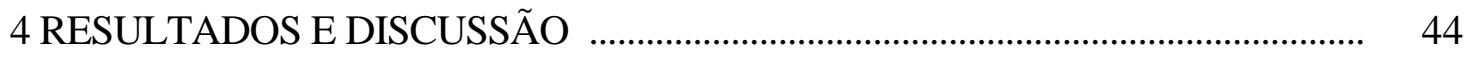

5 CONCLUSÕES............................................................................................ 76

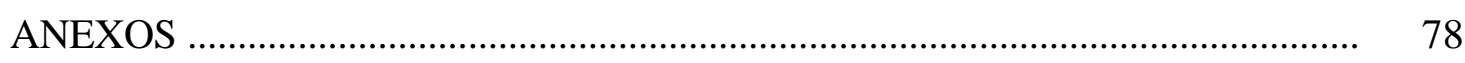

REFERÊNCIAS BIBLIOGRÁFICAS ................................................................. 81 


\section{LISTA DE TABELAS}

Página

1 Estatísticas Descritivas - dados e variáveis referentes à amostra de préescolares.

2 Distribuição dos pré-escolares segundo sexo e estrato populacional.

3 Distribuição dos pré-escolares segundo a origem étnica (cor da pele) em cada estrato

4 Distribuição dos pré-escolares segundo a origem étnica (sobrenome italianos ou não-italianos) e subgrupos

5 Distribuição dos pré-escolares segundo a origem étnica das mães (sobrenome italianos ou não-italianos) e subgrupos.

6 Frequiência de crianças segundo acesso do domicílio à rede de esgoto

7 Distribuição dos pré-escolares segundo a disponibilidade de energia elétrica.

8 Distribuição dos pré-escolares segundo a procedência da água usada para beber na sua residência

9 Freqüência de pré-escolares segundo o material de construção da moradia.............

10 Relação número de cômodo por morador nos cinco grupos de famílias estudados. 
11 Idade das mães ao nascimento das crianças pré- escolares.

12 Distribuição dos pré-escolares segundo os níveis de escolaridade materna (anos 56 de estudo)

13 Distribuição dos pré-escolares segundo a renda per capita mensal familiar

14 Distribuição dos pré-escolares segundo a presença de quintal em sua residência.

15 Tipo de uso do quintal pela família das crianças pré-escolares.

16 Distribuição dos pré-escolares segundo a relação estatura por idade, com relação ao conjunto dos estratos estudados $(n=2538)$.

17 Distribuição de crianças pré-escolares segundo a relação peso por estatura, com relação ao conjunto dos estratos estudados $(n=2538)$.

18 Distribuição dos pré-escolares segundo a relação estatura por idade, tendo como população de referência NCHS.

19 Distribuição de crianças pré-escolares segundo a relação peso por estatura, tendo como população de referência NCHS. 


\section{LISTA DE FIGURAS}

Página

1 Diferentes níveis que compõem o ambiente de um organismo .............................. 09

2 Distribuição dos pré-escolares quanto ao sexo ...................................................... 71

3 Distribuição dos pré-escoalres segundo a cor da pele ............................................ 71

4 Distribuição dos pré-escolares e suas mães de acordo com o sobrenome ................ 71

5 Distribuição dos pré-escolares quanto a presença de rede de esgoto e energia elétrica na residência

6 Distribuição dos pré-escolares quanto a procedência de água para beber ............... 72

7 Distribuição dos pré-escolares quanto ao material de construção da moradia ........ 72

8 Distribuição dos pré-escolares quanto ao número de cômodos por morador na residência

9 Distribuição dos pré-escolares de acordo com a idade da mãe ao seu nascimento .

10 Distribuição dos pré-escolares quanto a escolaridade da mãe (anos de estudo) .... 73

11 Distribuição dos pré-escolares quanto a renda per capita familiar ....................... 73

12 Distribuição dos pré-escolares quanto a presença de quintal na residência ........... 73

13 Distribuição dos pré-escolares quanto ao uso dos quintais ................................... 73

14 Distribuição dos pré-escolares quanto ao escore $\mathrm{z}$ de estatura-pela-idade $(\mathrm{n}=2538)$ 
15 Distribuição dos pré-escolares quanto ao escore $\mathrm{z}$ de peso-pela-estatura $(n=2538)$

16 Distribuição dos pré-escolares quanto ao escore $\mathrm{z}$ de estatura-pela-idade (NCHS)

17 Distribuição dos pré-escolares quanto ao escore z de peso-pela-estatura (NCHS)

18 Comparação entre a curva padrão de referência do sexo feminino e os estratos estudados

19 Comparação entre a curva de referência do sexo masculino e os estratos estudados 


\title{
A MIGRAÇÃO COMO ESTRATÉGIA ADAPTATIVA EM POPULAÇÕES HUMANAS RURAIS DE NOVO CRUZEIRO, MG, PARA PIRACICABA, SP.
}

\author{
Autora: ANA PAULA BRANCO DO NASCIMENTO \\ Orientadora: $\operatorname{Prof}^{\mathrm{a}} \mathrm{Dr}^{\mathrm{a}}$ SILVIA MARIA GUERRA MOLINA
}

\section{RESUMO}

Em nossa espécie, entre as estratégias adaptativas relevantes, encontra-se a migração, que permitiu ao ser humano ocupar novos ambientes, em busca de condições de vida melhores que as possíveis ou acessíveis em seu local de origem. Atualmente, a migração se constitui, no sentido genético, no principal fator evolutivo da espécie humana. Condições de vida adversas tendem a se refletir na capacidade de obtenção de alimentos. As crianças de uma população são particularmente sensíveis, refletindo-se facilmente em seu desenvolvimento físico, deficiências ou privações alimentares. Em trabalho anterior, dessa Equipe, foi identificado em Piracicaba, SP, grande contingente de migrantes originados do município de Novo Cruzeiro, MG. No presente trabalho aprofundou-se o estudo desta migração rural, caracterizando indicadores de adaptação relativos a crianças que permaneceram no ambiente de origem (Novo Cruzeiro, MG), crianças filhas de migrantes, residentes no novo local (Piracicaba, SP, constituindo-se estratos populacionais com ambos os pais migrantes, apenas o pai e apenas mãe migrante) e de crianças com ambos os pais paulistas residentes em Piracicaba, SP. Desta forma, entre os indicadores da adaptabilidade humana estudados no presente trabalho, foi empregado o estado nutricional de crianças pré-escolares. Os indicadores do 
desenvolvimento físico (pelo qual foi identificado o estado nutricional) foram o peso e a estatura das crianças, como também o sexo e a idade década uma. Entre as demais variáveis que podem afetar o seu desenvolvimento, foram estudados aspectos genéticos tais como: cor da pele e origem étnica da criança de acordo com seu sobrenome e de acordo com o sobrenome da família da mãe. Também foram estudados aspectos do ambiente da criança que poderiam influenciar seu desenvolvimento, tais como escolaridade materna, número de habitantes por cômodo na residência, material de construção da habitação, serviços de água e esgoto, presença e tipo de uso de quintais. Constatou-se pelos indicadores estudados, que há melhor qualidade de vida entre os habitantes do município de Piracicaba no que se refere a melhores condições de infraestrutura habitacional (água encanada, rede de esgoto, eletricidade e habitações de alvenaria) como também melhor renda familiar e maior escolaridade materna. $\mathrm{O}$ índice utilizado para definir os pontos de corte na avaliação da situação nutricional dos préescolares foi obtido com base nas unidades de desvio padrão ou escores z. A curva de referência foi a do National Center for Health Statistic (NCHS). Foram constatados casos de desnutrição em ambas as regiões estudadas, acima do esperado numa população saudável. Por outro lado, evidenciourse que a maioria das crianças (mais de $84,1 \%$ ) encontraram-se na faixa de "eutróficas" o que de acordo com as teorias de Ecologia Humana revisada,s sugere que em ambos os locais as populações humanas estão sendo bem sucedidas quanto a suas estratégias adaptativas. Foram identificados casos de sobrepeso e obesidade, mas apenas nas crianças de famílias que residem em Piracicaba. $\mathrm{O}$ aumento dessas ocorrências é característico de um modo de vida moderno e é um fator de risco para as populações residentes em Piracicaba, ao qual passaram a se expor as populações migrantes. 


\title{
THE MIGRATION AS AN ADAPTIVE STRATEGY IN HUMAN RURAL POPULATIONS FROM NOVO CRUZEIRO, MG, TO PIRACICABA, SP
}

\author{
Author: ANA PAULA BRANCO DO NASCIMENTO \\ Adviser: Prof ${ }^{a} \mathrm{Dr}^{\mathrm{a}}$ SILVIA MARIA GUERRA MOLINA
}

\section{SUMMARY}

In our species, among the more relevant adaptive strategies is the migration, which allows humans to occupy new environments searching for better life conditions than the ones possible or accessible in the original location. Nowadays, the migration is, in a genetic sense, the major evolutionary factor of mankind. Adverse life conditions tend to reflect in the capacity to obtain food. The children of a population are particularly susceptible, easily reflecting in their physical development, deficiency and food privations. In a previous work of our group, a large contingency of migrants from Novo Cruzeiro, MG, was identified in Piracicaba, SP. In the present work, the rural migration of this particular population was investigated in detail by characterizing relative adaptation indicators of children who remained in their original environment (Novo Cruzeiro, MG), migrants' children residents at the new location (Piracicaba, SP, constituted of population strata with both parents migrants, only the father migrant and only the mother migrant) and children who both parents are São Paulo state natives and residents in Piracicaba, SP). Thus, among the indicators of human adaptation used in this work, the nutritional status of pre-school children was used. The physical development indicators used (from which the nutritional status was identified) were the weight and 
the height of the children, as well as the sex and the age of each one. Among the others variables that can affect the development, genetic aspects such as skin color and ethnical origin of the children in accordance with their own surnames and in accordance with their mother family, were studied. Moreover, it was also studied aspects of the children environment, which could influence their development, such as mother's school level, number of inhabitants per room per house, material from which the house was made, water and sewer public services, backyard presence and its use. Based on the indicators used in this study, it was observed that there is better life quality among the inhabitants from Piracicaba when better condition of infra-structure (piped water, sewer and electric nets, and bricklaying houses), as well as better family income, and higher mother school level are concerned. The index used to define the cutting points in the nutritional evaluation of the pre-school children was obtained based on the units of standard error or score-z. The reference curve was that of the National Center for Health Statistic (NCHS). Under-nutrition cases in both studied regions above the expected for a healthy population were observed. On the other hand, the majority of the children (more than $84,1 \%$ ) was within the "eutrophic" level, which according to the revised Human Ecological theories, suggests that in both places the human populations are being successful as for their adaptive strategies. It was identified cases of over-weight and obesity, but only in the children whose families are residents in Piracicaba. The increase of these occurrences is a characteristic of the modern way of life and is one risk factor to the populations living in Piracicaba, which the migrant populations have now been exposed. 


\section{INTRODUÇÃO}

\subsection{O problema e sua importância}

Constatou-se a relevância de investigar a migração de Novo Cruzeiro, MG, para Piracicaba, SP, como estratégia adaptativa, após os resultados da “Avaliação GenéticoAntropológica do desenvolvimento físico de crianças pré-escolares e escolares do município de Piracicaba, SP” (Molina, 1997). Nesse trabalho, foi evidenciado entre outros aspectos, uma grande ocorrência, entre os migrantes residentes em Piracicaba, de indivíduos nascidos em municípios de Minas Gerais. Dentre os municípios apontados, destacoutse Novo Cruzeiro, tradicionalmente habitado por famílias de agricultores dedicados ao plantio de subsistência. Segundo dados fornecidos pela própria prefeitura do município de Novo Cruzeiro, nos últimos 40 anos, praticamente não houve aumento de população local, além de se constatar êxodo do campo para a cidade. Isso indica que esse município vem-se constituindo em um campo de repulsão, fonte de migrantes para outras regiões do país, inclusive, Piracicaba, SP. Novo Cruzeiro é uma cidade onde a maioria da população vive na zona rural e está localizada na região do Vale do Jequitinhonha, considerada uma das mais pobres do Brasil e do mundo.

A partir do trabalho citado anteriormente, Chade (2000) abordou a migração humana como uma estratégia adaptativa, utilizando dados sobre o desenvolvimento físico de crianças pré-escolares de Novo Cruzeiro e de duas instituições públicas de ensino de Piracicaba (referentes ao ano de 2000), como indicador da adaptabilidade humana, em ambos os locais. Como no presente trabalho, variáveis genéticas e do ambiente também foram estudadas. Entretanto, em Chade (2000), as crianças não 
tiveram seu estado nutricional classificado de acordo com o padrão internacional do National Center for Health Statistics (NCHS), mas apenas foram comparados os dados de desenvolvimento físico entre as populações dos dois locais estudados, os quais indicaram diferenças de desenvolvimento, sendo as crianças de Piracicaba, mais pesadas com relação à idade que as de Novo Cruzeiro.

O presente trabalho pretendeu dar continuidade a tais investigações, uma vez que o fenômeno da migração vem ocorrendo amplamente na espécie humana sendo relevante seu estudo sob diversas abordagens. Dentre os fatores que podem desencadear os movimentos migratórios, estão a busca por um melhor emprego e maior renda, assim as pessoas acabam se concentrando naquelas localidades que oferecem melhores condições de sobrevivência. No entanto, a transição de um modo de vida pré-urbano para um mais modernizado, como no caso da migração estudada, pode acarretar a exposição a fatores estressores, constatando-se eventualmente problemas sociais e de saúde, decorrentes da migração, sendo as crianças, as mais vulneráveis às mudanças nas condições ambientais.

Nesse sentido, foram efetuadas comparações entre as condições sócioeconômicas e ambientais das famílias das crianças residentes em Novo Cruzeiro, com as daquelas famílias que migraram daquele local e hoje residem em Piracicaba. Buscourse investigar se os migrantes estão obtendo condições de vida similares ou superiores às dos moradores do local de origem o que justificaria o deslocamento, caracterizando-o como uma estratégia adaptativa bem sucedida. Também foram comparadas as famílias do local de origem, Novo Cruzeiro, com aquelas residentes em Piracicaba e com ambos os pais nascidos no estado de São Paulo, supostamente um padrão ou controle das possibilidades adaptativas em Piracicaba, por já estarem estabelecidas no local há mais tempo ou mesmo, mais de uma geração.

Desta forma, o presente trabalho se propôs a utilizar parâmetros do desenvolvimento físico de crianças pré-escolares matriculadas em instituições públicas de ensino no ano de 2000, como indicador da adaptabilidade de populações humanas. Assim, a partir dos dados analisados, pretendeutse discutir se a migração rural de Novo Cruzeiro, MG, para Piracicaba, SP, vem se caracterizando ou não, como estratégia adaptativa bem sucedida. O estado nutricional foi classificado de acordo com a 
população de referência internacional (NCHS), usando os índices antropométricos estatura-pela-idade e peso-pela-estatura.

\subsection{Objetivos}

\subsubsection{Objetivo Geral}

Avaliar a eficiência da migração de populações humanas rurais de Novo Cruzeiro, MG, para Piracicaba, SP, como estratégia adaptativa.

\subsubsection{Objetivos Específicos}

$>$ Descrever o desenvolvimento físico de crianças pré-escolares residentes em Novo Cruzeiro, MG e em Piracicaba, SP, identificando a incidência de desnutrição e obesidade nas populações de crianças estudadas;

Investigar variáveis de natureza genética e do ambiente nas populações de Novo Cruzeiro, MG, e de Piracicaba, SP, que, de acordo com a literatura, podem influenciar o desenvolvimento físico das crianças. 


\section{REVISÃO DA LITERATURA}

\subsection{Migração humana}

Os fluxos migratórios têm sido de grande importância para a espécie humana, apresentando diferentes características quanto à suas causas, intuitos e consequiências. Segundo Saldanha (1968), que estudou município próximo a Piracicaba, SP, ao longo da evolução da espécie humana, o fenômeno migratório intensificou-se e a mobilidade dos indivíduos de nossa espécie aumentou, dissolvendo isolados e misturando populações, ampliando o seu tamanho e tornando improvável a ocorrência de oscilação genética. Devido à sua grande intensidade, a migração é a principal responsável atualmente pelo padrão evolutivo da espécie humana (Kormondy \& Brown, 2002).

O fenômeno migratório no Brasil tornourse especialmente ativo a partir de 1880 como consequiência da libertação dos escravos. O número total de imigrantes que chegaram no Brasil desde 1819 até 1954 atingiu 5 milhões e estes migrantes se estabeleceram principalmente no sul do País. Italianos, espanhóis e japoneses vieram em sua maioria para São Paulo enquanto os russos, alemães e outros povos procuraram os estados do sul (PR, SC e RS) e os portugueses se distribuíram em SP e RJ (Saldanha, 1968).

Vários são os fatores que podem desencadear a migração, mas para entendê- la é necessário inseri-la em um contexto econômico e social. Em um estudo sobre migração ruratrural, onde a expansão do capitalismo rural era apontada como fator chave desencadeador, Chamleyl (1997), relacionou processos históricos de mudança ecológica e migração. Nesse trabalho, o autor comenta que a migração nem sempre está 
relacionada a impactos ambientais negativos, mas que ela não pode ser considerada como um modo efetivo para resolver problemas relacionados à falta de recursos, pois acaba sobrecarregando a área receptora.

Molina (1970), também estudando migração rurałrural, desenvolveu um modelo do processo migratório o qual identifica os fatores que levam um indivíduo a migrar de uma região a outra. Dentre estes, foram relacionados: a) fatores tradicionais, tais como acompanhar a família; b) fatores afetivos, os quais, na visão e palavras dos próprios migrantes seriam: conhecer o mundo, desejo de aventura e "ser seu destino"; c) fatores normativos: valores, normas, conhecimento; d) fatores psicossociais tais como, atitudes e sentimentos; e) fatores racionais e do ambiente: arrendamento alto, procura de trabalho, terras fracas.

Como comentado acima, o movimento da população sobre o espaço ocorreu em toda a história da humanidade, sendo um dos responsáveis pelo povoamento dos continentes e a diversificação cultural hoje existente. Entretanto, após o surgimento da indústria, a migração interna ganhou um contorno diferente do que até então possuía. A formação de uma sociedade urbana-industrial impôs transformações no meio rural que em grande parte resultaram na destruição das atividades de subsistência, colocando o campo como local de origem de intensos fluxos migratórios em direção aos centros urbanos (Durham, 1984; Nunes, 2002).

Nunes (2002) destacando as abordagens teóricas sobre migração interna, enfatiza que a decisão de migrar de uma área rural para uma área urbana está relacionada a duas variáveis principais: o diferencial urbano-rural de renda real e a probabilidade de obtenção de um emprego urbano. De acordo com este autor, a partir da análise dessas duas variáveis o migrante tomaria a decisão de migrar ou não para uma área urbana. Para esse autor, não há dúvidas de que a migração interna é um fenômeno decorrente das desigualdades regionais sendo estas encaradas como o motor principal das migrações, pois, enquanto determinadas áreas são favorecidas pelo progresso, outras sofrem um processo de "empobrecimento". Entretanto, a migração não se constitui apenas de força de trabalho em movimento, mas, à medida que o migrante carrega consigo sua cultura, hábitos e modo de vida construídos em seu local de origem, ela também se torna um 
movimento espacial de difusão e integração da diversidade cultural e social, contribuindo para a derrubada das fronteiras culturais do território, mesmo que seja um movimento contraditório por também recriar novas territorialidades.

A migração é considerada um evento capaz de alterar, entre outros elementos, os padrões de organização familiar e a interação mãe-criança que podem determinar estados de saúde e doença (Mota, 1999). Assim a migração pode vir a se caracterizar como uma resposta adaptativa a uma dada condição estressora. É importante frisar que as crianças são particularmente vulneráveis às mudanças nas condições ambientais.

De acordo com Mota (1999), as fontes de estresse são aquelas que "têm o efeito de ameaçar ou perturbar a dinâmica do estado estável do qual a vida do organismo depende ou de ameaçar fazê-lo". Isto pode se traduzir em necessidade de adaptação para a sobrevivência, face a eventos que atuam como estressores na medida em que sobrecarregam ou excedem os recursos adaptativos da pessoa ou grupo de pessoas numa dada circunstância.

É importante considerar que o significado que os indivíduos conferem às mudanças e aos eventos são particulares, ou seja, uma situação pode ser reconhecida como estressante para um indivíduo e para outro não. Indivíduos ou famílias podem vivenciar diferentes situações estressoras e buscar estratégias específicas de resistência às mesmas, como por exemplo a opção de migrar ou permanecer no local de origem. Assim como, após a migração, podem ser encontradas diferentes condições no local de recepção, as quais podem influenciar em maior ou menor medida o sucesso adaptativo dos migrantes, no novo local.

A ecologia humana apresenta um enfoque interdisciplinar sobre as relações entre uma população humana e seu ambiente incluído neste, aspectos físicos, políticos e sócioeconômicos. Seu ponto central é a preocupação com os meios pelos quais as populações humanas se organizam com o objetivo de se manter e se reproduzir em seu meio ambiente e assim, interessa-se pelos processos adaptativos das populações humanas (Moran, 1990). Desta forma, no contexto da Ecologia Humana, a migração pode ser abordada como uma estratégia adaptativa. 


\subsection{Adaptabilidade humana}

Um dos pontos principais da Ecologia Humana é o conceito de Adaptação (Moran, 1990). Este conceito tem sido central na investigação da ecologia de grupos humanos, mas é utilizado de formas distintas pelas diferentes áreas de conhecimento. Além disso, mesmo dentro de uma mesma disciplina, adaptação e adaptabilidade se confundem e são definidas de formas diversas, dependendo do autor considerado (Adams, 2002).

Do ponto de vista biológico-evolutivo, adaptação refere-se a mudanças genéticas que conferem à espécie um maior sucesso reprodutivo. No sentido não evolucionista $\mathrm{e}$ mais comum, adaptação pode se referir às mudanças fisiológicas e comportamentais provocadas por mudanças ambientais. O conceito de adaptação tem considerável poder explicativo, quando empregado de modo abrangente, com o objetivo de estudar processos pelos quais uma população interage com seu ambiente (Moran, 1990).

Migliano (2000), por sua vez, ressaltou que a adaptação refere-se tanto ao processo pelo qual os organismos aumentam a sua capacidade de explorar os recursos dentro de um dado nicho, quanto às características que lhe permitem fazê-lo e que o processo adaptativo é mediado pelo nível de competição intra e interespecífica (por meio de estratégias adaptativas) e pela seleção natural. Embora as características adaptativas tenham somente um valor relativo e temporário, definido pelo equilíbrio de custo e benefício em cada circunstância específica, estas podem resultar em tendências adaptativas que se repetem ao longo da evolução, sendo o tamanho do corpo de um animal a principal dessas características. O padrão de crescimento de um indivíduo é geneticamente determinado, mas pode ser alterado durante o processo de desenvolvimento (fase de crescimento), caracterizando o fenômeno de plasticidade ou adaptabilidade e depende de fatores ambientais agindo sobre o crescimento, tais como quantidade de alimentos disponíveis, temperatura, quantidade de oxigênio, entre outros. Por outro lado, a adaptação genética refere-se a alterações nas frequiências genotípicas através das gerações, pelo processo de seleção natural. Quanto ao processo de crescimento, é constatado que tanto fatores genéticos como do ambiente exercem sua 
influência. Cabe considerar ainda, que em termos de adaptabilidade, a capacidade de reduzir o processo de crescimento ou parar de crescer que pode ser deflagrada em função de restrições do ambiente, visando a manutenção do metabolismo normal é estritamente adaptativa, mas a estatura final resultante pode não se constituir, em si, uma vantagem adaptativa (Adams, 2002).

Conforme discutido em Kormondy \& Brown (1998), em princípio, a adaptabilidade humana é uma expressão usada para descrever o estudo das bases biológicas da flexibilidade de populações humanas. Mas, ressaltam que para a espécie humana, a adaptabilidade envolve aspectos muito mais amplos do que suas respostas fisiológicas ao ambiente, uma vez que esta modifica o ambiente por meio da cultura e do comportamento, de forma que é preciso uma abordagem mais complexa para se entender a adaptação humana, envolvendo tanto fatores do ambiente físico natural, como os relacionados à cultura, além dos determinantes genéticos.

Dado o caráter interdisciplinar do presente trabalho, cabe esclarecer também outro conceito fundamental em Ec ologia Geral e Humana que é o de ambiente. Segundo Foley (1993), ambiente é um conceito variável. Compreende desde características físicas básicas, tais como temperatura, precipitação, solo, até entidades bióticas, como as espécies simpátricas (as que partilham um mesmo local). Salienta ainda, que o meio ambiente de qualquer organismo abrange também outros membros da mesma população e espécies com os quais ele pode manter interações genéticas e sociais. Assim, esse autor, também enfatiza que o ambiente, não é uma simples lista de fatores geográficos e bióticos, mas tudo aquilo (físico, biológico e social) que entra em contato com um organismo, considerado do ponto de vista de suas relações ecológicas. Os ecólogos estudam as relações entre os organismos e seu ambiente, relações estas que podem ser extremamente variáveis bem como, os componentes de um organismo e de um ambiente não permanecem constantes. Conforme representado na Figura 1, abaixo, o que um organismo representa em um nível faz parte do meio ambie nte em outro nível. 


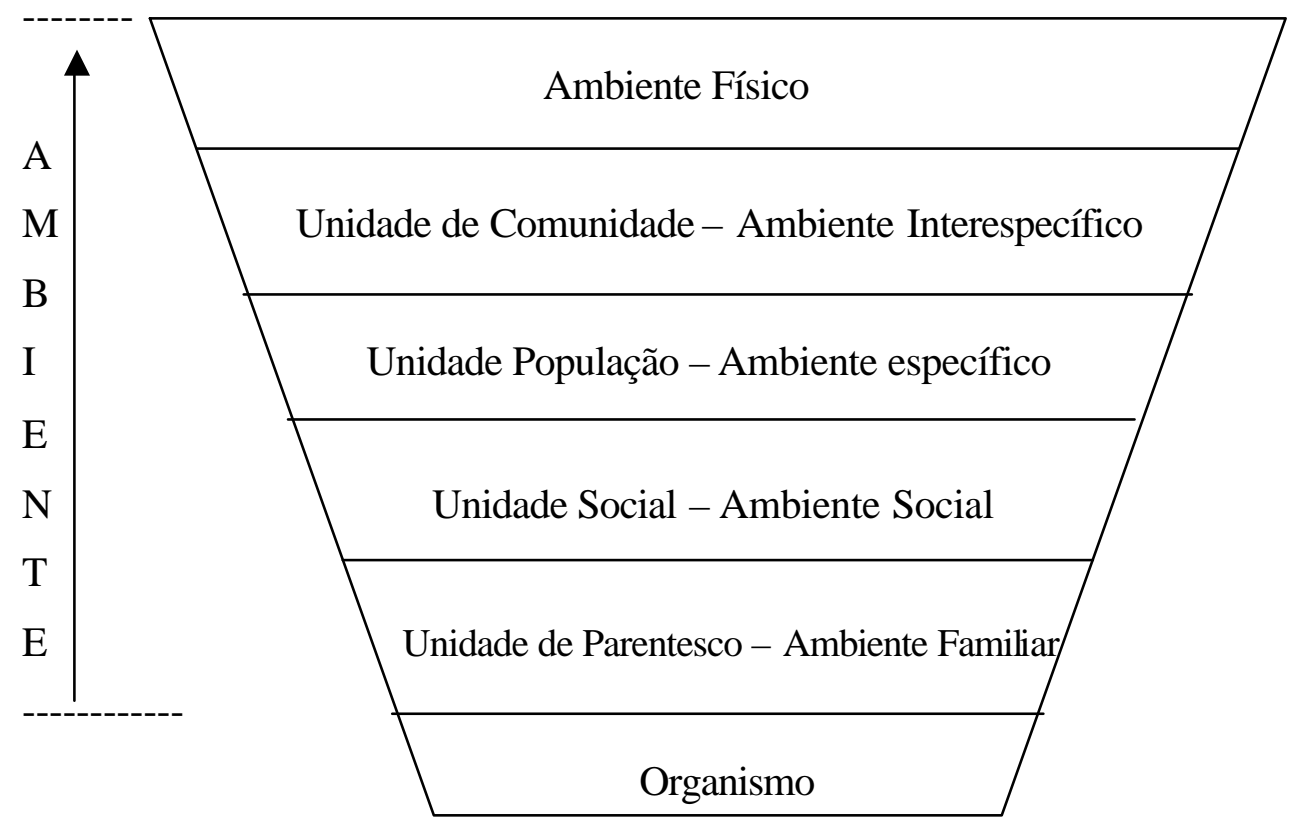

Figura 1- Diferentes níveis que compões o ambiente de um organismo. Cada unidade faz parte do ambiente do agrupamento que vem abaixo (adaptado de Foley, 1993). Observação: os termos população e comunidade estão empregados, nesta figura, no sentido adotado pela Ecologia Geral; significando respectivamente, um conjunto de indivíduos da mesma espécie e um conjunto de espécies diferentes, que habitam um mesmo local num mesmo período de tempo

Moran (1994), empregando os conceitos de adaptação e de ambiente tal como discutidos acima, ressalta que as adaptações são decorrentes de fatores físicos e químicos do ambiente, da interação com outras espécies e da interação com outros indivíduos da mesma espécie. Dessa forma os indivíduos podem responder a alterações no ambiente de maneira diferenciada por meio de ajustes reguladores, de aclimação e de desenvolvimento. As respostas reguladoras ocorrem de forma rápida e refletem a flexibilidade fisiológica e comportamental de um organismo. Quase todo comportamento é uma forma de respostas reguladoras que serve para manter uma relação estável com meio ambiente ou que permite um ajuste a mudanças ocorridas no mesmo. Já as respostas de aclimação levam mais tempo para entrar em operação, pois exigem uma mudança na estrutura do organismo. Para que ocorram, é preciso que haja 
um estímulo externo por um período de tempo suficiente. São geralmente reversíveis quando cessa a situação que produziu a alteração orgânica; as respostas de desenvolvimento são irreversíveis e ocorrem durante o crescimento e desenvolvimento do indivíduo. Essas respostas são ajustamentos do organismo às condições ambientais que predominam durante o período de desenvolvimento. Durante esse período, o organismo é capaz de se mo ldar às condições ambientais predominantes (plasticidade genética e conseqüente plasticidade fenotípica).

Begossi (1993) ressaltou que a adaptabilidade é um dos pilares da ecologia evolutiva sendo esta a capacidade de um organismo de se perpetuar e é medida pelo sucesso reprodutivo desse organismo. A noção de adaptação é central para várias abordagens antropológicas. No geral, ela pode ser definida como diferentes estratégias que o homem criou para explorar os recursos naturais e para enfrentar as limitações ecológicas que pesam sobre a reprodução dos recursos naturais e dos próprios grupos humanos. O estudo da adaptabilidade humana enfatiza a plasticidade das respostas humanas ao ambiente. Esta plasticidade manifesta-se em termos socioculturais e fisiológicos (Moran, 1994).

Em Mace (1999), é ressaltado que a história da vida humana, sob a perspectiva da ecologia evolutiva, caracteriza-se por uma forte influência cultural sobre as decisões reprodutivas e que há evidências de que o próprio declínio da fertilidade ao longo da vida de uma mulher (a evolução da menopausa) teria ocorrido porque o investimento, no sucesso reprodutivo futuro das crianças já existentes, seria mais vantajoso que continuar a ter os próprios filhos em idade avançada. Essa autora associa, nas populações humanas, tanto a evolução da menopausa quanto a ocorrência do fenômeno da transição demográfica (caracterizado pela redução de taxas de natalidade e mortalidade) à intensidade do investimento dos genitores em seus filhos, crianças que de fato competem entre si pelo esforço dos pais. Neste sentido, a busca da otimização desse investimento pode ser a chave para a compreensão dos dois fenômenos relacionados acima, ambos típicos e característicos apenas da espécie humana.

A discussão sobre a adaptabilidade humana está centrada em como as populações humanas, ao interagirem umas com as outras e com seus ambientes, procuram se 
acomodar aos problemas ambientais específicos. Segundo Moran (1994) a adaptabilidade humana, diz respeito ao êxito ecológico, podendo ser avaliada por meio de critérios demográficos, energéticos ou nutricionais. Os critérios nutricionais fornecem um índice satisfatório de adaptabilidade, visto que o consumo de alimentos reflete o conhecimento acerca dos recursos, a capacidade de explorá-los e a capacidade de atingir um determinado nível de potencial de trabalho (Morán, 1990).

Assume-se portanto, no presente trabalho, o estado nutricional dos filhos existentes como um indicador adequado da adaptabilidade humana, sabendo-se que deficiências de estatura refletem um histórico de desnutrição pregressa e deficiências de peso refletem deficiência nutricional atual (Schieri et al., 1993, Adams, 2002), ressaltando-se que a capacidade de obtenção de alimentos (e seu efeito sobre o desenvolvimento de crianças) relaciona-se estritamente à adaptação humana, sendo portanto este, um indicador fidedigno da mesma. Os resultados do presente estudo também fornecem elementos para aprofundar a discussão de tal proposição.

\subsection{Desenvolvimento físico de crianças}

Bogin \& Loucky (1997) defendem o emprego do crescimento e desenvolvimento infantil, como indicadores sensíveis da qualidade social, econômica e do ambiente político, em que vivem. Segundo os autores, o uso da antropometria seria indicado como um índice de qualidade ambiental, pois o fenótipo humano é altamente plástico, tendo uma grande capacidade de se ajustar de acordo com mudanças ambientais, em particular às estressantes.

A velocidade do crescimento e a estatura alcançada nas diferentes dades são fenótipos amplamente condicionados pela herança genética dos indivíduos. A realização plena desse potencial, entretanto, depende da existência de um ótimo estado nutricional e por extensão, de um bom estado de saúde, de uma alimentação adequada e de boas condições de vida em geral. Tal dependência é particularmente importante nos primeiros anos de vida, sendo essa a circunstância que faz com que a avaliação do crescimento na 
infância seja freqüentemente utilizada tanto para aferir o estado de saúde e de nutrição de crianças individuais quanto para indicar as condições gerais de vida que prevalecem nas sociedades (Monteiro \& Conde, 2000).

Molina (1997), desenvolveu um trabalho onde foram estudadas crianças préescolares e escolares da cidade de Piracicaba, SP, com o objetivo de analisar a influência dos componentes genéticos e fatores ambientais sobre seu desenvolvimento físico. A autora ressaltou a influência das condições de vida, como alimentação e saúde, no desenvolvimento físico de crianças, lembrando que crianças bem alimentadas e orientadas tendem a se desenvolver mais em termos de peso, estatura e aprendizagem, do que aquelas que sofrem privações, incluindo as de ordem materiais.

Segundo Monteiro \& Conde (2000), a desnutrição na infância, indicada pelo comprometimento severo do crescimento linear e(ou) pelo emagrecimento extremo da criança constitui um dos maiores problemas enfrentados por sociedades em desenvolvimento, podendo levar a dificuldades no aproveitamento escolar e diminuição da estatura e da capacidade produtiva na idade adulta. Estudos epidemiológicos sobre indicadores da obesidade na infância, por outro lado, são ainda muito escassos e quase sempre restritos a países desenvolvidos, para que se tenha idéia da real importância dessa condição em sociedades em desenvolvimento.

Nesse sentido, observa-se claramente que trabalhos que procuram relacionar as influências socioambientais sobre o desenvolvimento humano abordam diferentes aspectos. Como exemplo pode-se citar Campbel \& Sanjur (1972) que, utilizando um modelo conceitual baseado na visão de que o desenvolvimento humano acontece em um ambiente ecológico, procuraram analisar o impacto de mudanças sociais atuais, como mães que trabalham fora e são sozinhas, sobre a qualidade da dieta de crianças préescolares em Winnipeg, Canadá.

Grillo et al. (2000) analisaram variáveis sócio-econômicas estudadas em trabalhos sobre fatores de risco para desnutrição. Assim concluíram que as moradias construídas de alvenaria, como também a presença de rede de esgoto, número menor de irmãos, maior nível de escolaridade materna e a renda familiar per capita maior que 1 salário mínimo, influenciam positivamente o estado nutricional da criança. 
Para Amoroso (1981), a questão de se a mudança do ambiente rural para o urbano é deletéria ou não aos padrões nutricionais de migrantes rurais, ainda é objeto de controvérsias. Assim, em seu estudo, utilizou critérios nutricionais para analisar a situação de famílias que chegam a Manaus vindas do interior e também levou em consideração fatores sócio-econômicos, como renda e tempo de residência, como fatores condicionantes da dieta.

Vignerova et al. (1998) estudaram a influência de fatores sócio-ambientais, como educação da mãe, tamanho da comunidade, número de crianças na família e ordem de nascimento, no desenvolvimento físico de crianças da República Tcheca utilizando medidas de peso e estatura em relação à idade. Constataram que a educação dos pais refletia um nível maior de consciência, proporcionando uma melhor distribuição de recursos, o que levaria a um estilo de vida mais saudável incluindo uma dieta mais adequada, atividades de lazer e educação extra às crianças.

Kim (1991) estudou o desenvolvimento físico de crianças em Aymara uma comunidade pastoreira do Altiplano Boliviano. Medidas antropométricas da população foram comparadas com dados publicados para outras populações andinas, rurais e urbanas. Acreditava-se que o crescimento atrasado, tamanho do corpo pequeno, e tamanho maior do tórax fossem características das crianças andinas de grandes altitudes como resposta adaptativa ao estresse ambiental. Os autores sugerem que esta interpretação seja reconsiderada sendo que a falta de recursos, ocasionando uma alimentação inadequada, também pode estar influenciando o desenvolvimento físico das crianças dessa população.

Numa abordagem mais genética da questão do desenvolvimento físico e adaptação, Migliano (2001) trabalhou com dados de crianças da Amazônia (caboclos do médio Solimões), e buscou explicar as diferenças existentes entre a estatura de diferentes populações humanas como resultado de processos adaptativos que ocorrem através de respostas plásticas durante o desenvolvimento do indivíduo (ontogênese) como através do processo de seleção natural ao longo das diferentes fases da vida do indivíduo. A autora verificou que especialmente na população de recém-nascidos, existe tanto uma capacidade de resposta plástica a variações ambientais (verificadas por variações 
sazonais nas medidas de peso estatura de recém nascidos associadas a variações sazonais na disponibilidade de alimentos), como uma resposta adaptativa a longo prazo, indicada pela estatura ao nascer, sendo esta resposta verificada por meio do estudo da mortalidade diferencial. Também nesse caso o desenvolvimento físico foi empregado como indicador da adaptabilidade da população estudada.

\subsection{Estado Nutricional}

Como já mencionado, desde a segunda metade deste século vem ocorrendo um grande crescimento da população urbana no mundo. Esse fato, para os países ricos, esteve associado a maiores avanços científicos, tecnológicos e, especialmente, a melhores níveis sócioeconômicos. Nos países de baixa renda, ao contrário, o processo de urbanização não foi acompanhando pelo mesmo nível de progresso econômico. O crescimento acelerado das populações urbanas aumentou a pobreza, trazendo graves consequiências sociais, nutricionais, ambientais e de saúde, uma vez que um número cada vez maior de famílias passam a viver em favelas superlotadas, com acesso limitado a infra-estruturas básicas que lhes permitam um estado nutricional saudável (Grillo et al., 2000).

Para crianças em idade pré-escolar, uma dieta adequada é muito importante para promover crescimento, desenvolvimento e saúde. A escolha de alimento é de suma importância para o estabelecimento de hábitos alimentares que provavelmente continuarão na vida adulta (Sepp et al., 2002).

Em relação aos hábitos alimentares é importante frisar que estes são consolidados praticamente na infância a partir de 1-2 anos (Tojo et al., 1996) e tendem a permanecer ao longo da vida. Os fatores fisiológicos, sócio-culturais e psicológicos influenciam na formação dos hábitos alimentares, além destes serem condicionados pela disponibilidade dos alimentos (Adams, 2002). Portanto, é importante assegurar às crianças uma dieta tão variada quanto possível já a partir dessas idades tão precoces. 
A família, na maioria das sociedades ainda é a responsável pela formação dos hábitos alimentares das crianças, com menor idade, pois são os pais (e com freqüência a mãe) os responsáveis pela compra e o preparo das refeições (Garbandella et al., 1999).

O grau de educação da família e sua condição sócio-econômica têm efeitos consideráveis sobre o modo de vida e hábitos alimentares das crianças. O grau de educação da mãe é um dos melhores indicadores da qualidade da dieta das crianças (Tojo et al., 1996).

Kassouf (1994) analisando os fatores que afetam o estado de saúde das crianças constatou que a educação da mãe, infra-estrutura do domicílio e renda familiar têm impacto positivo na saúde da criança. A autora observou que quando a intensidade de ocupação dos pais aumenta, menos tempo é dedicado aos cuidados com as crianças, ressaltando a necessidade de uma melhoria na qualidade e na quantidade de creches.

Diversos estudos têm demonstrado a importância dos fatores sócio-econômicos na determinação da saúde infantil. Segundo França et al. (2001) dentre estes fatores, a educação da mãe e a renda familiar têm sido considerados elementos básicos, por serem indicadores de disponibilidade de recursos e conhecimento ou comportamento em relação à saúde da criança. No entanto, existe ainda heterogeneidade em relação às variáveis utilizadas para a aferição dos diferenciais sócio-econômicos: alguns autores empregam o conceito de classe social, outros utilizam ocupação, renda, educação, estado civil das mães, e mesmo diversas variáveis relativas às condições de moradia. Essas diversas abordagens evidenciam a importância de se mensurar mais de uma dimensão dos determinantes sociais.

À medida que a participação da mulher no mercado de trabalho cresce, aumenta a demanda por serviços de cuidado infantil fora dos domicílios, em particular nas creches (Araújo, 2001). Inicialmente, no Brasil estas estiveram vinculadas ao atendimento de populações de baixa renda voltado para a alimentação, higiene e segurança física das crianças (Rapoport \& Piccinini, 2001). Atualmente, até mesmo as mães que não trabalham fora começaram a buscar estes espaços de socialização para as crianças. 
Ainda de acordo com Rapoport \& Piccinini (2001), a própria Constituição Brasileira de 1988 reconheceu a creche como uma instituição educativa, sendo um direito da criança, uma opção da família e um dever do Estado. A partir da nova LDB (20/12/1996) a creche passou a ser incluída como parte da educação infantil responsável pelas crianças até os três anos de idade e as pré-escolas para crianças de quatro a seis anos.

Com objetivo de avaliar a qualidade nutricional das refeições consumidas pelas crianças nas creches, pertencentes a faixa etária de 2 a 6 anos em creches municipais de Teresina, Cruz et al. (2001) constataram deficiência de energia e inadequação de proteínas, demonstrando a necessidade de um contínuo monitoramento das metas do programa e de aperfeiçoamento do serviço visando à melhoria da qualidade da dieta, com especial atenção para as recomendações nutricionais.

Vannucchi et al. (1990) salientaram que a orientação para a formação de hábitos alimentares adequados deve ser em parte assumida pelo sistema educacional e de saúde, bem como pelos meios de comunicação. Neste sentido, as instituições educacionais exercem um papel de extrema importância tanto na formação de hábitos alimentares, como também com medidas de intervenções, tendo a oportunidade de monitorar tanto crianças com baixo peso como crianças com excesso de peso.

Ruffo (1997) coloca que quanto mais precocemente as crianças incorporarem hábitos que condicionem "erros alimentares", mais cedo surgirão as doenças resultantes do comportamento alimentar.

\subsubsection{Desnutrição e Obesidade}

Uma alimentação adequada permite que a criança alcance o seu potencial genético de crescimento e desenvolvimento e ajuda na promoção e na manutenção da saúde, favorecendo uma situação de bem-estar. Por outro lado, as deficiências alimentares podem conduzir a criança a um grave estado de desnutrição, que se reflete em seu crescimento físico, desenvolvimento mental e intelectual, além de provocar 
desequilíbrios morfológicos e funcionais os quais, dependendo da intensidade e duração poderão ser irreversíveis (Unicef, 1998; Cruz et al., 2001).

A desnutrição na infância, indicada pelo comprometimento severo do crescimento linear e(ou) pelo emagrecimento extremo da criança, constitui um dos maiores problemas enfrentados por sociedades em desenvolvimento, seja por sua elevada frequiência, seja pelo amplo espectro de danos que se associam àquelas condições. Estima-se que $38,1 \%$ das crianças menores de cinco anos que vivem em países em desenvolvimento padecem do comprometimento severo do crescimento ("stunting") e que 9,0\% apresentem emagrecimento extremo ("wasting") (Unicef, 1998; Monteiro \& Wolney, 2000).

No caso do sexo feminino, o retardo do crescimento na infância determina mulheres adultas de baixa estatura sujeitas a um risco maior de gerar crianças com baixo peso ao nascer (Kramer, 1987).

Embora uma significativa parcela da população infantil sofra de complicações da fome crônica, o excesso de peso está aumentando em todo o mundo. No Brasil, existem hoje cerca de três milhões de crianças com idade inferior a dez anos apresentando tal problema. Segundo as teorias ambientalistas de determinação do excesso de peso, ele prevalece nas regiões mais desenvolvidas do país, onde está mais adiantado o processo de modernização industrial, com conseqüentes mudanças de hábitos e em crianças menores de cinco anos. Assim, é mais freqüente durante os primeiros anos de vida, associada a práticas de desmame precoce e difusão de normas dietéticas infantis incorretas, as quais estimulam a superalimentação (Corso et al., 2003).

Desse modo, ao mesmo tempo em que declina a ocorrência da desnutrição em crianças e adultos num ritmo bem acelerado, aumenta a prevalência de sobrepeso e obesidade na população brasileira (Filho \& Rissin, 2003). Estabelece-se, dessa forma, um antagonismo de tendências temporais entre desnutrição e obesidade, definindo uma das características marcantes do processo de transição nutricional do país.

De acordo com Sawaya \& Roberts (2003), existe uma quantidade significativa de evidências epidemiológicas mostrando que a baixa estatura nutricional aumenta o risco de obesidade futura. Informação semelhante foi transmitida pela televisão: "uma 
pesquisa feita em Maceió comprovou o que os cientistas já desconfiavam: crianças desnutridas estão se transformando em adultos obesos. A obesidade é uma das consequiências mais graves da desnutrição infantil, um problema comum em todas as 135 favelas da cidade” (Programa Globo Repórter, 28/11/2003).

Neste sentido, Adams (2002), explica que as crianças sofrendo de desnutrição tendem a se adaptar ao baixo consumo de nutrientes através de uma redução na sua taxa de crescimento de forma a manter o funcionamento fisiológico num estado de equilíbrio. Assim a baixa estatura é considerada por este autor como uma acomodação (resposta às condições impostas por um ambiente) à desnutrição ao invés de uma adaptação, já que possui conseqüências danosas.

A obesidade vem aumentando dramaticamente, não apenas nos países desenvolvidos, mas também nos subdesenvolvidos, como o Brasil, especialmente em indivíduos mais pobres. As projeções para uma epidemia global de obesidade são tão graves, que segundo a Organização Pan-Americana de Saúde (OPAS/OMS), no Brasil, é preciso adotar com urgência estratégias nacionais e internacionais de saúde pública para combatê-la. De acordo com a Organização Mundial de Saúde (OMS) a obesidade é uma doença na qual o excesso de gordura acumulada nos tecidos adiposos chegou a um nível que pode ser prejudicial à saúde.

Estudos epidemiológicos sobre indicadores da obesidade na infância são ainda muito escassos, e quase sempre restritos a países desenvolvidos, de tal forma que não se tem uma idéia da real importância dessa condição em sociedades em desenvolvimento. A importância da obesidade em adultos, demonstrada em muitos paises inclusive no Brasil, justifica que indicadores dessa enfermidade sejam monitorados em outros grupos etários, como seria o caso das crianças (Monteiro \& Wolney, 2000).

\subsection{Quintais domésticos}

O quintal doméstico é uma das variáveis do ambiente que exerce influência sobre o estado nutricional da população. Isto porque existe uma correlação positiva entre os 
produtos que são produzidos nos quintais e a freqüência com que são consumidos pela famílias.

Guimarães (1998), em estudo sobre a importância de quintais domésticos com relação à alimentação e rendas familiares, entre suas conclusões; indica o quintal como importante para a diversificação dos alimentos presentes na alimentação diária. A ausência do mesmo pode ser um fator de restrição da dieta, em especial dos alimentos fonte de vitaminas, minerais e fibras, como hortaliças e frutas. Outros aspectos bastante relevantes referentes aos quintais, segundo Angelo (1999), seriam a conservação de espécies cultivadas, introdução de novas espécies conservando-se germoplasma e a produção de plantas medicinais, conduzida por populações tradicionais.

$\mathrm{O}$ uso de quintais tem sido uma estratégia de subsistência empregada desde o neolítico, e sua forma e função estão intimamente relacionadas à evolução da sociedade, cultura e agricultura. A domesticação dos animais e o cultivo de plantas pelo homem marcam a transição da economia coletora para a economia cultural-nômade, onde continuaram as coletas, mas os seres humanos plantavam e cuidavam da sua horta, além de criar animais (Hollingshead, 1970). Assim contavam com recursos adicionais para satisfazer a maior parte de suas necessidades e não se limitavam apenas ao simples colher daquilo que lhes oferecia a natureza.

Entretanto, na sociedade moderna, sua forma e função vêm sendo modificadas e adaptadas às novas exigências sócio-econômicas, devido às mudanças impostas pelo desenvolvimento capitalista urbano-industrial. Estas mudanças, principalmente no que se refere ao trabalho, causaram rompimentos com os antigos valores e a aquisição de novos (Brandão, 1981). Os quintais vão deixando de ser prioridade para a família, que deixa seus hábitos e empenham-se em ganhar dinheiro para adquirir bens de mercado, que muitas vezes já foram produzidos no próprio quintal.

Em relação à contribuição dos quintais na alimentação da família de pequenos produtores, o estudo realizado por Ambrosio (1996), na Microbacia D’Água de Vera Cruz, no estado de São Paulo, mostra que em todas as propriedades a mulher é quem mais trabalha nos quintais. Ela cuida dos canteiros, plantio, irrigação, capina e colheita. De modo geral é a mulher quem decide o que plantar. Segundo Shiva \& Dankealman 
(1996), os conhecimentos locais a respeito de processos e recursos naturais sempre foram transmitidos pelas mulheres de uma geração para as mulheres da geração seguinte. Estas foram originalmente as produtoras de alimentos em todo o mundo e continuam a ter uma importância central nos sistemas de produção de alimentos do Terceiro Mundo.

Os quintais alteram pouco os ambientes tradicionais, enquanto utilizam ao máximo os recursos naturais. São caracterizados por baixos custos e riscos, são potencialmente importantes para trazer benefícios nutricionais, econômicos, psíquicos e de conservação in situ da grande diversidade que podem abrigar (Cleveland \& Soleri, 1987).

Em muitas partes do mundo, o quintal ainda abriga um dos sistemas mais utilizados de produção de recursos, principalmente nas áreas rurais, e é de extrema importância para populações urbanas de países em desenvolvimento, que o integram à sua estratégia de sobrevivência. A pressão populacional, juntamente com as condições econômicas e políticas de distribuição de terras, tornam as propriedades cada vez menores para a população, e este é um fator que tem favorecido o desenvolvimento desses sistemas de produção alimentar muito intensivos em algumas localidades (Ambrosio et al., 1996).

De acordo com Frère et al. (s/d), a maior parte das capitais de estados do Brasil, confrontam-se com um problema de crescimento intenso em uma situação pouco adaptada para acolher este aumento populacional. Este fenômeno deveu-se não apenas ao aumento da natalidade, mas sobretudo, à chegada de novas populações que migraram das zonas rurais para as cidades. Segundo esse autor as populações migrantes são atraídas pelos centros urbanos em busca de melhores condições de vida e na esperança de um melhor futuro para os seus filhos no que diz respeito a educação, saúde e perspectivas profissionais. Estas famílias chegam na cidade com poucos recursos financeiros e procuram imediatamente uma fonte de renda. Deste modo o cultivo no quintal é uma forma de segurança durante dias difíceis, onde a renda não mais permite a compra integral de alimentos para as três refeições diárias ou medicamentos. 
Em Belém, a agricultura urbana é praticada por cerca de $56 \%$ da população dos bairros mais pobres. Para $41 \%$ desta população, as micro produções vegetais, desenvolvidas nos seus quintais, permitem uma melhor alimentação e o acesso a plantas medicinais, necessárias ao tratamento das doenças da família (Frére et al., 1999). É uma agricultura preventiva para famílias pobres que não possuem outras alternativas.

Quanto à capacidade de obtenção de alimentos, essencial para a adaptabilidade de uma população (e que também se reflete nas médias de peso e estatura da mesma), os quintais domésticos podem assumir uma grande importância. Cleveland \& Soleri (1987) definem o quintal como um sistema suplementar de produção de alimento que pode ser manejado e controlado pelos membros da unidade doméstica. Oferecem recursos que podem ser alimentos, ervas, combustíveis, medicamentos, forragens, materiais para construção e outros ofícios, sombra, espaço social e lazer, recursos genéticos, flores e embeleza mento.

Em países de terceiro mundo, como o Brasil, onde grande parte da população é extremamente carente, os quintais podem se constituir numa ótima alternativa para suplementar a dieta alimentar de famílias pobres que possuem uma área cultivável em seu domicílio (Angelo, 1999).

\subsection{Antropologia Nutricional}

As condições nutricionais de uma população humana são o resultado inseparável de forças biológicas e culturais. A antropologia nutricional é uma abordagem teórica interdisciplinar, que reúne pesquisadores que investigam os problemas relacionados à nutrição sob um ponto de vista contextual, combinando teoria e método tanto das ciências sociais quanto da nutrição. Esta abordagem surgiu da integração de quatro linhas de pesquisa: (1) da longa tradição dos estudos de dieta que existia dentro da ciência da nutrição; (2) do estudo de hábitos alimentares, tanto na antropologia quanto na nutrição, que investiga os aspectos não-nutricionais da alimentação (identidade cultural, tradição culinária, estrutura social, status social, e mudanças culturais); (3) da 
investigação dos aspectos cognitivos da alimentação (significados não-nutricionais do alimento); e (4) dos estudos ecológicos (Kandel et al., 1980).

Ainda de acordo com Kandel et al. (1980) a grande força dos estudos ecológicos é que em princípio eles permitem relacionar fatores biológicos e culturais dentro de um mesmo nível de análise. Assim, uma explicação ecológica para uma deficiência nutricional na primeira infância, em uma população agrícola de Terceiro Mundo, pode incluir num mesmo grau de magnitude, por exemplo, o tamanho e a composição familiar, as práticas de amamentação calórica, os métodos de cultivo, os altos níveis de infestação crônica de parasitoses e os baixos níveis educacionais e de rendimentos.

Uma das formas de se avaliar o "sucesso" ecológico de uma população é através de sua qualidade de vida. Em termos biológicos, isto pode ser feito através de padrões médicos ou demográficos, tais como tamanho populacional ao longo do tempo, morbidade, mortalidade ou status nutricional, por exemplo (Moran, 1994).

A abordagem ecológica é importante pois permite delinear os elementos de um sistema dinâmico, determinado como os vários elementos funcionam em conjunto, identificando perigos e áreas de estresse potencial, prevendo mudanças, e investigando respostas adaptativas $\mathrm{e}(\mathrm{ou})$ deletérias às mudanças esperadas e inesperadas no sistema (Jerome et al., 1980 citado Adams, 2002).

A desnutrição humana é um problema ecológico, já que é o resultado de interações de vários ambientes que formam a ecologia da comunidade investigada físico, biológico, social, e cultural (incluindo as restrições econômicas e as prioridades políticas). A disponibilidade do alimento e nutrientes para uma população vai depender, entre outros fatores, do clima, do tipo de solo, das práticas agrícolas, dos métodos de estocagem, do transporte e da comercialização (Adams, 2002).

Dietas inadequadas podem estar relacionadas à pobreza, à insuficiência de terras, ao tamanho da família, à falta de alimento, ao conhecimento inadequado das necessidades nutricionais, a costumes que limitam o consumo de alimentos nutricionalmente importantes, ou a qualquer combinação destes outros fatores. A desnutrição infantil em países menos desenvolvidos raramente é causada apenas pela inadequação da dieta (Jellife et al., 1989). 
A antropologia nutricional utiliza métodos e técnicas de pesquisa de várias disciplinas: nutrição, economia agrícola, bioquímica, antropologia física, biomedicina, antropologia cultural, sociologia, psicologia, ciência política, entre outra, essenciais para o estudo das dimensões sociais, culturais, e psicológicas da produção e distribuição alimentar. Assim, não existe um método na antropologia nutricional, mas diferentes perspectivas metodológicas, que são utilizadas dependendo dos problemas a serem enfrentados (Adams, 2002).

Os métodos de investigação nutricional podem ser divididos em dois grandes grupos: aqueles que investigam diretamente o consumo de alimento (recordatório de 24 horas, consumo estimado, consumo mensurado, história dietética, e questionário de freqüência alimentar), e aqueles relacionados ao status nutricional resultante (antropometria nutricional, composição corpórea, estudos bioquímicos, imunológicos e clínicos). Neste trabalho o método escolhido foi a antropometria.

\subsubsection{Antropometria}

A antropometria vem sendo usada como ferramenta metodológia em vários tipos de estudos relevantes. Desta forma é elucidativo para o estudante de áreas não diretamente relacionadas à nutrição humana, eventual leitor do presente trabalho interdisciplinar, dispor de uma revisão abrangendo alguns de seus aspectos fundamentais, conforme apresentados abaixo.

Os dados mais fáceis de coletar e mais informativos sobre o estado nutricional de uma população resultam da pesquisa antropométrica. As medidas mínimas a serem coletadas são a altura e o peso dos indivíduos. Em combinação com os dados sobre sexo e idade, é possível estimar o estado nutricional da população, comparando-se com padrões internacionais.

A antropometria preocupa-se com a medida das variações das dimensões, proporções e de alguns aspectos da composição física do corpo humano, em diferentes situações nutricionais. A pesquisa antropométrica pode detectar deficiências de 
crescime nto e tem sido utilizada para investigar dois dos maiores problemas nutricionais do mundo: a desnutrição e a obesidade. A antropometria é o mais utilizado dos métodos porque tem baixo custo, relativamente fácil de executar, os equipamentos são portáveis, além de produzir uma indicação rápida do estado nutricional de uma população (Adams, 2002).

Desde o início da década de 80, o crescimento e o desenvolvimento dos indivíduos (principalmente das crianças com até 10 anos de idade) têm sido considerados como bons indicadores nutricionais e de saúde de uma população. O crescimento e desenvolvimento de uma criança é muito susceptível à disponibilidade de alimento e à incidência de doenças que, por sua vez, refletem as condições sociais, culturais, econômicas e físicas do ambiente (Kassouf, 1994; Monteiro \& Conde, 2000a).

Medidas de comprimento ou estatura em relação à idade são consideradas como medidas de duração da desnutrição, ou seja, da história nutricional passada (crônica). Elas demonstram a inibição ou o atraso no crescimento linear devido a deficiências em nutrientes ou energia. Por outro lado, medidas de peso para estatura são um índice do status presente (agudo) de desnutrição (WHO, 1985).

Os termos wasted (atrofia nutricional) e stunted (nanismo nutricional), foram introduzidos pela primeira vez por Waterlow (1972), para diferenciar entre as duas causas da desnutrição. O nanismo nutricional refere-se a um retardamento do crescimento do esqueleto, resultando numa redução da estrutura final (estatura baixa). $\mathrm{O}$ nanismo está frequentemente associado a condições econômicas desfavoráveis, infecções crônicas ou repetidas, ou consumo alimentar inadequado. Estas crianças não são a prioridade em termos de saúde pública, como são aquelas com atrofia, por apresentarem proporções corpóreas relativamente normais (Monteiro \& Conde, 2000b; Adams, 2002). De acordo com esses autores, a atrofia nutricional indica um déficit na massa de tecidos e gordura (magreza), quando comparado à quantidade esperada num indivíduo da mesma estatura ou estatura. Pode ser tanto o resultado de uma deficiência em ganhar peso, como da perda de peso propriamente dita, e pode estar sujeita a variações sazonais na aquisição de alimento ou à prevalência de doenças. Uma das suas 
prinicipais características é poder se desenvolver rapidamente, mas sob condições favoráveis, também pode regredir com rapidez.

A medida linear básica utilizada na antropometria é a estatura, que reflete o crescimento do esqueleto. A estatura é, reconhecidamente, o mais valioso indicador de longo prazo do crescimento ou de sua deficiência. Estaturas anormalmente baixas podem refletir em desnutrição crônica, mas ao contrário do peso, a estatura não é uma medida variável, e não pode descrever uma subnutrição aguda. A interpretação correta da estatura depende do conhecimento preciso da idade do indivíduo. O peso de um indivíduo fornece uma medida mais sensível às influências ambientais momentâneas do que a estatura (Monteiro \& Conde, 2000a; Adams, 2002; Maestro, 2002).

\subsubsection{1 Índices Antropométricos}

Os índices antropométricos nada mais são do que razões entre duas medidas corpóreas expressas através de quocientes ou percentagens. Os índices, como combinações de medidas, tem a função de interpretar e agrupar informações. Os indicadores mais comuns de desnutrição são taxas derivadas de medidas de estatura, peso e idade: peso-pela-estatura, peso-pela-idade e estatura-pela-idade. O peso-pelaestatura, por exemplo, é um indicador de desnutrição e obesidade quando o indivíduo é comparado a uma pessoa "normal" (referência) da mesma estatura (WHO, 1985). Uma outra vantagem oferecida pelos índices antropométricos baseia-se em que eles refletem as duas principais causas da desnutrição: a infecção e as deficiências alimentares (Morán, 1994).

\section{Peso-pela-estatura}

A relação peso e a estatura fornecem uma medida do quão magro ou gordo é um indivíduo, e pode ser considerada como uma estimativa aproximada da composição corpórea. Ao relacionar peso a estatura, ao invés da idade, podemos distinguir um baixo 
peso corpóreo devido à perda de tecidos moles (atrofia nutricional) de um baixo peso causado por um esqueleto pequeno. É a melhor medida para avaliar mudanças corpóreas de curto prazo.

Quando o índice de peso/altura é deficiente, de acordo com os padrões internacionais, temos um indicador muito sensível de quais indivíduos precisam de atenção imediata (desnutrição aguda) e a necessidade de atuar rapidamente para evitar a desnutrição grave (Morán, 1994). Em contrapartida, uma elevada incidência de pesospara-estatura altos (sobrepeso) pode ser considerado como um indicador adequado de obesidade, já que a maior parte dos indivíduos com altos índices são obesos (Monteiro \& Conde, 2000a).

\section{Estatura-pela-idade}

Reflete o crescimento linear adquirido, e seu déficit indica deficiências cumulativas, de longo prazo, de saúde e nutrição. Um crescimento deficiente (nanismo nutricional) pode ser causado tanto por um fator inibitório persistente (infecções repetitivas, por exemplo), de longo prazo, quanto por algum evento pontual passado (uma doença grave) (Cruz et al., 2001; Monteiro \& Conde, 2000a).

A Organização Mundial de Saúde não recomenda o termo baixa estatura-pelaidade como sinônimo de desnutrição crônica, já que não é possível distinguir uma baixa estatura-pela-idade entre uma população onde a maior parte das crianças é geneticamente pequena e não possui, necessariamente, alguma deficiência nutricional, e uma população em que a estatura-pela-idade baixa é patológica (nanismo nutricional). Apesar de ainda não ser possível definir até que ponto uma criança com nanismo nutricional está sofrendo de desnutrição crônica, não há dúvidas de que seu status nutricional indica a existência de influências ambientais negativas para o crescimento. Uma alta incidência de baixas estaturas-pela-idade na população indica más condições de vida e saúde, que podem incluir dietas deficientes. Deficiências nutricionais específicas, como de vitaminas e minerais, podem ter algum papel, mas até hoje nada foi comprovado (Adams, 2002; Monteiro \& Conde, 2000b; Martins et al., 2002). 


\section{Peso-pela-idade}

O peso-pela-idade reflete a massa corpórea com relação à idade, e é influenciado tanto pela estatura quanto pelo peso do indivíduo, e sua interpretação é complexa (WHO 1995b). Este índice não acrescenta nenhuma informação àquelas já citadas pelos dois indicadores anteriores. Uma elevada proporção de baixos pesos-pela-idade na população pode indicar tanto desnutrição aguda como condições de vida insatisfatórias, ou seja, uma situação crônica passada e a desnutrição aguda de hoje (Morán, 1994).

\subsubsection{Avaliação Antropométrica}

Para se classificar o estado nutricional dos indivíduos de uma população é necessário a adoção de critérios para esta classificação, como também pontos de corte. No entanto, esses critérios adotados nem sempre são apresentados com clareza na literatura. Segundo Reichenheim \& Hasselman (2001) a escolha deste critério é um dos desafios enfrentados por epidemiologistas pois refere-se à eficiência dos estudos.

Maestro (2002) considerou o escore z como o índice apropriado para definir os pontos de corte na avaliação do crescimento e evolução nutricional durante a infância. De acordo com a autora, o escore $\mathrm{z}$ foi calculado a partir do valor observado em cada indivíduo subtraído do valor da mediana, dividido pelo desvio padrão. Considerando significativo necessitando de intervenção nutricional, aqueles casos abaixo do ponto de corte de escore $\mathrm{z}<2$ desvios-padrão (DP) e aqueles superiores a 2 DP. Entretanto, Monteiro \& Conde (2000a) calcularam o escore z correspondente a estatura/idade de cada criança subtraindo-se sua estatura da média de estatura esperada para idade e sexo de acordo com o padrão de referência, dividindo o resultado da subtração pelo desviopadrão relativo à média esperada. Segundo os autores esse escore expressa a distância, em unidades de desvio-padrão, que a estatura de uma criança mantém com relação a média de estatura esperada para sua idade e sexo. No entanto Monteiro \& Conde (2000b) e Maestro (2002), adotaram como nível de corte para identificar déficits de 
estatura e sobrepeso, 2 DP aquém ou além da mediana do índice antropométrico na população de referência.

Martins et al. (2002) utilizaram como padrão de referência o indicador estatura/idade, sendo considerados com risco de baixa estatura valores abaixo do percentil 5 (P5). Já no estudo de Post et al. (1999) foram consideradas com déficit de peso ou estatura, as crianças com índices de estatura/idade e peso/estatura inferiores a dois desvios-padrão abaixo da mediana da referência norte-americana (NCHS).

Fica evidente que os pontos de corte utilizados para caracterizar a desnutrição são amplamente aceitos como aqueles <-2 DP e para obesidade os escores > 2 DP, pela literatura visitada. No entanto, a Organização Mundial de Saúde utiliza como pontos de corte até 3 DP abaixo ou acima da mediana (OMS, 1983).

A OMS recomenda a utilização do curva de referência do National Center for Health Statistic (NCHS, 1977) como padrão. No entanto, recentemente, o referencial de crescimento NCHS, utilizado mundialmente, foi revisado, com o objetivo de corrigir e(ou) minimizar falhas. A principal crítica ao padrão do NCHS de 1977 é quanto à procedência do banco de dados que gerou as curvas de crescimento. As informações das crianças de zero a 36 meses de idade foram coletadas longitudinalmente pelo Fels Research Institute, entre crianças brancas de classe média, residentes em Ohio (EUA) no período de 1929 a 1975. Já os dados dos indivíduos de 2 a 18 anos resultaram de uma combinação de três estudos seccionais representativos da população americana, compilados pelo NCHS, o qual levaram em consideração todos os grupos étnicos e classes sociais (Soares, 2003). Dessas limitações e diferenças metodológicas resultou uma disjunção na curva, acarretando abruptas mudanças nos índices antropométricos quando a criança alcança dois anos. Um novo referencial antropométrico de crescimento foi publicado recentemente pelo Centers fo Disease Control and Prevention (CDC), em substituição àquele elaborado pelo NCHS (Soares, 2000).

Ainda segundo Soares (2000), observa-se pela literatura confusão e(ou) indecisão no meio profissional face à escolha de população de referência como também em relação aos pontos de corte. 


\subsection{Histórico de Novo Cruzeiro, MG}

O município de Novo Cruzeiro está localizado no Vale do Jequitinhonha, considerada uma das regiões mais pobres do Brasil e do mundo.

Novo Cruzeiro deve seu nome à denominação que foi dada a moeda nacional, em 1942. Os primeiros habitantes da região eram servidores de um latifundiário, em torno de 1880. Não há vestígios de que se tenham índios no território do município que entretanto, possui um distrito denominado Itaipé, nome indígena que se supõe ter sido adotado em virtude da grande quantidade de madeira e pedras existente no local. $\mathrm{O}$ povoado que deu origem a Novo Cruzeiro, foi fundado em 1917. Anteriormente já existia na região o povoado denominado Asvessas, fundado em 1880, pelo desbravador Honório de Souza (Ferreira, 1959). Esta cidade integrou o município de Araçuaí até 1942, quando foi elevado à categoria de município, compreendendo seis distritos: Caraí, Lufa, Marambinha, Itaipé e Novilhona, perdendo Caraí e Marambinha posteriormente, mas sendo elevados à categoria de distritos, os povoados de Queixada e Catugi. Em 1959, aquele município compreendia os seguintes distritos: Catugi, Itaipé, Lufa, Novilhona e Queixada. De acordo com os dados do recenseamento geral de 1950, a população do município constituía-se de 28581 habitantes, sendo estimadas para 1955 , 30638 pessoas. As principais aglomerações urbanas eram as da sede e das vilas de Itaipé, Lufa e Novilhona, havendo 91,94\% da população na zona rural e apenas 8,06\% naqueles centros urbanos. Segundo aquele censo, 39,28\% da população do município se dedicava à agricultura, pecuária e sivilcultura, enquanto que 48,56\% a atividades domésticas não remuneradas e atividades escolares discentes. A indústria extrativista contava com $0,30 \%$; a indústria de transformação com $0,72 \%$; o comércio de mercadorias com $0,94 \%$; a prestação de serviços com 1,55\%; os transportes, as comunicações e armazenagem, com 0,29\%, as profissões liberais figuravam com 0,03\%, e outras. Havia portanto, pouco mais de $1 / 3$ da população dedicada à agricultura, pecuária e silvicultura (em números absolutos descontados os trabalhadores não remunerados, os discentes e os inativos), em segundo lugar constatava-se o setor de prestação de serviços. As indústrias mais significativas eram as de aguardente, de cana e 
as de queijo e manteiga. A agricultura concentrava-se principalmente na produção de milho, feijão, alho, cana-de-açúcar, mandioca e café, nessa ordem, gerando entretanto menos da metade da renda da atividade pecuária, assentada principalmente na produção de bovinos e suínos entre outros, com maior destaque para os primeiros. Em 1959, o território municipal era cortado por $164 \mathrm{Km}$ de estradas de rodagem e naquele ano foram registrados na Prefeitura Municipal, duas caminhonetes e dois caminhões. Constavam no município, 7 estabelecimentos comerciais atacadistas, 5 desses na sede e 253 varejistas, dos quais 84 na cidade; uma agência bancária, duas bibliotecas, um hospital com 20 leitos e um serviço de saúde, dois hotéis, uma pensão e um cinema. Havia no município uma Agência de Estatística, órgão integrante do sistema estatístico brasileira. A porcentagem de alunos matriculados, relativa à população em idade escolar era de 25,23\%. O número de estabelecimentos de ensino variou entre 1954, 1955 e 1956 respectivamente de 42 para 38 e 34 (Ferreira, 1959).

Em Novo Cruzeiro, em 1950 havia aproximadamente 28600 habitantes e foram estimados para 1955 aproximadamente 30600. A população estimada para 1996 naquele município foi de 31000 habitantes, $25,8 \%$ dos quais residentes na zona urbana e 74,2\% na zona rural, contra aproximadamente $8 \%$ e $92 \%$ respectivamente, na década de 50 . Entretanto, segundo dados fornecidos pela própria prefeitura do município no ano de 2000 (coleta dos dados), nos últimos 40 anos Novo Cruzeiro não foi evidenciado aumento populacional além de ser registrado êxodo do campo para a cidade, o que continua válido em 2003 (http://netpage.estaminas.com.br/glpa/historia.htm acessado em 03/12/2003).

\subsection{Breve histórico de Piracicaba, SP.}

"A fundação de Piracicaba data de meados do século XVIII e a origem do povoamento foi a necessidade de um núcleo agrícola que funcionou durante muito tempo como fonte de abastecimento de víveres, primeiro das minas de Cuiabá e depois da colônia de Iguatemi. Desta forma, embora a cana-de-açúcar esteja ligada desde o 
início à história de Piracicaba, não foi ela a causa do povoamento e nem era cultivada em caráter de monocultura", o que só começou a acontecer a partir de 1950 (Wiendl, 1970 citado em Molina, 1997).

Segundo Maluf (1988), Piracicaba é uma cidade extremamente caracterizada pela migração, o que é evidenciado até mesmo pela comparação da alteração do número de habitantes entre 1900 e 1920, que de 25374 passou a 67732, alteração esta, devida em grande parte à vinda de imigrantes para trabalhar nas lavouras de café.

Os estrangeiros se estabeleceram no campo e na cidade, ativando o pequeno comércio e introduzindo novos costumes. Eram principalmente portugueses, espanhóis e italianos. Depois vieram os japoneses. Tantos imigrantes trouxeram características culturais diversas à cidade chegando a distinguir de modo especial algumas regiões da mesma (Molina, 1997).

O Bairro dos Alemães é uma reminiscência da primeira imigração alemã que ocorreu em 1852. Perto de distrito de Artemis há um local denominado Colônia Japonesa, no qual viveu um nobre japonês, que imigrou em 1917 com 10 famílias. Dr. Paulo de Morais Barros, médico, voltou do Japão impressionado com a capacidade de trabalho dos japoneses e contratou 40 famílias para morar na fazenda Pau D'alho, de sua propriedade. $\mathrm{O}$ contrato excluía os velhos e doentes, exigia que a família tivesse pelo menos três enxadas e por isso algumas famílias precisaram adotar filhos para atender às exigências para a imigração. A colônia japonesa contemporânea constitui-se de quase 250 famílias, integradas à vida da cidade, sendo motivo de orgulho os diplomas de nível superior da maioria dos filhos de imigrantes japoneses. Em 15/08/1978, o Jornal de Piracicaba comemorou os 60 anos da imigração japonesa à cidade.

Os mais antigos imigrantes de língua árabe chegaram à região por volta de 1890 . Estes imigrantes tiveram no passado a atividade de mascates, os quais também faziam a comunicação entre as diversas localidades da região, levando junto as suas mercadorias, encomendas e recados. A comunidade árabe organizou na cidade uma associação destinada principalmente a amparar esses imigrantes para que não passassem por dificuldades. Esses, ao chegarem recebiam hospedagem, alimentação e uma mala com mercadorias para começar a ganhar a vida. Um descendente destes imigrantes, hoje 
professor universitário, declarou "nunca se admitiu que um árabe peça esmolas na rua, por isso ele sempre encontra ajuda dos patrícios para se firmar".

Em 1920, as notícias já desestimulavam a imigração italiana para a cidade, pois esses imigrantes tiveram, participações importantes nas greves operárias realizadas na cidade em 1917 e 1919. Em 1919 a imprensa divulgou planos dos grevistas, desarticulando-os e afirmando que "era coisa de estrangeiro". Segundo o Jornal de Piracicaba (01/08/1994), os organizadores do movimento foram presos e indiciados sob a acusação de quererem instaurar o bolchevismo em Piracicaba.

Entretanto, em 1905, pelo menos metade dos habitantes da cidade era de origem italiana e por isso esta foi a mais forte influência em Piracicaba. A presença italiana é forte também no campo. Muitos imigrantes permaneceram fiéis à terra. Aproveitando o desmembramento de grandes glebas, tornaram-se proprietários rurais e atualmente a maioria fornece cana para as usinas. É o caso típico de Sant'Ana e Santa Olímpia, bairros rurais localizados a doze quilômetros de Piracicaba. Sua origem se liga à chegada ao Brasil, por volta de 1877 de um grupo de tiroleses, emigrados de Trento, então território Austríaco. Uma das famílias imigrantes (os Vitti) conseguiu comprar, depois de algum tempo, uma fazenda em Piracicaba, que a partir de 1910 começou a ser dividida entre seus descendentes, dando origem àqueles bairros. Com a crise do café, os tiroleses cultivaram cereais, mas logo depois passaram para a cana-de-açúcar (Maluf, 1988).

Segundo o historiador Guilherme Vitti, "os primeiros imigrantes chegaram a Piracicaba, então Cidade da Constituição, no período de 1861 a 1874. Eram alemães, suíços e americanos que trouxeram para a cidade o primeiro surto de artesanato e pequenas indústrias.”(Jornal de Piracicaba, 01/08/1994). Esses imigrantes eram ferreiros, carpinteiros, funileiros, ourives.

Ainda no Jornal de Piracicaba (01/08/1994) Terce também descreve como presença mais marcante a dos imigrantes italianos, seguida à distância pelos síriolibanenses, espanhóis, portugueses, alemães, japoneses e judeus. A vinda dos italianos em grandes massas está registrada desde 1887. "Eles eram incentivados pelas elites piracicabanas a manter suas identidades e valores étnicos". Segundo essa mesma 
professora, ocorreu na região a primeira experiência com o emprego da mão-de-obra livre, feita pelo senador fazendeiro, Nicolau Vergueiro, por volta de 1840, quando já havia indícios do fim da escravidão no Brasil. Entretanto, ocorreram maus tratos nas fazendas e muitos imigrantes buscaram outras regiões, retornaram à Itália ou dirigiramse às cidades.

Em 1968, em trabalho rigorosamente científico, Saldanha identificou em Capivari, Município que faz fronteira com Piracicaba, ao sul desta última, distando da mesma 50 quilômetros por estrada de rodagem, 57\% de mistura italiana, ou seja de indivíduos descendentes total ou parcialmente de italianos, enquanto 39\% eram descendente total ou parcialmente de brasileiros, registrando um fluxo gênico daqueles imigrantes, igual a 33,14\%, concordante com as taxas de migração das duas gerações anteriores à realização de sua pesquisa.

Em 1969, entre os proprietários rurais residentes, 58\% eram filhos de brasileiros (pai e mãe); 35\% de estrangeiros (pai e mãe), sendo apenas 7\% descendentes de casamento de brasileiro e estrangeiro. Estimourse que $47 \%$ dos proprietários receberam suas terras em herança. Por outro lado, no conjunto total de proprietários (residentes e não residentes), $42 \%$ eram estrangeiros, contra $7 \%$ da população total, reafirmando a maior proporção de estrangeiros, em relação aos brasileiros natos, entre os proprietários rurais (Wiendl, 1970 citado em Molina, 1997).

Piracicaba hoje é um importante pólo regional de desenvolvimento industrial e agrícola, está situada em uma das regiões mais industrializadas e produtivas de todo o Estado, onde se concentra uma população aproximada de 1,2 milhões de habitantes. A condição econômica do município é estável, favorecendo a instalação de grandes indústrias. Um distrito industrial muito bem estruturado, adequado a um plano de desenvolvimento equilibrado, é também fator de atração para novas indústrias (http://www.ciagri.usp.br/piracica/hist_p.htm acessado em 03/12/2003). 


\section{CASUÍSTICA E MÉTODOS}

\subsection{Municípios Estudados}

Novo Cruzeiro, MG localiza-se no nordeste daquele estado, a $115 \mathrm{Km}$ de Teófilo Otoni e em linha reta, dista da capital do estado, $347 \mathrm{Km}$, no rumo norte-nordeste; latitude $17^{\circ} 28^{\prime}$ sul; longitude $41^{\circ} 52^{\prime}$ oeste, a $772 \mathrm{~m}$ de altitude em relação ao mar. Sua área total abrange $2433 \mathrm{Km}$ e com 31000 habitantes no ano de 2000, dos quais 8000 residem na zona urbana e 23000 na zona rural. As atividades econômicas consistem no plantio de um modo geral, principalmente do café e na criação de gado. A grande maioria da população sobrevive de aposentadoria do INSS e da Prefeitura Municipal.

Piracicaba, SP situada no interior do estado, a $180 \mathrm{Km}$ da capital, latitude $22^{\circ} 42^{\prime}$ sul e longitude $47^{\circ} 38^{\prime}$ oeste, a $554 \mathrm{~m}$ de altitude em relação ao mar. Sua área total abrange 1312,20 Km. A área urbana compreende 158,06 Km, abrigando 95\% da população e a área rural constitui-se $1154,24 \mathrm{Km}$. Suas principais atividades econômicas relacionamse à agricultura e à indústria, tendo em 2000, 329.158 habitantes, sendo a população rural estimada em 11.784 indivíduos e a urbana 317.374 .

\subsection{Constituição das Amostras}

Crianças pré-escolares matriculadas no ano de 2000 nas instituições públicas da cidade de Novo Cruzeiro, num total de 60 crianças. 
Crianças pré-escolares matriculadas no ano de 2000 em trinta e duas instituições públicas de Piracicaba, perfazendo um total de 3996 crianças.

Cabe ressaltar que o termo "pré-escolar" assume no presente trabalho, o sentido amplo, referindo-se desde bebês às crianças maiores, que ainda freqüentam as Escolas Municipais de Educação Infantil (E.M.E.I.). Refere-se portanto a crianças que ainda não ingressaram na $1^{\mathrm{a}}$ série do $1^{\mathrm{o}}$ grau.

\subsection{Coleta dos dados}

Para a coleta desses dados elaborourse um questionário semi-quantitativo (anexo), contendo as informações necessárias ao desenvolvimento desta pesquisa.

Os dados de Piracicaba foram fornecidos pela Secretaria da Educação do Município de Piracicaba, SP, mediante as fichas de coleta preenchidas como recomendado em reunião específica, por Carolina Chade e prof ${ }^{a}$ Silvia M.G. Molina, aos Agentes de Saúde das E.M.E.I. Em contrapartida, o município solicitou o diagnóstico nutricional dessas crianças, a partir da análise realizada com os dados de peso, estatura, sexo e idade.

\subsubsection{Peso e Estatura}

As tomadas de peso e estatura das crianças matriculadas na rede pública de ensino de Piracicaba também foram conduzidas pela própria rede de Agentes Escolares de Saúde no Município de Piracicaba e por Chade (2000) em Novo Cruzeiro, MG, após treinamento oferecido por Molina. Foram utilizadas balanças antropométricas, das marcas ARJA ou Filizola.

Antes do início das tomadas de peso, em todas as ocasiões, as balanças foram reguladas com pesos de metal somando 2,0 kg. Para as tomadas de peso das crianças foram observados os seguintes procedimentos: travoutse o braço da balança; 
movimentoutse o peso maior até o valor estimado para a criança; as crianças foram pesadas apenas com as roupas íntimas; movimentourse o peso menor até a balança atingir o equilíbrio; travou-se a balança para retirar a criança; anotou-se o valor obtido em kg, com duas casas decimais, sendo de $100 \mathrm{~g}$ a variação mínima registrada pelo equipamento; reconduziu-se os pesos ao valor zero.

Para as medidas de estatura das crianças, foram adotados os seguintes procedimentos: solicitourse às crianças que retirassem seus sapatos e subissem na balança antropométrica, assumindo uma postura ereta, com os braços ao longo do corpo, pés paralelos e cabeça normalmente erguida, com a linha do canto externo do olho em plano horizontal e paralela ao plano que passa pelo conduto auditivo; aproximou-se o eixo horizontal e perpendicular à escala da régua da balança antropométrica até que este seja apoiado no couro cabeludo da criança; registroutse o valor obtido, com aproximação de $0,5 \mathrm{~cm}$ As crianças de até 23 meses de idade foram medidas na posição deitada segundo um modelo padronizado.

\subsection{Relato do cotidiano das crianças nas E.M.E.I.}

Tendo em vista que os dados deste estudo foram coletados por Agentes de Saúde das E.M.E.I., que receberam treinamento oferecido pela orientadora do presente trabalho, foram realizadas visitas e conversas informais com uma das coordenadoras das E.M.E.I., com o objetivo de melhor conhecer o cotidiano das crianças. Dessa forma, foi possível obter informações sobre os hábitos diários das crianças referentes ao período das 7:00 às 17:00 horas, o qual passam na E.M.E.I. Dentre eles se destacam os horários, quantidade e qualidade da alimentação, a qual é diferenciada de acordo com a etapa de desenvolvimento das crianças. Geralmente é adotada uma classificação diferencial entre crianças de até 23 meses e de 24 meses em diante. Também são incentivados hábitos que variam desde cuidados com a higiene, orações, até ações como amarrar o próprio calçado. A coordenadora da E.M.E.I., visitada (Vila Independência), relatou que o cardápio seguido é o mesmo em todas as creches, sendo preparados pelas merendeiras. 
Tanto seu conteúdo como a porção servida a cada criança segue orientação de nutricionista.

\subsection{Processamento dos dados}

Os dados coletados foram compilados em banco de dados correspondentes à ficha de coleta, elaborada no software EPI-INFO (Dean et al., 1994), versão 6.04. Utilizourse o módulo CHECK, para se evitar erros durante a entrada dos dados e poupar tempo através de instruções para operações automáticas como por exemplo a relação peso/estatura e estatura/idade. Para identificar eventuais erros após a digitação das 4056 fichas, foi utilizado o módulo ANALYSES, o qual forneceu a freqüência de cada variável, sendo possível a identificação e correção de falhas.

Posteriormente, os dados foram exportados para o software Statystical Analysis System (SAS). A eficiência do processo de conversão (pelo EPI-INFO) e interpretação dos dados (pelo SAS) foi conferida obtendo-se média, desvio padrão, soma, valor máximo e mínimo, número de indivíduos e número de valores perdidos para cada variável, no conjunto de dados original (em EPI-INFO) e nos dados transferidos para o SAS.

\subsubsection{Estratos populacionais}

Para melhor avaliação dos dados $(\mathrm{n}=4056)$, dentro dos objetivos propostos, tornourse necessária a caraterização dos seguintes estratos populacionais:

1. crianças com ambos os pais mineiros, residentes em Novo Cruzeiro (CCMG).

2. crianças com ambos os pais mineiros residentes em Piracicaba (PMMG).

3. crianças com pai e mãe paulistas, residentes em Piracicaba (PMSP).

4. crianças com pai mineiro e mãe paulista, residentes em Piracicaba (MAEMG).

5. crianças com pai paulista e mãe mineira, residentes em Piracicaba (PAIMG). 
Neste sentido, para avaliar a migração como estratégia adaptativa foram comparadas as crianças do item 1 (geneticamente originadas de Minas Gerais e vivendo neste ambiente) com as crianças dos demais grupos. Entre os grupos 1 e 2 foram comparadas populações de indivíduos mineiros, geneticamente semelhantes, vivendo em ambientes distintos (Minas Gerais e Piracicaba); entre 1 e 3, foram comparados grupos de indivíduos com origens genéticas diferentes. Entre 1 e 4 e 1 e 5, foram comparados indivíduos com patrimônio genético de Minas Gerais e mestiços com Paulistas, mas variando se o indivíduo migrante é o pai ou a mãe, respectivamente, avaliando-se portanto o efeito desse diferencial. Foram comparadas as distribuições obtidas quanto às classificações nutricionais e demais variáveis em estudo, em cada um dos estratos populacionais estudados.

É importante destacar que em função desse procedimento, as crianças préescolares cujos pais nasceram em outro estado que não MG e SP, e hoje residem em Piracicaba, foram excluídas das análises aqui apresentadas. Assim, os cinco subgrupos relatados acima somam um total de 2538 crianças.

\subsubsection{Seleção das variáveis}

Dentre as variáveis coletadas através do questionário respondido pelas famílias das crianças (pais ou responsável), algumas foram selecionadas para as análises apresentadas neste trabalho. Optou-se pelas variáveis que influenciam significativamente a situação nutricional da criança, conforme constatado na literatura visitada.

Ressalta-se que as variáveis "presença e tipo de uso do quintal" receberam destaque no presente trabalho, por ter sido evidenciado em estudo anterior dessa Equipe (Nascimento et al., 2003), a importância destas para a qualidade da alimentação e que o abandono de práticas tradicionais de plantio de cultivos e criações realizados nos quintais, pode levar a uma queda no estado nutricional das famílias incluindo suas crianças. Desse modo, foi interessante estudá-la verificando o uso de quintais por 
famílias com um modo de vida pré-urbano (Novo Cruzeiro) e por famílias mais modernizadas (Piracicaba).

Cabe destacar também a relevância da variável genética: "origem étnica de acordo com o sobrenome da mãe (italiano ou não)". Esta variável foi estudada com o objetivo de caracterizar a ocorrência atual de sobrenomes dessa origem no município, uma vez que Piracicaba se caracterizou no passado, como receptor de migrantes dessa origem (Saldanha, 1968). Além disso, em trabalho anterior dessa Equipe (Molina, 1997), a mesma mostrourse significativa em sua influência sobre o desenvolvimento fisico das crianças. Foram classificados os sobrenomes da mãe de cada uma das crianças de Novo Cruzeiro, agrupando-os quanto à origem, como "italianos" e "não italianos". Os critérios desta classificação foram obtidos de Guérios (1973) ; Germano-Perecin ${ }^{1}$, Nobre-Ferraz ${ }^{2}$ e Forastieri ${ }^{3}$ (comunicações pessoais) conforme apresentado em Molina (1997).

3.5.3 Descrição das variáveis estudadas

\subsubsection{Indicadores do desenvolvimento físico}

$>$ Peso corporal da criança $\left(\mathbf{X}_{\mathbf{1}}=\mathrm{PESOKG}\right)$. Variável contínua, expressa em quilogramas, com três casas decimais que foi empregada no cálculo da variável peso/estatura.

Dstatura da criança $\left(\mathbf{X}_{\mathbf{2}}=\right.$ ESTATURACM). Variável contínua, expressa em centímetros, com duas casas decimais que foi empregada no cálculo das vaiáveis estatura/idade e peso/estatura.

Idade da criança ( $\mathbf{X}_{\mathbf{3}}=$ IDADEMESES). Variável contínua, expressa em meses, sem casas decimais, sendo a aproximação feita para o valor inteiro anterior, se a fração

\footnotetext{
${ }^{1}$ Dra. Marli Germano-Perecin, historiadora de Piracicaba, SP.

${ }^{2}$ Sr. Manoel Nobre Ferraz, tradicional conhecedor de heráldica de famílias de Piracicaba.

${ }^{3}$ Dr. João Carlos Forastieri, médico e estudioso de origens, tradições e heráldica de famílias de Piracicaba e região.
} 
da idade da criança, em dias, correspondeu a até 14, e para o próximo valor inteiro se essa fração correspondeu a 15 dias ou mais.

Sexo da criança $\left(\mathbf{X}_{\mathbf{4}}=\mathrm{SEXO}\right)$. Variável expressa em duas categorias, $0=$ feminino e $1=$ masculino.

\subsubsection{Indicadores do ambiente}

Idade da mãe ao nascimento da criança $\left(\mathbf{X}_{5}=\right.$ IDMNASC). Variável expressa em cinco categorias: $1=$ mães com idade igual ou inferior a 15 anos; $2=$ mães com idade entre 16 e 19; $3=$ mães com idade entre 20 e 29; $4=$ mães com idade entre 30 e 39; e $5=$ mães com idade superior a 40 anos.

Escolaridade da mãe ( $\mathbf{X}_{\mathbf{6}}=$ ESCOLM). Variável expressa em 5 categorias de acordo com anos de estudo ( $0=$ não estudou; $1=1$ a 4 anos de estudo; $2=4$ a 8 anos; $3=9$ a 11 anos de estudo e $5=$ mais que 11 anos de estudo).

Renda familiar per capita $\left(\mathbf{X}_{7}=\mathrm{RENDA}\right)$. Variável calculada a partir da soma das rendas de todos os indivíduos de cada residência dividida pelo números de moradores e pelo salário mínimo do período da coleta $(151,00)$.

Número de cômodos por moradores nas residências $\left(\mathbf{X}_{8}=\mathrm{COMMOR}\right)$. Variável considerada como indicador do nível sócio-econômico sendo expresso com quatro categorias: $1=$ menos que 0,5 cômodos para cada morador; $2=$ entre 0,5 e 1,$0 ; 3=$ entre 1,0 e 2,0; $4=$ maior que 2,0 cômodos por morador.

Presença de rede de esgoto na residência ( $\mathbf{X}_{\mathbf{9}}=$ ESGOTO). Variável expressa em duas categorias, $0=$ não possui rede de esgoto; $1=$ possui rede de esgoto.

$>$ Presença de energia elétrica na residência ( $\mathbf{X}_{\mathbf{1 0}}=$ ENERGIA). Variável expressa em duas categorias, $0=$ não possui eletricidade; $1=$ possui eleticidade.

$>$ De onde vem a água para beber $\left(\mathbf{X}_{11}=\right.$ ÁGUA). Variável expressa em quatro categorias, $1=$ rede pública; $2=$ poço; $3=$ rio, córrego, lagoa; $4=$ outro. 
Material da construção da residência ( $\mathbf{X}_{12}=$ MATERIAL). Variável expressa em seis categorias: $1=$ tijolos; $2=$ madeira; $3=$ barro/madeira; $4=$ papelão/lata; $5=$ madeira/tijolos; e 6= outro.

Presença de quintais e tipo de uso dos mesmos ( $X_{13}=$ PQUINTAL e $\mathbf{X}_{14}=$ USOQUINT). Variáveis categóricas, $\mathrm{X}_{19}$ expressa em duas categorais, $0=$ ausente; $1=$ presente e $\mathrm{X}_{20}$, também categórica, tem $\mathrm{n}^{\mathrm{o}}$ de níveis definidos em função do estudo dos dados compilados, quais sejam, 1=plantação de alimentos e/ou remédios; 2=coleta de alimentos ou remédios; $3=$ criaçãode animais; 4= outro uso.

\subsubsection{Indicadores genéticos}

Origem étnica da criança quanto à cor da sua pele $\left(\mathrm{X}_{15}=\mathrm{ETNIPELE}\right)$. Variável expressa em quatro categorias, $0=$ caucasóide; $1=$ negróide; $2=$ asiática; $3=$ mulata; 4=nada consta.

Origem étnica quanto aos sobrenomes da mãe ( $\mathbf{X}_{16}=$ ETNOMEM). Variável expressa em duas categorias, $0=$ não-italiana; $1=$ italiana.

Origem étnica quanto aos sobrenomes da criança ( $\left.\mathbf{X}_{17}=E T N O M E C\right)$. Variável expressa em duas categorias, $0=$ não-italiana; $1=$ italiana.

\subsection{Análise dos dados}

\subsubsection{Avaliação Antropométrica}

A partir dos dados de peso, estatura, sexo e idade das crianças, os índices antropométricos estatura-pela-idade e peso-pela-estatura foram calculados e comparados com o padrão de medidas da população de referência do NCHS, recomendada pelo OMS. 
Adotoutse como mais apropriado para definir os pontos de corte na avaliação nutricional a classificação com base nas unidades de desvio padrão ou escore-z (obtido mediante o valor da variável observada no indivíduo, subtraído do valor da mediana, dividido pelo desvio padrão da população de referência). Este índice evidencia a diferença entre a população de referência e a população estudada.

Escore $\mathrm{z}=$ valor individual - mediana da população de referência desvio-padrão da população de referência

As crianças classificadas como "eutróficas" apresentaram valores de estaturapela-idade e peso-pela -estatura distando até dois escores -z da mediana da população de referência, como sugerido pelo NCHS. No entanto, no presente estudo foram classificadas também as crianças cujos escore z distam entre 1 e 2 DP da mediana como faixa indicadora de risco. A proporção de crianças com escore-z entre -2 e -3 DP foram indicadas como portadoras de desnutrição leve a moderada, e abaixo de -3 DP com desnutrição grave (pregressa) se o índice antropométrico for estatura/idade (ZEI) e desnutrição aguda (atual) se o índice antropométrico for peso/estatura (ZPE). Por outro lado, as crianças com ZPE entre 2 e 3 DP foram classificadas com sobrepeso com risco para obesidade e aquelas cujos escore-z foi maior que 3 DP com relação à mediana da população de referência, como portadoras de obesidade grave.

De acordo com a literatura, numa população com boas condições de saúde e nutrição, a proporção de crianças com escore z menores que -2 não devem ultrapassar $2,3 \%$, que corresponde à frequência de crianças geneticamente baixas e(ou) magras. $\mathrm{O}$ número de crianças entre 1 e 2 DP não deve ser superior a 13,6\% e as demais crianças $(84,1 \%)$ devem ter escore z igual a zero (Ometto et al., 2000; Silva et al., 2000).

\subsubsection{Análise estatística}

A comparação entre os estratos populacionais foi realizada no programa SAS, empregando o teste de Cochran-Mantel-Haenszel $(\mathrm{CMH})$. Este teste foi aplicado para 
analisar as proporções númericas das variáveis nos cinco grupos. O CMH é usado para comparar subgrupos de populações independentes, dois a dois, obtendo uma comparação global da resposta da variável nos subgrupos (Walker, 1997). Assim foram avaliadas as diferenças estatisticamente significativas entre as distribuições obtidas em cada variável, no grupo de famílias residentes em Novo Cruzeiro com as distribuições obtidas em cada um dos outros quatro grupos de famílias residentes em Piracicaba. listadas acima. Este teste é calculado de acordo com fórmula apresentada abaixo:

$$
x_{c m h}^{2}=\frac{\left(\sum_{j=1}^{k} N U M_{j}\right)^{2}}{\sum_{j=1}^{k} D E N_{j}}
$$

onde:

$$
N U M_{J}=\frac{x_{1 j} \cdot n_{2 j}-x_{2 j} \cdot n_{1 j}}{N_{j}}
$$

$$
D E N_{J}=\frac{n_{1 j} \cdot n_{2 j} \cdot\left(x_{1 j}+x_{2 j}\right) \cdot\left(N_{J}-x_{1 j}-x_{2 j}\right)}{N_{J}^{2} \cdot\left(N_{J}-1\right)}
$$

Os resultados foram expressos em tabelas e gráficos de radar, e os grupos cujas distribuições diferiram das famílias de Novo Cruzeiro foram destacados com um asterisco $(*)$, ao nível de significância alfa de $5 \%(\alpha=0,05)$. 


\section{RESULTADOS E DISCUSSÃO}

A tabela 1 descreve todas as variáveis coletadas, assim como a média, desvio, soma, valor mínimo e máximo, obtidas para comparação após a exportação dos dados do programa Epi Info para o SAS.

Tabela 1. Estatísticas Descritivas - dados e variáveis referentes à amostra de préescolares

\begin{tabular}{lcccccc}
\hline \multicolumn{1}{c}{ VARIÁVEIS } & N & MÉDIA & S & SOMA & MIINIMO & MÁXIMO \\
\hline PESOKG & 3648 & 19808 & 5,754 & 78203 & 3,450 & 55,000 \\
ESTATURACM & 3875 & 108726 & 14,751 & 421314 & 5,000 & 138,000 \\
IDADEMESES & 4010 & 60,081 & 21,520 & 240924 & 1,000 & 98,000 \\
SEXO & 3562 & 0,487 & 0,500 & 1735 & 0,000 & 1 \\
IDMNASC & 3760 & 24791 & 5941 & 93212 & 10060 & 49770 \\
ESCOLP & 3561 & 6,218 & 2,954 & 22141 & 0,000 & 12,000 \\
ESCOLM & 3859 & 6,484 & 2,968 & 25021 & 0,000 & 12,000 \\
CORDAPELE & 4056 & 0,833 & 1,325 & 3378 & 0,000 & 4,000 \\
ETNOMEM & 3727 & 0,883 & 0,321 & 3291 & 0,000 & 1,000 \\
ETNOMEC & 3728 & 0,879 & 0,326 & 3276 & 0,000 & 1,000 \\
COOM/MOR & 3857 & 0,947 & 0,510 & 3651 & 0,200 & 4,000 \\
CCMG & 60 & 1,000 & 0,000 & 60 & 1,000 & 1,000 \\
PAIMG & 2291 & 0,838 & 0,368 & 1921 & 0,000 & 1,000 \\
MAEMG & 123 & 0,911 & 0,287 & 112 & 0,000 & 1,000 \\
PMMG & 284 & 0,993 & 0,084 & 282 & 0,000 & 1,000 \\
PMSP & 1705 & 0,820 & 0,384 & 1398 & 0,000 & 1,000 \\
PQUINTAL & 4036 & 0,144 & 0,351 & 580 & 0,000 & 1,000 \\
USOQUINT & 1805 & 3,027 & 0,883 & 5464 & 0,000 & 4,000 \\
ESGOTO & 4056 & 0,039 & 0,193 & 157 & 0,000 & 1,000 \\
ENERGIA & 3931 & 0,118 & 0,322 & 462 & 0,000 & 1,000 \\
ÁGUA & 4048 & 1,187 & 0,681 & 4805 & 1,000 & 4,000 \\
TIPODEMOR & 4057 & 4,000 & 0,000 & 16228 & 4,000 & 4,000 \\
PESO/ESTATURA & 3872 & 0,183 & 0,098 & 696 & 0,070 & 4,120 \\
ESTATUR/IDADE & 3870 & 2,234 & 1,733 & 8544 & 0,070 & 24,330 \\
\hline
\end{tabular}


Como já mencionado, neste estudo foram comparadas as diferenças entre os grupos de famílias residentes em Piracicaba com o grupo de famílias residente em Novo Cruzeiro, destacando-se particularmente as diferenças entre o grupo residente em Novo Cruzeiro e o grupo onde ambos os pais são migrantes e residem em Piracicaba. Neste sentido, não foram realizadas comparações entre os quatro grupos de famílias residentes em Piracicaba por não ir de encontro com os reais objetivos da pesquisa (avaliar a eficiência da migração de Novo Cruzeiro, MG para Piracicaba, SP.

Considerando-se somente as crianças que tiveram apenas o pai ou a mãe migrantes (PAIMG e MAEMG) e não ambos os genitores migrantes (PMMG), podemos notar que o número de homens migrantes (PAIMG) de Novo Cruzeiro para Piracicaba, é maior do que o número de mulheres migrantes (MAEMG). Ou seja, nas famílias em que há apenas um genitor vindo de MG, 56\% destes são os pais e 44\% são as mães. Aplicando-se um teste de $\chi^{2}$ aos valores absolutos (168 homens e 131 mulheres, valores mostrados em todas as tabelas) constata-se um desvio significativo ao nível $\alpha=0,05$. Porém, Camarano \& Abramovay (1999) enfatizaram que a migração feminina no Brasil tem superado a masculina em todas as décadas com exceção da década de 60. De acordo com esses autores, uma das consequiências do fenômeno diferencial por sexo é o aumento da masculinidade rural e uma redução desta nas áreas urbanas. Isto não se confirmou no presente estudo talvez por Piracicaba ter apresentado historicamente, mercado de trabalho para mão-de-obra masculina, por exemplo na construção civil e indústrias como a metalúrgica, empregando-os como técnicos, vigias e em outras funções. Este mercado poderia estar superando o tradicional para mulheres, como empregadas domésticas (Durham, 1984).

A tabela 2 (e a figura 2) nos permite visualizar um equilíbrio entre o sexo feminino e masculino nas crianças pré-escolares residentes no município de Piracicaba. Já no município de Novo Cruzeiro existe uma prevalência de crianças do sexo feminino $(62,3 \%)$ em relação ao sexo masculino $(37,7 \%)$, que freqüentam as creches. Assim, houve diferença significativa entre as distribuições de sexo das crianças residentes em Novo Cruzeiro (CCMG) e crianças filhas de pais nascidos no estado de São Paulo (PMSP) e entre aquelas onde apenas os pais migraram do estado de Minas Gerais 
(PAIMG). Nestes dois últimos grupos, ponderando-se o número de indivíduos pelo teste $\mathrm{CMH}$, as tendências de predomínio são invertidas em relação ao grupo CCMG.

Tabela 2. Distribuição dos pré-escolares segundo sexo e estrato populacional

\begin{tabular}{|c|c|c|c|c|c|}
\hline \multirow{2}{*}{ Sexo } & CCMG & PMMG & PMSP* & PAIMG * & MAEMG \\
\hline & $\mathrm{n} \quad \%$ & $\mathrm{n} \quad \%$ & $\mathrm{n} \quad \%$ & $\mathrm{n} \quad \%$ & $\mathrm{n} \quad \%$ \\
\hline Masculino & $20(37,7)$ & $140(48,8)$ & $968(51,1)$ & $89(53,0)$ & $64(48,9)$ \\
\hline Feminino & $33(62,3)$ & $147(51,2)$ & $926(48,9)$ & $79(47,0)$ & $67(51,1)$ \\
\hline Total & 53 & 287 & 1894 & 168 & 131 \\
\hline
\end{tabular}

É mostrado na tabela 3 (e figura 3) que a maioria das crianças residentes em Piracicaba são caucasóides (acima de 50\%), sendo diferente das crianças de Novo Cruzeiro onde o número de mestiços é maior (41,5\%).

Estudando-se a origem étnica, indicada pelo sobrenome da criança (tabela 4), constatou-se que em Novo Cruzeiro não houve nenhuma criança com sobrenome de origem italiana, e que houve apenas duas crianças no grupo de famílias migrantes com ambos os pais nascidos em MG com sobrenome italiano. Constatou-se também que os grupos de famílias em que a distribuição dos sobrenomes (italianos e não-italianos) diferiu do grupo de Novo Cruzeiro foram aqueles em que pelo menos um dos pais nasceu no estado de São Paulo. Foi encontrada entre os grupos da tabela 5, referente aos sobrenomes das mães, certa similaridade na porcentagem de sobrenomes de origem italiana em relação à distribuição dos sobrenomes encontrado na tabela 4. Porém, não foi significativo em relação ao grupo CCMG o grupo MAEMG (prob. $>\chi^{2} \mathrm{CMH}^{2} 0,06$ ) referente às famílias cujas mães vieram do estado de Minas Gerais. Esse resultado confirma que entre os indivíduos originados de Minas Gerais não existe uma porcentagem significativa de sobrenomes italianos. 
Tabela 3 Distribuição dos pré-escolares segundo a origem étnica (cor da pele) em cada estrato

\begin{tabular}{|c|c|c|c|c|c|}
\hline \multirow{2}{*}{ Cor da pele } & CCMG & PMMG* & PMSP* & PAIMG * & MAEMG * \\
\hline & $\mathrm{n} \quad \%$ & $\mathrm{n} \quad \%$ & $\mathrm{n} \quad \%$ & $\mathrm{n} \quad \%$ & $\%$ \\
\hline Caucasóide & $21(39,6)$ & $153(53,3)$ & $1353(71,3)$ & $120(71,4)$ & $88(67,2)$ \\
\hline Negróide & $10(18,9)$ & $16(5,6)$ & $183(9,6)$ & $10(6,0)$ & $9(6,9)$ \\
\hline Asiática & - & $11(3,8)$ & $33(1,7)$ & $6(3,6)$ & $1(0,7)$ \\
\hline Mestiço & $22(41,5)$ & $93(32,4)$ & $278(14,6)$ & $28(16,6)$ & $30(22,9)$ \\
\hline $\mathrm{N}$ consta & - & $14(4,9)$ & $52(2,8)$ & $4(2,4)$ & $3(2,3)$ \\
\hline Total & 53 & 287 & 1899 & 168 & 131 \\
\hline
\end{tabular}

Em contraste, Piracicaba tem um histórico de intensa imigração de italianos, constituindo os descendentes desses imigrantes, em 1905, metade de sua população. Constata-se no presente estudo, redução dessa proporção, em concordância com os dados apresentados em Molina (1997) em estrato populacional semelhante ao aqui estudado, entre os residentes em Piracicaba.

Tanto na tabela 4 quanto na tabela 5 (e figura 4), as quais se referem à origem étnica dos sobrenomes das crianças e das mães, respectivamente, nota-se que em relação aos grupos, aqueles onde ambos pais são mineiros (CCMG e PMMG) diferem estatisticamente daqueles das famílias residentes em Piracicaba, com exceção do grupo MAEMG da tabela 5. Como já esperado, o grupo que apresentou uma maior proporção de sobrenomes italianos foi o de ambos os genitores originados do estado de São Paulo (18\% na tabela 4 e $16,8 \%$ na tabela 5).

$\mathrm{Na}$ tabela 6 (e figura 5), referente à rede de esgoto, observa-se que o grupo CCMG, que se refere às famílias residentes em Novo Cruzeiro, difere significativamente de todos os outros grupos de famílias residentes na cidade de Piracicaba $(\mathrm{p}<0,05)$. Observa-se que $45,3 \%$ das famílias de crianças que freqüentam as creches de Novo 
Cruzeiro não possuem rede de esgoto na residência. Entretanto no município de Piracicaba, essa porcentagem é superior a $95 \%$ em todos os grupos.

Tabela 4. Distribuição dos pré-escolares segundo a origem étnica (sobrenome italianos ou não-italianos) e subgrupos

\begin{tabular}{|c|c|c|c|c|c|}
\hline \multirow{2}{*}{$\begin{array}{c}\text { ORIGEM } \\
\text { ÉTNICA }\end{array}$} & CCMG & PMMG & PMSP* & PAIMG * & MAEMG * \\
\hline & $\mathrm{n} \quad \%$ & $\mathrm{n} \quad \%$ & $\mathrm{n} \quad \%$ & $\mathrm{n} \quad \%$ & $\mathrm{n} \quad \%$ \\
\hline Italiano & - & $2(0,7)$ & $307(18,0)$ & $13(8,1)$ & $11(8,9)$ \\
\hline Não-italiano & $53(100,0)$ & $282(99,3)$ & $1398(82,0)$ & $147(91,9)$ & $112(91,1)$ \\
\hline Total & 53 & 284 & 1705 & 160 & 123 \\
\hline
\end{tabular}

Tabela 5. Distribuição dos pré-escolares segundo a origem étnica das mães (sobrenome italianos ou não-italianos) e subgupos

\begin{tabular}{|c|c|c|c|c|c|}
\hline ORIGEM & CCMG & PMMG & PMSP* & PAIMG * & MAEMG \\
\hline ÉTNICA & $\mathrm{n} \quad \%$ & $\mathrm{n} \quad \%$ & $\mathrm{n} \quad \%$ & $\mathrm{n} \quad \%$ & $\mathrm{n} \quad \%$ \\
\hline Italiano & - & $6(2,1)$ & $288(16,8)$ & $14(8,9)$ & $8(6,3)$ \\
\hline Não-italiano & $53(100,0)$ & $276(97,9)$ & $1422(83,2)$ & $143(91,1)$ & $119(93,7)$ \\
\hline Total & 53 & 282 & 1710 & 157 & 123 \\
\hline
\end{tabular}

O saneamento básico é de importância fundamental para a manutenção do bom estado nutricional da criança, uma vez que a protege de doenças infecciosas, por exemplo, a diarréia, que consome suas reservas energéticas podendo levá-la à desnutrição ou a morte (Martins et al., 2002).

Em relação à presença de energia elétrica, nota-se novamente uma diferença na distribuição dessa variável em todos os grupos de famílias residentes em Piracicaba, em relação ao grupo CCMG (Tabela 7 e figura 5). 
Tabela 6. Freqüência de crianças segundo acesso do domicílio à de rede de esgoto

\begin{tabular}{|c|c|c|c|c|c|}
\hline \multirow{2}{*}{$\begin{array}{l}\text { Rede de } \\
\text { esgoto }\end{array}$} & CCMG & PMMG* & PMSP * & PAIMG* & MAEMG * \\
\hline & $\mathrm{n} \quad \%$ & $\mathrm{n} \quad \%$ & $\mathrm{n} \quad \%$ & $\%$ & $\%$ \\
\hline Sim & $29(54,7)$ & $279(97,2)$ & $1833(96,5)$ & $163(97,0)$ & $127(96,9)$ \\
\hline Não & $24(45,3)$ & $8(2,8)$ & $66(3,5)$ & $5(3,0)$ & $4(3,1)$ \\
\hline Total & 53 & 287 & 1899 & 168 & 131 \\
\hline
\end{tabular}

Tabela 7. Distribuição dos pré-escolares segundo a disponibilidade de energia elétrica

\begin{tabular}{|c|c|c|c|c|c|}
\hline \multirow{2}{*}{$\begin{array}{l}\text { Energia } \\
\text { Elétrica }\end{array}$} & CCMG & PMMG* & PMSP* & PAIMG * & MAEMG * \\
\hline & $\mathrm{n} \quad \%$ & $\mathrm{n} \quad \%$ & $\mathrm{n} \quad \%$ & $\mathrm{n} \quad \%$ & $\mathrm{n} \quad \%$ \\
\hline Sim & $38(71,7)$ & $269(93,7)$ & $1669(88,2)$ & $152(91,0)$ & $116(88,5)$ \\
\hline Não & $15(28,3)$ & $18(6,3)$ & $224(11,8)$ & $15(9,0)$ & $15(11,5)$ \\
\hline Total & 53 & 287 & 1893 & 167 & 131 \\
\hline
\end{tabular}

Constata-se portanto, que crianças filhas de pais migrantes estão obtendo mais recursos para a garantia de um bom estado de saúde, no que se refere à eletricidade $(93,7 \%)$ e rede de esgoto $(97,2 \%)$ do que aquelas que residem em Novo Cruzeiro $(71,7 \%$ e 54,7\%; respectivamente). Segundo trabalho de Kassouf (1994), tanto a falta de eletricidade como do sistema de esgoto teve impacto no desenvolvimento físico de crianças quanto à estatura, afetando significativamente a saúde nas regiões Sudeste e Sul, no setor rural e nas famílias de baixa renda. Segundo essa autora, tais variáveis estão relacionadas à melhoria nas condições higiênicas e à melhor qualidade de vida.

Portanto, de acordo com os dados do presente estudo, pode-se assumir que há melhor qualidade de vida para os residentes na cidade de Piracicaba, SP, do que em Novo Cruzeiro, MG. Isto é particularmente relevante para as crianças até três anos de 
idade, em que o crescimento estatural é mais vulneráveis às condições ambientais (Martins et al., 2002).

Uma outra variável ambiental relevante para a saúde da população é de onde a família obtém a água para beber. Na tabela 8 (e figura 6), constata-se que pelo menos 90\% das famílias estudadas residentes em Piracicaba obtém a água da rede pública, não estando muito distante das famílias de Novo cruzeiro (88,7\%). Martins et al. (2002), em sua pesquisa sobre crescimento de estudantes de ensino fundamental e médio no estado de São Paulo, observou que a baixa estatura, reflexo do estado nutricional que se estabelece ao longo da infância, está associado à cidade com maior proporção de moradias sem água tratada. Kassouf (1994) observou um nível mais alto de mortalidade nas moradias sem sistemas de encanamento e esgoto, mostrando que a presença de infraestrutura habitacional é importante para evitar que as populações sejam expostas a doenças infecciosas e contagiosas.

Tabela 8. Distribuição dos pré-escolares segundo a procedência da água usada para beber na sua residência

\begin{tabular}{lcccccc}
\hline $\begin{array}{l}\text { Procedência } \\
\text { de água }\end{array}$ & $\begin{array}{c}\text { CCMG } \\
\mathrm{n}\end{array} \%$ & $\mathrm{n} \%$ & PMMG & \multicolumn{2}{c}{ PMSP } & \multicolumn{2}{c}{ PAIMG } & MAEMG \\
\hline Rede Pública & $47(88,7)$ & $275(96,1)$ & $1706(90,0)$ & $159(94,6)$ & $125(95,4)$ \\
Poço & $6(11,3)$ & $3(1,1)$ & $56(3,0)$ & $4(2,4)$ & - \\
Rio, lagoa, ... & - & - & $4(0,2)$ & - & - \\
Outro & - & $8(2,8)$ & $128(6,8)$ & $5(3,0)$ & $6(4,6)$ \\
Total & 53 & 286 & 1894 & 168 & 131 \\
\hline $\begin{array}{l}\text { Nota: * Indica grupos que diferem significativamente do grupo CCMG pelo teste de CMH, com nível de } \\
\text { significância alfa de 5\% ( } \alpha=0.05)\end{array}$
\end{tabular}

Quanto ao material de suas moradias (tabela 9 e 7), observourse que mais de $90 \%$ das famílias que residem em Piracicaba habitam casas de tijolos, enquanto que em Novo Cruzeiro este número se reduz para 26,4\% (p<0,05). A maioria das habitações das 
crianças de Novo Cruzeiro (73,6\%) é construída com outro tipo de material, que não constava no questionário ou houve omissão do dado. No entanto, Cha de (2000) verificou que $80 \%$ das moradias de MG são de adobe.

Tabela 9. Frequiência de pré-escolares segundo o material de construção da moradia

\begin{tabular}{|c|c|c|c|c|c|}
\hline \multirow{2}{*}{$\begin{array}{c}\text { Material de } \\
\text { construção }\end{array}$} & \multirow{2}{*}{$\begin{array}{c}\text { CCMG } \\
\text { n } \% \\
\end{array}$} & PMMG* & PMSP* & PAIMG * & MAEMG * \\
\hline & & $\mathrm{n} \quad \%$ & $\mathrm{n} \quad \%$ & $\mathrm{n} \quad \%$ & $\mathrm{n} \quad \%$ \\
\hline TIJOLOS & $14(26,4)$ & $273(95,2)$ & $1844(97,3)$ & $162(96,4)$ & $122(93,9)$ \\
\hline MADEIRA & - & $5(1,7)$ & $24(1,3)$ & $3(1,8)$ & - \\
\hline BARRO/MADEIRA & - & - & $1(0,05)$ & - & - \\
\hline PAPELÃO/LATA & - & - & $1(0,05)$ & - & - \\
\hline MADEIRA/TIJOLOS & - & $9(3,1)$ & $22(1,1)$ & $3(1,8)$ & $5(3,8)$ \\
\hline OUTRO & $39(73,6)$ & - & $4(0,2)$ & - & $3(2,3)$ \\
\hline TOTAL & 53 & 286 & 1894 & 168 & 131 \\
\hline
\end{tabular}

Nota: * Indica grupos que diferem significativamente do grupo CCMG pelo teste de CMH, com nível de significância alfa de $5 \%(\alpha=0.05)$

Um outro indicador do nível sócio-econômico, levantado neste trabalho, foi a relação do número de cômodos por morador em cada residência (tabela 10 e figura 8). As tendências das distribuições do número de cômodos por morador, dos grupos com apenas o pai ou apenas a mãe originado de MG diferem daquelas do grupo residente em MG. Todos os grupos entretanto, têm o maior número de famílias concentrado na proporção de 0,6 a 1 cômodo por morador. Por outro lado, nas famílias em que o pai e a mãe são do estado de SP, observoutse que domicílios com mais de 1 cômodo por morador, correspondem a 23,5\%. Quando apenas um dos pais é migrante de MG, o pai ou a mãe, constatourse os valores intermediários de 17,9\% e 19,9\%, respectivamente. Houve pouca diferença nos valores encontrados entre famílias residentes em Novo Cruzeiro, MG e em Piracicaba, SP, mas com ambos os genitores migrantes, 13,2\% e $14,3 \%$, sugerindo que a mestiçagem decorrente dos casamentos inter-áreas, envolvendo 
um indivíduo natural do local de recepção tende a elevar o nível sócio-econômico da família e assim, as condições para o bom desenvolvimento físico das crianças, com relação às condições de vida de crianças filhas de pai e mãe migrante, no que se refere às suas necessidades materiais.

Grillo et al. (2000) verificaram que o estado nutricional de crianças está associado a condições de saneamento básico, pois 100\% das crianças eutróficas pertenciam ao grupo de famílias moradoras em domicílios ligados à rede de esgoto, diferente das crianças consideradas desnutridas (47\%). Foi evidenciado que o número de crianças eutróficas que moravam em casa de alvenaria (73\%) era maior que as desnutridas $(46,7 \%)$.

Tabela 10. Relação número de cômodos por morador nos cinco grupos de famílias estudados

\begin{tabular}{|c|c|c|c|c|c|}
\hline \multirow{2}{*}{$\begin{array}{l}\mathrm{N}^{\mathrm{o}} \text { Cômodos } \\
\text { por morador }\end{array}$} & CCMG & PMMG & PMSP & PAIMG * & MAEMG * \\
\hline & $\mathrm{n} \quad \%$ & $\mathrm{n} \quad \%$ & $\mathrm{n} \quad \%$ & $\mathrm{n} \quad \%$ & $\mathrm{n} \quad \%$ \\
\hline$<=0,5$ & $16(30,2)$ & $85(29,6)$ & $417(21,9)$ & $54(32,1)$ & $26(19,8)$ \\
\hline $0,6-1,0$ & $30(56,6)$ & $161(56,1)$ & $1038(54,6)$ & $84(50,0)$ & $79(60,3)$ \\
\hline $1,1-1,5$ & $5(9,4)$ & $26(9,1)$ & $327(17,2)$ & $18(10,7)$ & $19(14,5)$ \\
\hline $1,6-2,0$ & $1(1,9)$ & $14(4,9)$ & $98(5,2)$ & $11(6,6)$ & $6(4,6)$ \\
\hline Mais que 2 & $1(1,9)$ & $1(0,3)$ & $19(1,1)$ & $1(0,6)-$ & $1(0,8)$ \\
\hline Total & 53 & 287 & 1899 & 168 & 131 \\
\hline
\end{tabular}

Quanto à faixa etária da mãe ao nascimento da criança (tabela 11 e figura 9), evidenciou-se que em Novo Cruzeiro nenhuma mãe tinha menos de 15 anos, mas em relação aos grupos de famílias residentes em Piracicaba as ocorrências nesta faixa etária variaram entre $7 \%$ e $10 \%$. Embora as freqüências de idade da mãe ao nascimento da criança, dos 16 aos 19 e 20 aos 29 anos sejam as predominantes em todos os grupos, há 
maior número de casos na faixa entre 20 e 29 anos. Por outro lado, ao nascimento da criança, apenas de $1,0 \%$ a 2,4\% das mães estavam na faixa acima dos 40 anos. Em termos de tendência da distribuição apenas o grupo de pais nascidos em MG (PAIMG) diferiu daquele de famílias residentes em $\mathrm{MG}(\mathrm{CCMG})$, o que sugere que suas esposas, naturais do local de recepção dos migrantes, tendem a ter filhos mais jovens que nos demais estratos estudados, não apresentando nenhum caso de mãe acima dos 40 anos, superando inclusive o grupo residente em MG no que se refere ao percentual de mães até 19 anos. Estes valores correspondem respectivamente a 32,1\% para as famílias residentes em MG e 36,9\% para as famílias onde apenas o pai é migrante deste local. Observando-se o grupo em que a mãe é migrante, constata-se apenas 19,1\% de idades ao nascimento do filho com mães até 19 anos e a maior incidência entre todos os grupos da faixa entre os 20 a 29 anos (58,8\%). É possível que a migração esteja elevando a idade da mãe ao nascimento da criança, uma vez que a mesma pode estar se dedicando prioritariamente à busca de um emprego no local de recepção. Torna-se interessante investigar a ocorrência de irmãos mais velhos nestes casos. Por outro lado, não se constatou aumento de gestações acima dos 40 anos neste grupo.

Quanto à influência da idade materna ao nascimento da criança, é sabido que as taxas de mortalidade materna são elevadas para mães menores de 20 anos, chegam ao mínimo na faixa dos 20 aos 30 anos e a seguir voltam a aumentar até o final dos anos férteis. Embora seja possível reduzir as taxas de mortalidade resultantes de complicação obstétrica controlando-se fatores sócio-econômicos como nutrição e cuidados pré-natais, o fator idade materna continua influenciando o risco de forma isolada e independente (Silva \& Chinaglia, s/d). Da mesma maneira, em estudo sobre gêmeos, cientistas norteamericanos demonstraram que quando estes são filhos de mães com mais de 25 anos inclusive aquelas na faixa etária dos 40 anos - são mais propensos a sobreviver ao primeiro ano de vida do que os bebês gêmeos de mulheres adolescentes ou com idade próxima aos 20 anos. As razões para a disparidade entre as faixas etárias continuam obscuras, mas podem decorrer de diversos fatores como diferença de escolaridade, de nível de renda e de classe social entre mães mais novas e as mais velhas (Health, 2002). Isso sugere que mães mais velhas poderiam, em geral, ser mais saudáveis que as jovens. 
Além de que a diferença de recursos pode influenciar o desenvolvimento dos bebês e mães mais jovens podem tanto ainda não terem completado seu próprio amadurecimento físico e psíquico como serem mais suscetíveis a problemas financeiros, o que pode interferir em sua capacidade de cuidar da criança e nas condições emocionais e materiais que podem lhes oferecer.

Tabela 11. Idade das mães ao nascimento das crianças nos cinco grupos estudados

\begin{tabular}{|c|c|c|c|c|c|}
\hline Idade da & CCMG & PMMG & PMSP & PAIMG * & MAEMG \\
\hline $\begin{array}{c}\text { mãe ao } \\
\text { nascimento }\end{array}$ & $\mathrm{n} \quad \%$ & $\mathrm{n} \quad \%$ & $\mathrm{n} \quad \%$ & $\mathrm{n} \quad \%$ & $\mathrm{n} \quad \%$ \\
\hline Menor que 15 & - & $23(8,0)$ & $134(7,0)$ & $17(10,1)$ & $13(9,9)$ \\
\hline $16-19$ & $17(32,1)$ & $48(16,7)$ & $426(22,4)$ & $45(26,8)$ & $12(9,2)$ \\
\hline $20-29$ & $24(45,2)$ & $160(55,8)$ & $998(52,6)$ & $82(48,8)$ & $77(58,8)$ \\
\hline $30-39$ & $11(20,8)$ & $49(17,1)$ & $323(17,0)$ & $24(14,3)$ & $27(20,6)$ \\
\hline Maior que 40 & $1(1,9)$ & $7(2,4)$ & $18(1,0)$ & - & $2(1,5)$ \\
\hline Total & 53 & 287 & 1899 & 168 & 131 \\
\hline
\end{tabular}

Dentre os fatores sócio-econômicos que influenciam a adequação nutricional da família, também se encontra o nível de escolaridade (anos de estudo) da mãe (tabela $12 \mathrm{e}$ figura 10). Araújo (1970) e Faria (1997) em estudos distintos, investigaram o nível de escolaridade da dona de casa, por assumirem que suas decisões influenciam tanto na preferência quanto nos hábitos de consumo familiares. Nos dois trabalhos, essa variável foi significativa, indicando que quanto maior o nível de escolaridade da mãe, maior a preocupação com o aspecto nutricional dos alimentos consumidos pela família. Carvalhes e Benício (2002) investigaram a capacidade materna de cuidar e desnutrição infantil. Os autores verificaram que a estrutura familiar adversa, indicada pela ausência 
de companheiro, quase triplicou o risco de desnutrição, assim como a baixa escolaridade mais do que duplicou esse risco.

No presente estudo, verificourse que $13,2 \%$ das mães de crianças de Novo Cruzeiro não estudaram, sendo que este número foi reduzido para as famílias que migraram para Piracicaba $(7,7 \%)$ e foi menor ainda nas famílias onde ambos pais são paulistas (2,8\%). O maior nível de escolaridade observado nas mães de famílias migrantes pode significar não só que a cidade de Piracicaba oferece vantagens educacionais; porém, estes dados podem indicar que as mães que tomam a decisão de migrar para centros urbanos são mais qualificadas do que aquelas não-migrantes.

Observou-se também que a escolaridade da mãe, foi maior nas famílias residentes em Piracicaba, particularmente no grupo PMSP, em que ambos, pai e mãe, são paulistas. A predominância em Novo Cruzeiro foi de mães que cursaram entre a $1^{\circ} \mathrm{e}$ $4^{\circ}$ série do ensino fundamental $(58,5 \%)$, assim como nas famílias em que ambos os pais são migrantes (54\%). Já nos outros grupos (não-migrantes e apenas um genitor de MG) a faixa de maior número de ocorrências foi a de 5 a 8 anos de estudo. Quanto a pelo menos ingresso no ensino superior, constatoutse apenas 1 mãe migrante contra 59 mães nascidas no estado de São Paulo. Houve diferenças significativas entre o grupo de famílias de Novo Cruzeiro (CCMG) e os grupos PMSP, PAIMG E MAEMG. Como no caso do indicador de nível-sócio econômico número de cômodos por morador no domicílio, casamentos inter-áreas favoreceram a elevação do nível de vida e novamente, as condições das famílias em que ambos são migrantes, não são muito diferentes daquelas das famílias que permaneceram em MG.

Thomas et al. (1990), obtiveram impacto positivo e significativo da educação da mãe sobre a estatura da criança tanto nas regiões urbanas quanto rurais do Nordeste Brasileiro. Da mesma maneira, na pesquisa de Kassouf (1994) a alfabetização da mãe e do pai mostrou efeito positivo na saúde da criança em áreas pobres, quando a renda per capita mensal familiar era menor que meio salário mínimo. Assim a autora concluiu que nas áreas pobres a saúde das crianças pode ser melhorada pelo decréscimo da taxa de analfabetismo dos pais. 
Tabela 12. Distribuição dos pré-escolares segundo os níveis de escolaridade materna (anos de estudo)

\begin{tabular}{|c|c|c|c|c|c|}
\hline \multirow{2}{*}{$\begin{array}{c}\text { Escolaridade } \\
\text { materna }\end{array}$} & CCMG & PMMG & PMSP* & PAIMG * & MAEMG * \\
\hline & $\mathrm{n} \quad \%$ & $\mathrm{n} \quad \%$ & $\mathrm{n} \quad \%$ & $\mathrm{n} \quad \%$ & $\mathrm{n} \quad \%$ \\
\hline Sem estudo & $7(13,2)$ & $22(7,7)$ & $54(2,8)$ & $12(7,1)$ & $5(3,8)$ \\
\hline $1-4$ & $31(58,5)$ & $155(54,0)$ & $373(19,7)$ & $50(29,8)$ & $46(35,1)$ \\
\hline $5-8$ & $10(18,9)$ & $93(32,4)$ & $895(47,1)$ & $72(42,9)$ & $54(41,2)$ \\
\hline $9-11$ & $5(9,4)$ & $16(5,6)$ & $518(27,3)$ & $31(18,4)$ & $24(18,3)$ \\
\hline$>11$ & - & $1(0,3)$ & $59(3,1)$ & $3(1,8)$ & $2(1,6)$ \\
\hline Total & 53 & 284 & 1891 & 167 & 130 \\
\hline
\end{tabular}

Monteiro \& Conde (2000b) estudaram a tendência secular da desnutrição e obesidade na infância na cidade de São Paulo e demonstraram que mudanças positivas no poder aquisitivo e nível de escolaridade materna exercem influência decisiva sobre o declínio dos déficits de estatura.

No entanto, a literatura tem indicado diferentes modos pelos quais a educação da mãe pode afetar a saúde da criança. Devido a um aumento da informação, as mães podem melhorar a qualidade da alimentação na promoção da saúde, fato que beneficiaria a saúde da criança. Além disso, a educação aumenta oportunidade para as mães, ampliando suas chances de participar no mercado de trabalho e de receber salários mais altos. Porém atividades como cuidar de crianças e amamentá-las podem ser reduzidas, o sendo capaz de afetar negativamente a saúde infantil. O nível educacional também pode interferir na decisão dos pais sobre o número de filhos, o que está relacionado à qualidade de vida das crianças que os genitores podem oferecer à criança. Jm número menor de filhos, possibita uma mobilização maior de recursos para cada um deles, principalmente nas famílias de baixa renda. Assim, famílias com com um número menor de filhos tendem a suprir melhor as necessidades das crianças, como também a proporcionar uma alimentação mais balanceada garantindo um bom estado nutricional. 
Grillo et al. (2000) quando compararam dois grupos de crianças, eutróficas e desnutridas, verificaram que a desnutrição pregressa estava associada a uma maior pobreza entre as famílias. Assim, encontraram famílias mais numerosas no grupo de crianças desnutridas do que no grupo das eutróficas. Este autor verificou que um maior número de filhos está associado a pequenos intervalos interpartais, resultando em efeitos adversos para a saúde e nutrição da criança. Também mostrou que as crianças com desnutrição pertenciam a famílias mais numerosas e sua ordem de nascimento era mais tardia.

Pela literatura revista (Molina, 1970; Martine, 1989) constatoutse que um dos motivos que leva um indivíduo ou uma família a migrar, está relacionado com a busca da melhoria na qualidade de vida de uma maneira geral, e particularmente com a busca por um melhor emprego e melhor renda. Para avaliar se o objetivo dos migrantes está sendo alcançado (até o momento), a renda familiar foi levantada. Calculourse a renda per capita, somando a remuneração mensal de cada membro do domicílio assalariado e dividindo o total obtido, pelo número de moradores e posteriormente pelo salário mínimo do período da pesquisa $(\mathrm{R} \$ 151,00)$.

$\mathrm{Na}$ tabela 13 (e figura 11), observa-se que existe diferenças significativas quanto à distribuição dos valores de renda per capita entre todos os grupos de famílias do município de Piracicaba e o grupo de Novo Cruzeiro, onde 92,5\% das famílias dispõem de até meio salário mínimo para a aquisição e manutenção de alimentação e saúde. Já nas famílias residentes em Piracicaba, integrantes deste estudo, essa proporção é reduzida aproximadamente pela metade.

É interessante observar que enquanto 7,5\% das famílias residentes em MG estão na segunda faixa de renda (0,5-1,0 salário), o número de famílias em que ambos os pais são migrantes, que se encontram nesta faixa, é cinco vezes maior $(37,3)$. Este é mais um dado que mostra uma melhoria econômica para as famílias que optaram por buscar melhor renda por meio da migração. Cabe ressaltar que quando o pai é migrante, há mais famílias na primeira faixa (entre 0 e 0,5 salários mínimos per capita) do que quando a mãe o é, indicando que possivelmente a renda do pai migrante deve ser menor que a do pai nascido no local de recepção dos migrantes ou que as colocações obtidas pelas 
mulheres migrantes sejam melhor remunerados do que as obtidas pelos homens migrantes. A remuneração é efetivamente maior na cidade de Piracicaba, uma vez que em MG não há nenhuma família com mais de 1 salário mínimo per capita, enquanto que a freqüência de famílias nestas condições correspondem a 19,8\% nas famílias em que ambos os genitores são migrantes, 38,4\% naquelas em que ambos são paulistas e 29,2\% e $29,1 \%$ respectivamente naquelas em que o pai ou a mãe são migrantes, novamente sugerindo que os casamentos inter-áreas facilitam a integração do migrante ao novo ambiente.

Campino (1986) estudando os aspectos sócio-econômicos da desnutrição no Brasil, conclui que a renda é o fator isolado mais importante na determinação do estado nutricional. De acordo com o autor, uma renda per capita abaixo de 1 salário mínimo coloca a família em risco de desnutrição.

Tabela 13. Distribuição dos pré-escolares segundo a renda per capita mensal familiar

\begin{tabular}{|c|c|c|c|c|c|}
\hline Renda per & CCMG & PMMG* & PMSP* & PAIMG * & MAEMG * \\
\hline capita & n $\%$ & $\mathrm{n} \quad \%$ & $\mathrm{n} \quad \%$ & $\mathrm{n} \quad \%$ & $\mathrm{n} \quad \%$ \\
\hline $0,0-0,5$ & $49(92,5)$ & $126(43,9)$ & $591(31,1)$ & $70(41,7)$ & $41(31,3)$ \\
\hline $0,5-1,0$ & $4(7,5)$ & $107(37,3)$ & $579(30,5)$ & $49(29,1)$ & $52(39,7)$ \\
\hline $1,0-2,0$ & - & $51(17,8)$ & $551(29,0)$ & $42(25,0)$ & $33(25,2)$ \\
\hline$>2,0$ & - & $7(1,0)$ & $178(9,4)$ & $7(4,2)$ & $5(3,8)$ \\
\hline
\end{tabular}

$\begin{array}{llllll}\text { Total } & 53 & 287 & 1899 & 168 & 131\end{array}$

Nota: * Indica grupos que diferem significativamente do grupo CCMG pelo teste de CMH, com nível de significância alfa de $5 \%(\alpha=0.05)$

Diversos estudos econômicos mostram a relação entre renda e consumo familiar, indicando que a capacidade das famílias de terem uma situação nutricional adequada é, comumente afetada pela renda disponível (Menezes et al., 2002; Silveira et al., 2002). Entretanto, cabe refletir que a alimentação numa residência situada em zona rural pode ser adquirida por outros meios que não o monetário. Estas outras fontes, tais como 
quintais ou mesmo trocas entre parentes, podem ser perdidas durante a migração. Assim, um aumento no nível de renda pode não refletir totalmente a disponibilidade efetiva de alimentos para a família.

Um outro fator que pode contribuir tanto para um aumento da renda familiar como para a variação da qualidade da alimentação, é a presença e o tipo de uso de quintais. De acordo com Guimarães (1998) a produção de alimentos nos quintais domésticos tem forte influência sobre a frequiência de consumo de frutas e hortaliças.

A presença de quintal nas residências da população estudada (tabela 14 e figura 12), não evidenciou diferenças significativas entre os grupos, porém observa-se que em Piracicaba existe uma pequena predominância de famílias com quintais (mais de 80\%) em relação a Novo Cruzeiro (75,5\%). Não houve entretanto, diferença significativa entre as distribuições dos diferentes grupos. No entanto, se faz necessário investigar o uso que as famílias fazem dos quintais, o que foi feito sucintamente no presente estudo (tabela 15 e figura 13).

Tabela 14. Distribuição dos pré-escolares segundo a presença de quintal em sua residência

\begin{tabular}{|c|c|c|c|c|c|}
\hline \multirow{2}{*}{ Quintal } & CCMG & PMMG & PMSP & PAIMG & MAEMG \\
\hline & $\mathrm{n} \quad \%$ & $\mathrm{n} \quad \%$ & $\mathrm{n} \quad \%$ & $\mathrm{n} \quad \%$ & $\mathrm{n} \quad \%$ \\
\hline Sim & $40(75,5)$ & $232(81,7)$ & $1651(87,3)$ & $143(85,6)$ & $109(83,9)$ \\
\hline Não & $13(24,5)$ & $52(18,3)$ & $239(12,7)$ & $24(14,4)$ & $21(16,1)$ \\
\hline Total & 53 & 284 & 1891 & 167 & 130 \\
\hline
\end{tabular}

Cabe considerar que uma adequada produção para auto-abastecimento familiar é de suma importância, pois aumenta a variedade dos alimentos consumidos, rompendo muitas vezes com a monotonia da dieta. Freqüentemente, as famílias de baixa renda não podem comprar no mercado hortaliças e frutas desejáveis. Por isso têm de produzi-las. 
Além disso, as ervas e especiarias cultivadas pela família enriquecem consideravelmente o sabor de muitos pratos tradicionais. (Nascimento et al., 2003b).

Quando Brandão (1981) relatou sobre alimentação de uma comunidade rural no processo de transição para a cidade, ficou evidente que a influência da cultura na alimentação de uma população vem de uma relação histórica do meio em que o indivíduo se desenvolveu, ou seja, da incorporação dos hábitos de sua família, de seus amigos, das pessoas com quem se relaciona em seu trabalho, de eventos que ocorrem em sua vida (como a situação financeira ) que o obriga a optar por um alimento ou outro, mesmo que este não tenha as características nutricionais necessárias a ele. Acredita-se que fatores como prazer, importância atribuída a alimentos sem "produtos químicos" e principalmente a necessidade, movam as pessoas a plantar retirando boa parte de sua alimentação do próprio quintal, assim como os costumes herdados tanto de gerações anteriores como adquiridos a partir do convívio com indivíduos da própria geração.

As populações humanas ao interagirem umas com as outras e com seus ambientes, procuram se ajustar a problemas ambientais, mesmo no caso de serem específicos (Moran, 1994).

Para as famílias que tinham quintal na residência, foi perguntado o tipo de uso do mesmo, sendo tal uso classificado em quatro categorias (como já mencionado antes): coleta de alimentos e/ou remédios; plantação de alimentos e/ou remédios; criação de animais e outros usos. Em relação à distribuição dos tipos de uso dos quintais, o grupo de famílias de Novo Cruzeiro diferiu dos demais grupos. Em Novo Cruzeiro, a grande maioria da população respondeu que utiliza os quintais para a plantação de alimentos para a subsistência e de remédios (87,5\%). Tanto as famílias migrantes quanto aquelas em que ambos os pais são do estado de São Paulo, utilizam seus quintais de outra forma que não as dos itens citados (36,3\% e 38\%, respectivamente). Segundo as famílias, este uso pode ser desde lazer, lavagem e secagem de roupas, como também a utilização do espaço para gerar renda. Assim, dentre os usos citados pode-se destacar: estacionamento para carros, oficina mecânica, guardar papelão que coletam, lanchonete, tanque para peixes, entre outros. 
Proporções expressivas de integrantes dos outros grupos, respectivamente PAIMG (34,6\%) e MAEMG (44,1\%), utilizam os quintais para a criação de animais, apesar das respostas serem distribuídas também nas outras categorias. É interessante comparar as tabelas 14 e 15, pois enquanto mais de $75 \%$ da população de todos os grupos afirmaram ter quintal em casa, menos da metade alegaram fazer uso dos mesmos.

Tabela 15. Tipo de uso do quintal pela família das crianças pré-escolares

\begin{tabular}{|c|c|c|c|c|c|}
\hline \multirow{2}{*}{ Uso do quintal } & CCMG & PMMG $^{*}$ & PMSP $^{*}$ & PAIMG & MAEMG * \\
\hline & $\mathrm{n} \%$ & $\mathrm{n} \quad \%$ & $\mathrm{n} \quad \%$ & $\mathrm{n} \quad \%$ & $\mathrm{n} \quad \%$ \\
\hline $\begin{array}{l}\text { Coleta de } \\
\text { alimentos ou } \\
\text { remédios }\end{array}$ & $2(8,3)$ & $2(1,5)$ & $41(4,9)$ & $6(7,4)$ & $1(1,7)$ \\
\hline $\begin{array}{l}\text { Plantação de } \\
\text { alimentos ou } \\
\text { remédios }\end{array}$ & $21(87,5)$ & $40(29,6)$ & $176(20,8)$ & $23(28,4)$ & $18(30,5)$ \\
\hline $\begin{array}{c}\text { Criação de } \\
\text { animais }\end{array}$ & $1(4,2)$ & $44(32,6)$ & $307(30,3)$ & $28(34,6)$ & $26(44,1)$ \\
\hline Outro & 0 & $49(36,3)$ & $322(38,0)$ & $24(29,6)$ & $14(23,7)$ \\
\hline Total & 24 & 135 & 845 & 81 & 59 \\
\hline
\end{tabular}

O estado de saúde das crianças pré-esolares foi avaliado pelo escore z de estatura pela idade $(\mathrm{E} / \mathrm{I})$ e peso pela estatura $(\mathrm{P} / \mathrm{E})$. As crianças foram classificadas conforme descrito no item casuística e métodos. Segundo Kassouf (1994) o escore z de estatura para idade indica ocorrências de estado crônico de desnutrição. Ou seja, esse índice reflete o crescimento linear adquirido e valores inferiores aos esperados para a idade e sexo, indicam deficiências cumulativas, de longo prazo, de saúde e nutrição, que podem ter sido causadas por uma doença grave ou deficiência nutricional no passado.

Em um primeiro momento, as crianças foram classificadas de acordo com seu escore z, sendo considerada como população de referência o conjunto total das crianças, 
ou seja, a soma dos cinco estratos caracterizados neste trabalho $(\mathrm{n}=2538)$. Assim foi comparado nas tabelas 16 e 17 a situação nutricional das crianças de cada estrato, em relação ao conjunto total estudado.

$\mathrm{Na}$ tabela 16, empregando-se como população de referência o conjunto de crianças estudadas no presente trabalho (2538), verifica-se que nenhuma das que freqüentavam as unidades de ensino, tanto em Novo Cruzeiro quanto em Piracicaba, apresentam escore z menor que -1 . Ou seja, ao se usar como população de referência todas as crinças do presente trabalho, não foi constatado nenhum caso de desnutrição grave nas crianças que freqüentaram as unidades de ensino no ano da coleta (2000), nestes municípios, nem mesmo crianças na faixa de risco $(-2<\mathrm{ZEI}<-1)$. Da mesmamaneira, mais de $85 \%$ das crianças de todos os grupos estão na faixa de "eutrofia" quanto à relação estatura/idade $(-1<\mathrm{ZEI}<1)$. Cabe destacar, que há 4,5\% das crianças com ambos os pais paulistas, que apresentaram estatura acima do esperado para a idade, o que pode se dever talvez à influência de fatores relacionados à origem étnica, favorecendo maior estatura que a esperada nessa faixa etária desse estrato da população estudada. Assim, a boa alimentação poderia estar favorecendo a expressão do patrimônio genético associado à maior estatura, característico de parte dessa população.

Tabela 16. Distribuição dos pré-escolares segundo a relação estatura-pela-idade, tendo como população de referência o conjunto dos estratos $(n=2538)$

\begin{tabular}{|c|c|c|c|c|c|}
\hline \multirow{2}{*}{ ZEI } & CCMG & PMMG & PMSP* & PAIMG & MAЕMG \\
\hline & $\mathrm{n} \quad \%$ & $\mathrm{n} \quad \%$ & $\mathrm{n} \quad \%$ & $\mathrm{n} \quad \%$ & $\mathrm{n} \quad \%$ \\
\hline ZEI $<-1$ & - & - & - & - & - \\
\hline$-1<\mathrm{ZEI}<1$ & $46(86,8)$ & $252(87,8)$ & $1633(90,5)$ & $154(91,7)$ & $114(87,0)$ \\
\hline $1<\mathrm{ZEI}<2$ & $2(3,8)$ & $10(3,5)$ & $90(5,0)$ & $6(3,6)$ & $3(2,3)$ \\
\hline $2<\mathrm{ZEI}<3$ & $1(1,9)$ & $15(5,2)$ & $40(2,2)$ & $2(1,2)$ & $7(5,4)$ \\
\hline $\mathrm{ZEI}>3$ & $4(7,6)$ & - & $41(2,3)$ & - & - \\
\hline Total & 53 & 277 & 1804 & 162 & 124 \\
\hline
\end{tabular}


A desnutrição grave acha-se freqüentemente associada a baixas condições sócioeconômicas, infecções crônicas ou repetidas e ingestão inadequada de nutrientes (Unicef, 1990; Kassouf, 1994; Soares, 2000). Neste sentido, no presente trabalho, quando a população de referência é o conjunto das crianças dos estratos estudados ( $\mathrm{n}=2538)$, mesmo entre as crianças que possuem condições ambientais desfavoráveis, de acordo com os indicadores apresentados acima, não foi encontrado caso de desnutrição grave. Isso indica que as diferenças na condições do ambiente, no sentido abragente adotado no presente trabalho, não estão interferindo na adaptabilidade dessas populações tal como indicado pela relação peso-pela-estatura. Resultado semeljhante foi obtido para o índice de estatura-pela-idade descrito abaixo.

Ainda empregando como população de referência o conjunto das crianças que formam o estrato populacional estudados neste trabalho, na tabela 17 , pode-se verificar que apenas duas crianças da população estudada como um todo, apresentaram risco para desnutrição aguda, (indicada pela relação peso por estatura), uma de Novo Cruzeiro e uma do município de Piracicaba e que não houve casos de desnutrição aguda. Por outro lado, há em três dos estrados da cidade de Piracicaba, crianças apresentando peso acima do esperado para sua estatura. $\mathrm{Na}$ faixa de risco de obesidade estão respectivamente 0,7\%, 3,1\% e 1,2\% das crianças dos grupos PMMG, PMSP e PAIMG. Com sobrepeso estão $0,4 \%$ e $0,2 \%$ das crianças respectivamente dos grupos PMMG e PMSP e apenas neste último, foram encontradas crianças obesas $(0,2 \%)$. Nestes últimos casos, o peso da criança está sugerindo nutrição inadequada, com excesso calórico. Apesar desses desvios, as distibuições entre os estratos populacionais não diferiram entre si, ainda que o grupo PMSP tenha se aproximado disto (prob. $>\chi^{2} \mathrm{CMH}=0,06$ ) e quanto a esta variável, todos os estratos populacionais apresentaram valores concentrados na faixa correspondente aos indivíduos "eutróficos".

Em relação aos resultados das tabelas 16 e 17 (figuras 14 e 15), não foram evidenciadas diferenças estatisticamente siginificativas na situação nutricional das crianças dos diferentes estratos, o que também indica que as crianças migrantes se ajustaram ou estão se ajustando aos fatores externos do local de recepção. 
Tabela 17. Distribuição de crianças pré-escolares segundo a relação peso-pela-estatura, tendo como população de referência o conjunto dos estratos $(n=2538)$

\begin{tabular}{|c|c|c|c|c|c|}
\hline \multirow{2}{*}{ ZPE } & CCMG & PMMG & PMSP & PAIMG & MAEMG \\
\hline & $\mathrm{n} \quad \%$ & $\mathrm{n} \quad \%$ & $\mathrm{n} \quad \%$ & $\mathrm{n} \quad \%$ & $\mathrm{n} \quad \%$ \\
\hline $\mathrm{ZPE}<-2$ & - & - & - & - & - \\
\hline$-2<\mathrm{ZPE}<-1$ & $1(1,9)$ & - & $1(0,1)$ & - & - \\
\hline$-1>\mathrm{ZPE}<1$ & $52(98,1)$ & $274(98,9)$ & $1742(96,5)$ & $160(98,8)$ & $124(100,0)$ \\
\hline $1<\mathrm{ZPE}<2$ & - & $2(0,7)$ & $56(3,1)$ & $2(1,2)$ & - \\
\hline $2<\mathrm{ZPE}<3$ & - & $1(0,4)$ & $3(0,2)$ & - & - \\
\hline $\mathrm{ZPE}>3$ & - & - & $3(0,2)$ & - & - \\
\hline Total & 53 & 277 & 1805 & 162 & 124 \\
\hline
\end{tabular}

No entanto, em um segundo momento, em que o estado nutricional das crianças foi comparado com a curva padrão de crescimento desenvolvida pelo NCHS, a qual é recomendada pela OMS, os resultados diferiram dos apresentados anteriormente. $\mathrm{Na}$ tabela 18 (e figura 16) constata-se casos de desnutrição grave (ZEI < -3), entre 5,2\% e $6,1 \%$, apenas entre as crianças que residem no município de Piracicaba. Também foi evidenciado casos de desnutrição leve a moderada $(-3<$ ZEI $<-2)$ nas crianças de todos os estratos (entre 1,9 e 3,1\%), sendo esta incidência, menor do que os casos de desnutrição grave. No município de Novo Cruzeiro foi detectada 28,3\% de crianças na faixa de risco, com este número reduzido para menos da metade nos estratos de Piracicaba (entre 9,2 e 12,2\%), os quais também estão acima da média considerada normal $(7 \%)$. Considerando que as crianças permanecem nas unidades de ensino por período integral, onde recebem desde cuidados de higiene e também, espera-se, uma alimentação balanceada, faz-se necessário rever a prática de intervenção nutricional adotada, tanto para crianças que apresentam casos de desnutrição, como para aquelas que se encontram na faixa de risco. Isto porque a percentagem de crianças desnutridas é superior a 3\%, considerada normal pela OMS. Um fato importante a ser ressaltado é que 
nas crianças que passam por restrições nutricionais até os seis anos, o organismo tende a poupar energia, a qual seria dispendida para o seu crescimento. Segundo Moran (1994) este ajustamento que ocorre ao longo do desenvolvimento da criança é irreversível, o qual implicará em uma baixa estatura para idade.

Os resultados deste trabalho, embora referentes ao ano de 2000, estão de acordo com a informação recente, veiculada pelo Jornal de Piracicaba, de 28/09/2003, o qual divulgou que o índice de desnutrição infantil no município é de 4,8\%, e em situação de risco se encontram 10,21\% das crianças. No entanto, o referido periódico não informou se as crianças que participaram dessas análises freqüentam unidades de ensino ou apenas são cadastradas nas Unidades Básicas de Saúde (UBSs) e(ou) Programas de Saúde Familiar (PSFs). Ainda no citado artigo, a nutricionista gerente do Sistema de Vigilância Alimentar e Nutricional (SISVAN) Márcia Morer, comentou que a situação melhorou um pouco de agosto de 2002 para 2003. No ano anterior a taxa de desnutrição foi de $6,22 \%$, e em risco estavam $12 \%$ das crianças. Segundo ela, essa redução pode ter ocorrido pelo aumento da freqüência das crianças às unidades de saúde.

Tabela 18. Distribuição de crianças pré-escolares segundo a relação estatura-pela-idade, tendo como população de referência NCHS

\begin{tabular}{|c|c|c|c|c|c|}
\hline \multirow{2}{*}{ ZEI } & CCMG & PMMG & PMSP & PAIMG & MAEMG \\
\hline & n $\%$ & $\mathrm{n} \quad \%$ & $\mathrm{n} \quad \%$ & $\mathrm{n} \quad \%$ & n $\%$ \\
\hline $\mathrm{ZEI}<-3$ & - & $15(5,2)$ & $110(5,8)$ & $10(5,9)$ & $8(6,1)$ \\
\hline$-3<\mathrm{ZEI}<-2$ & $1(1,9)$ & $4(1,4)$ & $34(1,8)$ & $4(2,4)$ & $4(3,1)$ \\
\hline$-2<\mathrm{ZEI}<-1$ & $15(28,3)$ & $35(12,2)$ & $194(10,3)$ & $19(11,3)$ & $12(9,2)$ \\
\hline$-1>\mathrm{ZEI}<1$ & $28(52,8)$ & $169(58,9)$ & $1046(55,2)$ & $108(64,3)$ & $84(64,1)$ \\
\hline $1<\mathrm{ZEI}<2$ & $5(9,4)$ & $44(15,3)$ & $353(18,6)$ & $20(11,9)$ & $16(12,2)$ \\
\hline $2<\mathrm{ZEI}<3$ & $3(5,7)$ & $11(3,8)$ & $115(6,1)$ & $4(2,4)$ & $6(4,6)$ \\
\hline $\mathrm{ZEI}>3$ & $1(1,9)$ & $9(3,2)$ & $42(2,2)$ & $3(1,8)$ & $1(0,7)$ \\
\hline Total & 53 & 276 & 1795 & 161 & 124 \\
\hline
\end{tabular}


Quando foi verificado a proporção de pré-escolares na faixa de "eutrofia", segundo OMS $(-2<\mathrm{ZEI}<2)$, todos os estratos tiveram uma percentagem igual (PMSP) ou superior (CCMG, PMMG, PAIMG e MAEMG) à esperada (84,1\%), quando se adotou como parâmetro populações de referência (NCHS, 2002).

Constatou-se ainda um número elevado de crianças com excesso de estatura para idade em todos os grupos. A curva de crescimento adotada como padrão pela OMS, é uma estimativa do que é normal ou não. A população utilizada para a curva padrão de crescimento é a população norte-americana, a qual devido tanto ao patrimônio genético como ao ambiente, difere da população aqui estudada. Assim, se de um lado, o emprego desta curva torna os resultados obtidos comparáveis com os da literatura científica internacional, por outro, torna-os sujeitos a imprecisões devido às razões ass inaladas acima. Isto é válido também para as análise de peso-pela-estatura.

$\mathrm{Na}$ tabela 19 (e figura 17), que analisa as relações de peso-pela-estaura, tendo como padrão a população do NCHS, nota-se diferenças estatisticamente significativas entre o grupo de crianças residentes em Novo Cruzeiro e aquelas residentes em Piracicaba. Houve quatro ocorrências de desnutrição aguda, o que indica alteração no estado nutricional atual, de duas crianças residentes em Novo Cruzeiro, uma no grupo onde ambos pais são migrantes e duas onde ambos pais são paulistas. No entanto, quando se adota o ponto de corte recomendado pela OMS $(-2<\mathrm{ZPE}<2)$, o índice de crianças consideradas com desnutrição atual em Novo Cruzeiro supera em quase quatro vezes $(11,3 \%)$ o considerado normal (3\%). Em relação às famílias de Novo Cruzeiro, entre as crianças de famílias migrantes há apenas $1 \%$ destas na faixa que necessita de intervenção. Nos grupos onde apenas um dos pais migraram, verificourse apenas uma criança com desnutrição aguda (no grupo MAEM G). É importante destacar também que o número de crianças na faixa de risco de desnutrição $(-2<\mathrm{ZEI}<-1)$ nas crianças que residem em Novo Cruzeiro é mais que três vezes maior $(24,5 \%)$ do que o considerado aceitável (7\%).

Entretanto, quando se analisa as crianças consideradas "eutróficas" $(-2<\mathrm{ZPE}<2)$, constata-se que todos os grupos possuem mais de $88 \%$ das crianças concentradas neste intervalo, o que caracteriza os grupos como tal, em boas condições de saúde. No entanto, 
cabe ressaltar que o número de crianças na faixa de risco, tanto para desnutrição grave $(28,3 \%)$ como para aguda (24,5\%), é alto no município de Novo Cruzeiro. Neste caso, torna-se necessário a ut ilização de outros métodos que venham a confirmar o estado nutricional dessas crianças.

Nota-se também na tabela 19, que não houve casos de obesidade entre as crianças residentes em Novo Cruzeiro. No entanto entre as crianças residentes em Piracicaba, houve casos de obesidade grave (ZPE>3) nos grupos PMMG (4\%), PMSP $(6,4 \%)$ e PAIMG $(3,1 \%)$. Quando se considera o ponto de corte da OMS em relação aos casos de obesidade (ZPE>2), esses números aumentam para 8\% (PMMG), 11,5\% (PMSP), 6,1\% (PAIMG) e 3,1\% (MAEMG). Assim, de acordo com os padrões internacionais todos os grupos de famílias que residem em Piracicaba estão acima do considerado aceitável.

Tabela 19. Distribuição de crianças pré-escolares segundo a relação peso-pela-estatura, tendo como população de referência NCHS

\begin{tabular}{|c|c|c|c|c|c|}
\hline \multirow{2}{*}{$\mathrm{ZPE}$} & CCMG & PMMG & PMSP $^{*}$ & PAIMG * & MAEMG ${ }^{*}$ \\
\hline & $\mathrm{n} \quad \%$ & $\mathrm{n} \quad \%$ & $\mathrm{n} \quad \%$ & $\mathrm{n} \quad \%$ & $\mathrm{n} \quad \%$ \\
\hline $\mathrm{ZPE}<-3$ & $2(3,7)$ & $1(0,3)$ & $2(0,1)$ & - & - \\
\hline$-3<\mathrm{ZPE}<-2$ & $4(7,6)$ & $2(0,7)$ & $7(0,4)$ & - & $1(0,8)$ \\
\hline$-2<\mathrm{ZPE}<-1$ & $13(24,5)$ & $21(7,6)$ & $87(4,9)$ & $10(6,2)$ & $6(4,9)$ \\
\hline$-1>\mathrm{ZPE}<1$ & $30(56,6)$ & $197(71,4)$ & $1171(65,2)$ & $121(75,2)$ & $98(79,0)$ \\
\hline $1<\mathrm{ZPE}<2$ & $4(7,6)$ & $33(12,0)$ & $321(17,9)$ & $20(12,4)$ & $15(12,1)$ \\
\hline $2<\mathrm{ZPE}<3$ & - & $11(4,0)$ & $92(5,1)$ & $5(3,1)$ & $4(3,2)$ \\
\hline $\mathrm{ZPE}>3$ & - & $11(4,0)$ & $115(6,4)$ & $5(3,1)$ & - \\
\hline Total & 53 & 276 & 1795 & 161 & 124 \\
\hline
\end{tabular}


Nas figuras 18 e 19 são demonstradas as curvas de crescimento dos estratos estudados, comparando-as com a curva de crescimento da população de referência (NCHS).

É comum encontrar filhos maiores que os pais, que, por sua vez, são maiores que os avós, que eram maiores que os bisavós. Isso porque a estatura média da população brasileira - e de outros países ainda em desenvolvimento - tende a aumentar a cada geração como reflexo das mudanças de hábitos e da melhora na qualidade de vida (Glaner \& Neto, 2003). Esse crescimento pode ser notado na última pesquisa realizada pelo IBGE sobre padrões de vida. Os números mostram que, em sete anos, a mulher brasileira cresceu em média dois centímetros - de 1,57 m para 1,59 m, enquanto os homens subiram três centímetros, de 1,69 m para 1,72 m. De acordo com Marcondes (1985), além da herança genética, o crescimento é relacionado a três fatores ambientais: alimentação, estimulação biopsicossocial e atividade física. Portanto, o crescimento depende da interação entre meio ambiente e o potencial genético. Contudo, Malina (1990) salienta que os homens são mais suscetíveis às influências ambientais que as mulheres. Assim sendo, acredita-se que a ação exercida pelo meio ambiente pode induzir maiores ou menores variações nas diferentes fases de crescimento do ser humano em diferentes décadas, juntamente com a tendência secular para o aumento da estatura.

A influência do ambiente no crescimento físico é comprovada em estudo mais recente feito por Bogin \& Loucky (1997). Eles compararam crianças mayas da Guatemala, de 4 a 14 anos, que migraram para os Estados Unidos da América do Norte. Estas crianças apresentaram-se mais altas, mais pesadas e com maior massa gorda e maior massa muscular do que as crianças que vivem na Guatemala. Porém, os imigrantes são mais baixos do que as crianças americanas da mesma faixa etária.

De certa forma, quantificar o número de indivíduos desnutridos ou obesos que existem em um ou outro estrato populacional é um procedimento complexo que requer muitas informações. No entanto o Centers for Disease Control and Prevention (CDC 2000) enfatiza que seus critérios não visam tanto o diagnóstico mas sim identificar grupos de indivíduos de risco. 
A má-nutrição definida como qualquer tipo de alimentação desbalanceada, que inclui tanto a ingestão de muita como de pouca comida (respectivamente supernutrição e subnutrição) é muito comum. Isto ocorre embora hoje em dia haja bastante comida no mundo para alimentar a todos com uma dieta completa com todos os nutrientes (Kormondy \& Brown, 2002). A subnutrição pode se caracterizar por falta de alimentos (calórica) e(ou) deficiência de aminoácidos (protéica), cujo resultado para o organismo é a inabilidade de produzir proteínas. Até mesmo nesses casos (subnutrição), o organismo humano possui estratégias de defesas biológicas (mesmo que não adaptativas a longo prazo) de maneira a ganhar tempo até que a ingestão normal seja recuperada. Como exemplo, a secreção de proteínas serosas como a albumina no intestino, um dos principais ajustes a períodos prolongados de deficiência protéica.

Segundo Soares (2003) o percentil do IMC (Índice de Masssa Corporal) alcançado por volta dos 6 anos de idade é mantido na adolescência. Assim, quanto mais cedo forem tomadas as medidas preventivas e iniciados os tratamentos serão evitados problemas futuros. Ainda de acordo com esse autor, indivíduos americanos que, quando crianças e adolescentes estavam na faixa do sobrepeso, em sua maioria, tornaram-se obesos aos vinte e cinco anos de idade.

Os principais fatores etiológicos da obesidade na infância são o desmame precoce, introdução inadequada de alimentos de desmame, emprego de fórmulas lácteas inadequadamente preparadas e inadequação na relação familiar (Fisberg, 1993 apud. Soares, 2000).

Em contraste, as sociedades modernizadas se confrontam com uma forma diferente de má-nutrição: a supernutrição. Em muitas populações, uma grande porcentagem de pessoas são obesas (muito gordas), sendo este considerado um problema de saúde pública em muitos países, inclusive no Brasil. A questão do aumento da adiposidade está relacionado tanto aos maus hábitos alimentares quanto ao sedentarismo que caraterizam o estilo de vida moderno.

Muitos são os fatores que influenciam a escolha de alimentos pelas pessoas, os quais variam entre os indivíduos, como também entre idade e sexo. Assume-se que em geral, a escolha alimentar é realizada de maneira a otimizar a relação custo/benefício, 
estando relacionada, entre outros fatores a: 1. mecanismos de transmissão cultural, tanto familiar como por outros indivíduos e pela mídia; 2. sentimentos e emoções que exercem papel importante na tomada de decisões pelos seres humanos; 3. condição econômica destacando-se a restrição imposta pela renda sobre os hábitos de consumo (Nascimento et al., 2003a). Convenções culturais também são envolvidas sobre quanto de alimento deve ser ingerido e quem deve comê-lo, porém nem todas são adaptativas em termos nutritivos. No entanto, problemas nutricionais não podem ser vistos isoladamente. Eles afetam a habilidade de uma população em lidar com muitos outros estressores, bem como a habilidade de obter recursos, como redução da capacidade de trabalho além de reduzir a resistência a doenças (Kormondy \& Brown, 2002).

Os ecólogos humanos vêem a má-nutrição como uma medida de fracasso ecológica, considerando a ocorrência da mesma como sinal de que a população não obteve sucesso na adaptação a um determinado ambiente (Kormondy \& Brown, 2002). Assim, no presente estudo, quando comparadas ambas populações de indivíduos mineiros, vivendo em ambientes distintos, analisando-se o estado nutricional das crianças, pode-se considerar a migração de Novo Cruzeiro para Piracicaba como uma estratégia adaptativa bem sucedida, uma vez que em ambas as regiões a maior parte das crianças encontra-se dentro da faixa considerada "eutrófica", superando inclusive a expectativa da população de referência (CDC, 2000).

No entanto, o aumento da incidência de sobrepeso e obesidade encontradas em Piracicaba (sociedade modernizada) quando comparadas à frequiência em Novo Cruzeiro (sociedade tradicional), pode ser considerada como um possível reflexo das falhas nas adaptações humanas a um estilo de vida urbano e um acréscimo potencial de risco aos migrantes. 


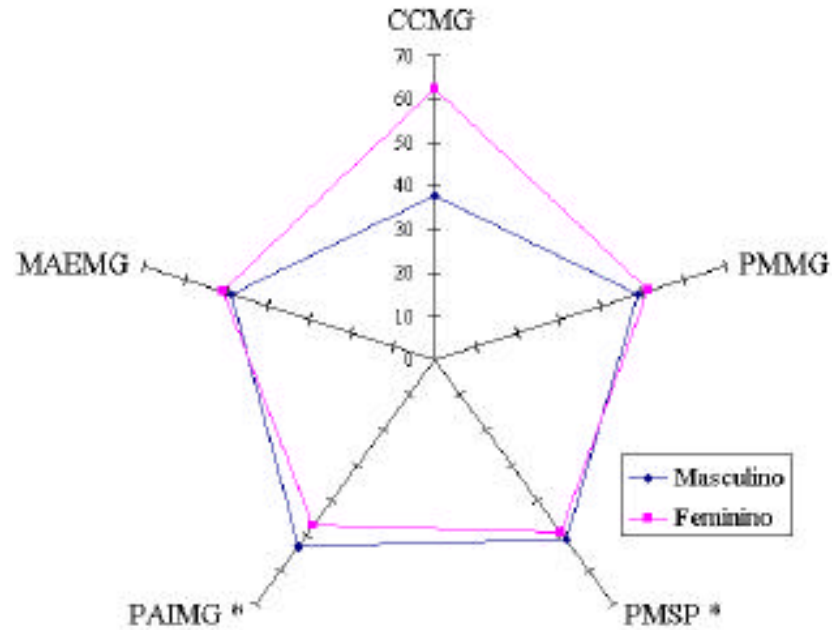

Figura 2- Distribução dos pré-escolares quanto ao sexo

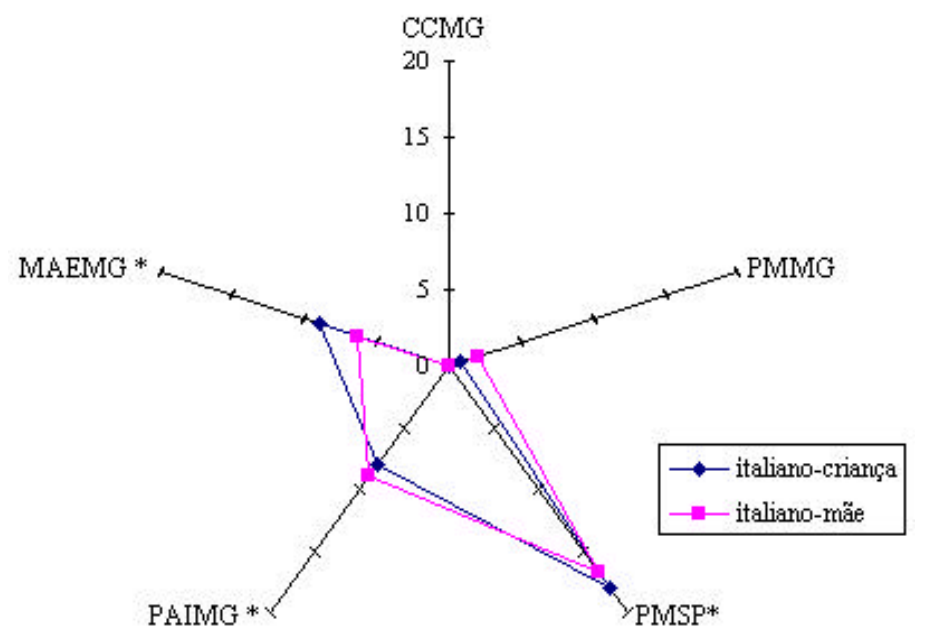

Figura 4- Distribuição dos pré-escolares e suas mães de acordo com o sobrenome

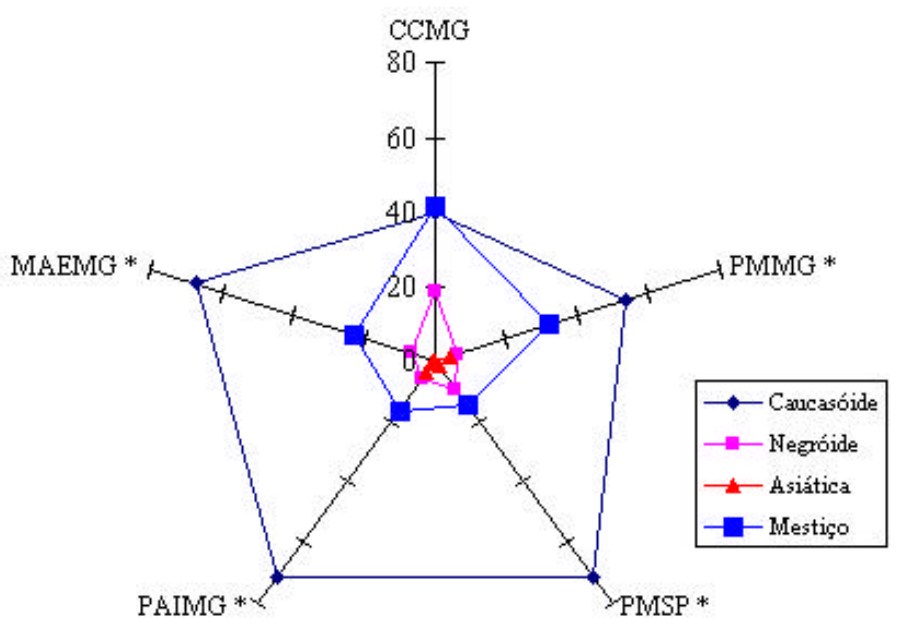

Figura 3- Distribuição dos pré-escolares segundo a cor da pele

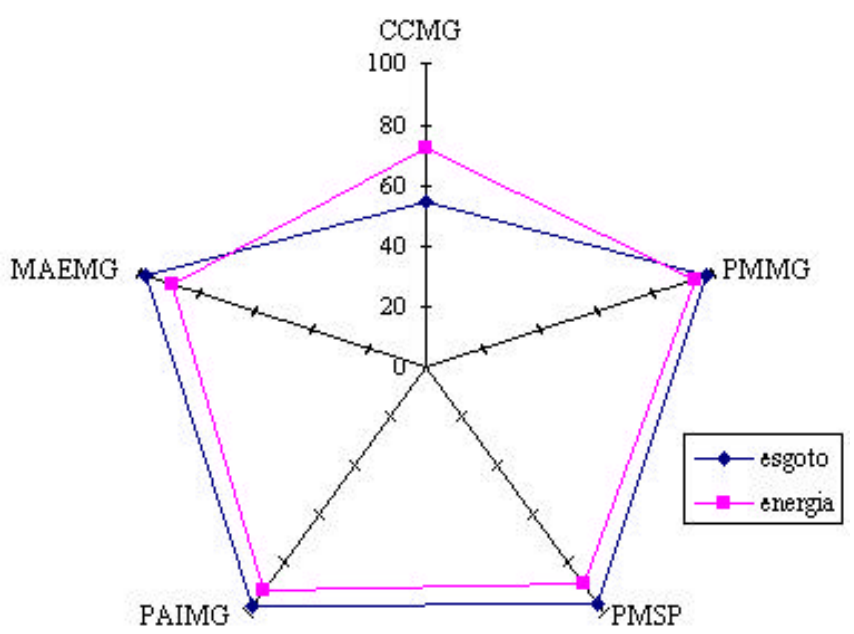

Figura 5- Distribuição dos pré-escolares quanto a presença de rede de esgoto e energia elétrica na residência 


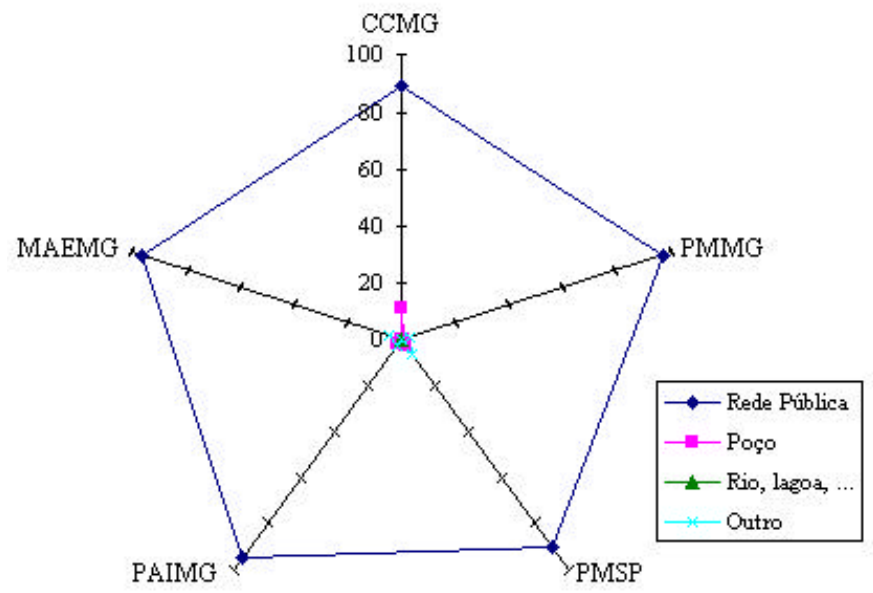

Figura 6- Distribuição dos pré-escolares quanto a procedência de água para beber

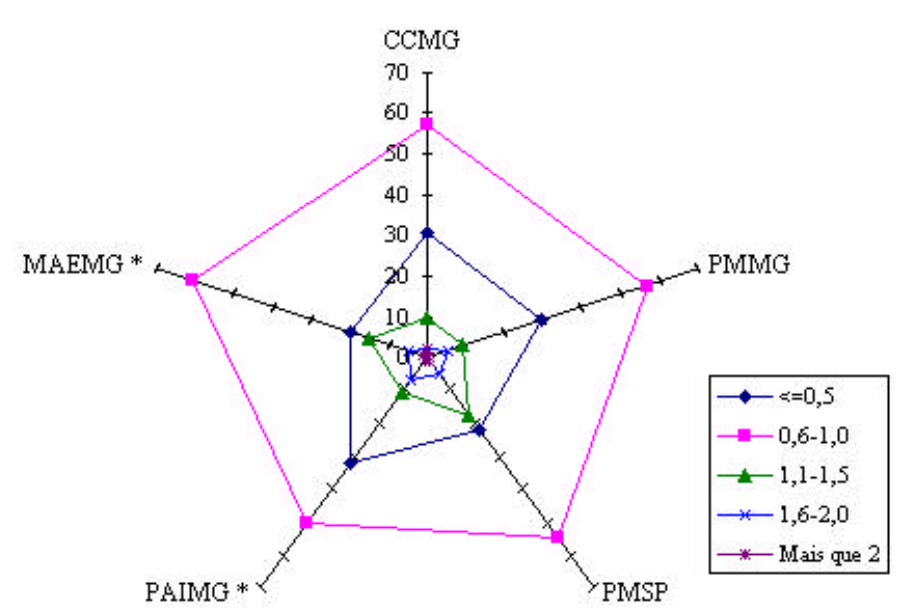

Figura 8- Distribuição dos pré-escolares quanto ao número de cômodos por morador na residência

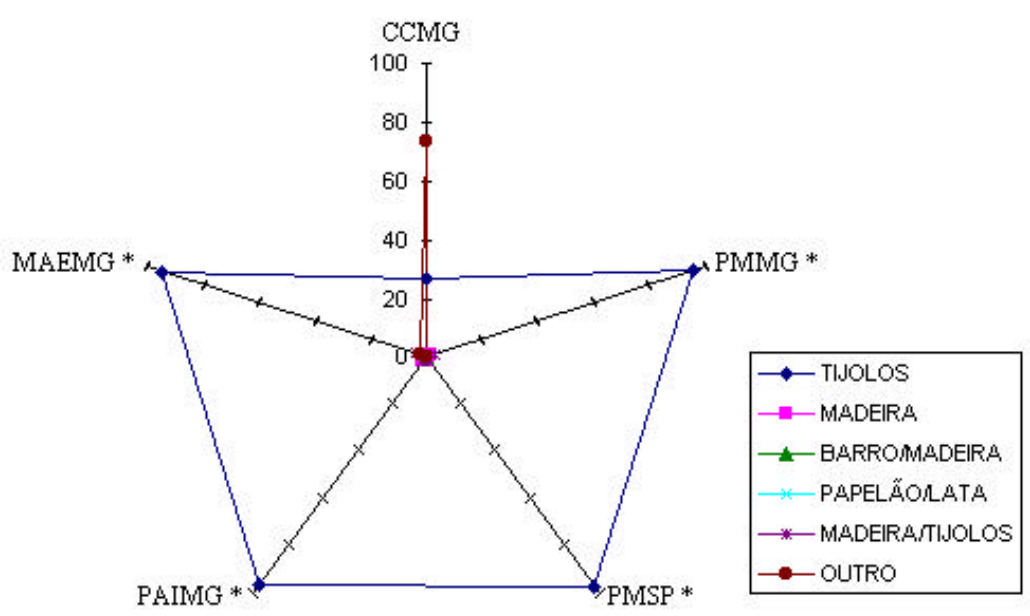

Figura 7- Distribuição dos pré-escolares quanto ao material de construção da moradia

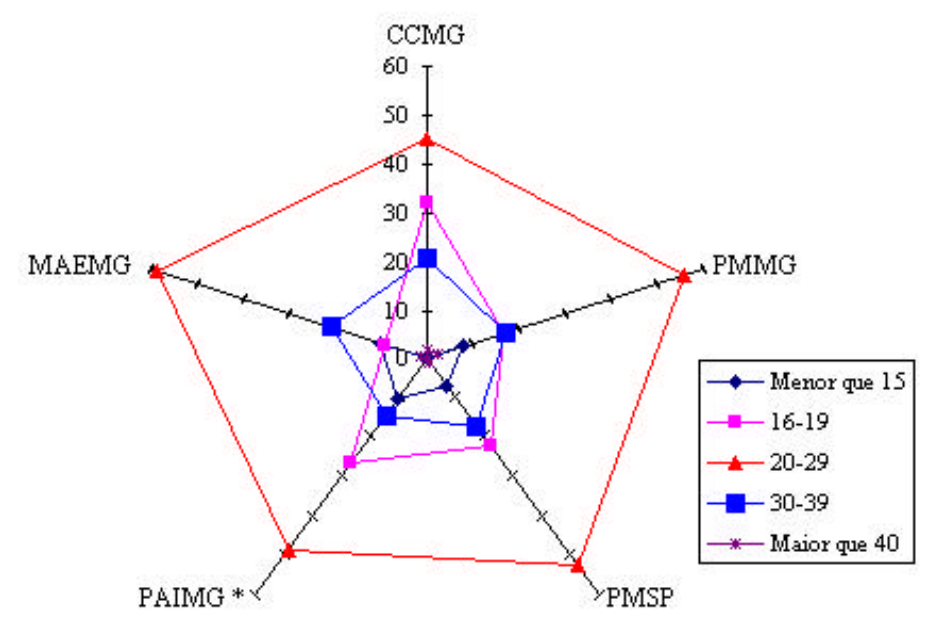

Figura 9- Distribuição dos pré-escolares de acordo com a idade da mãe ao seu nascimento 


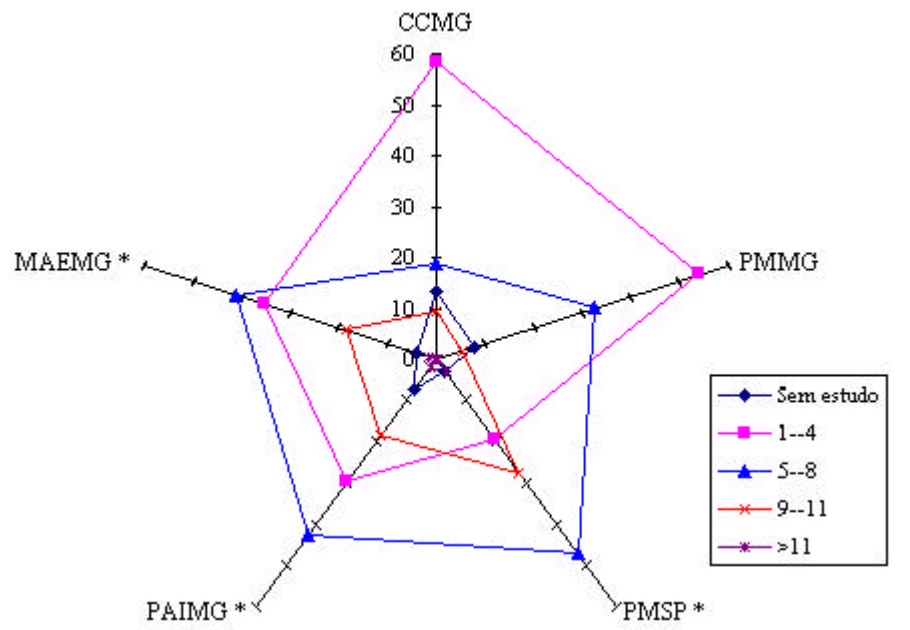

Figura 10- Distribuição dos pré-escolares quanto a escolaridade materna (anos de estudo)

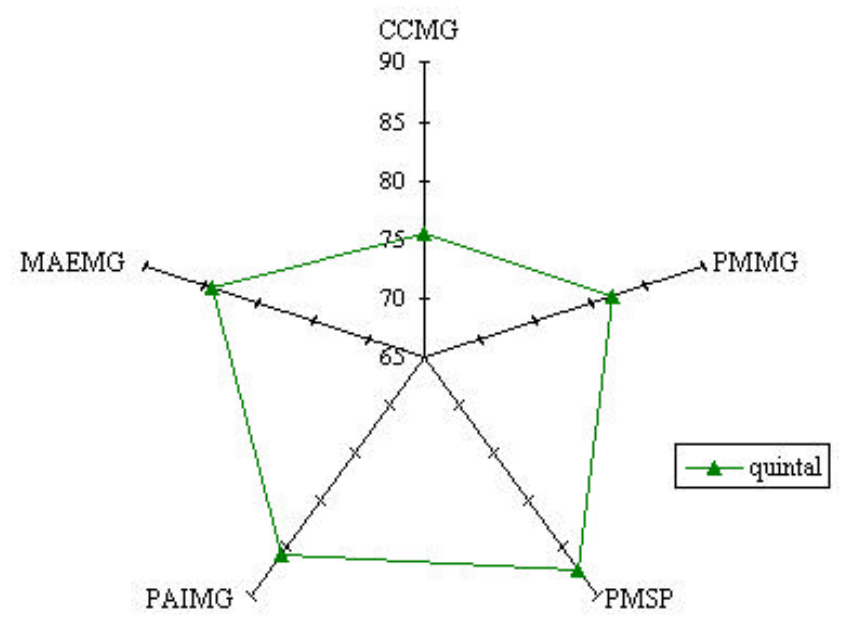

Figura 12- Distribuição dos pré-escolares quanto a presença de quintal na residência

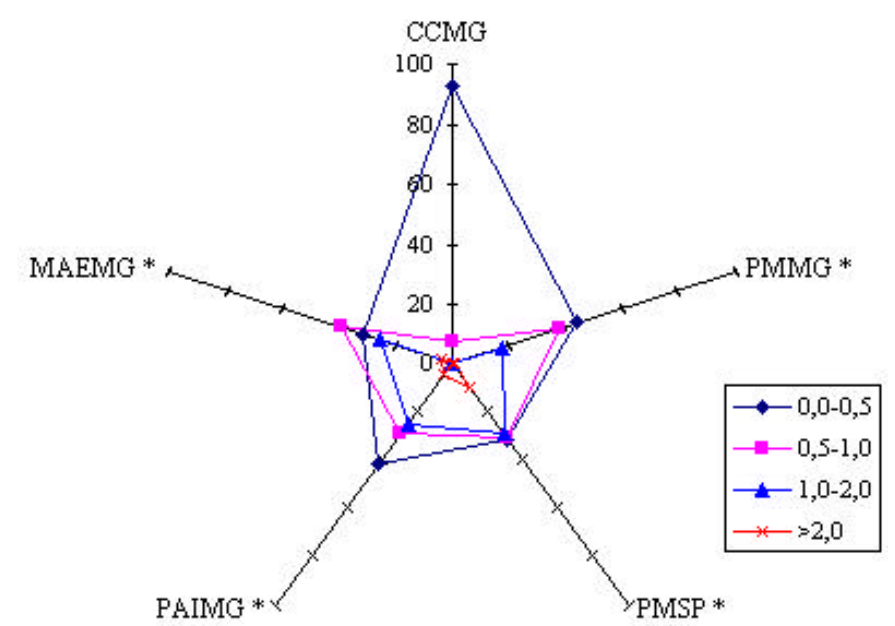

Figura 11- Distribuição dos pré-escolares quanto a renda per capita familiar

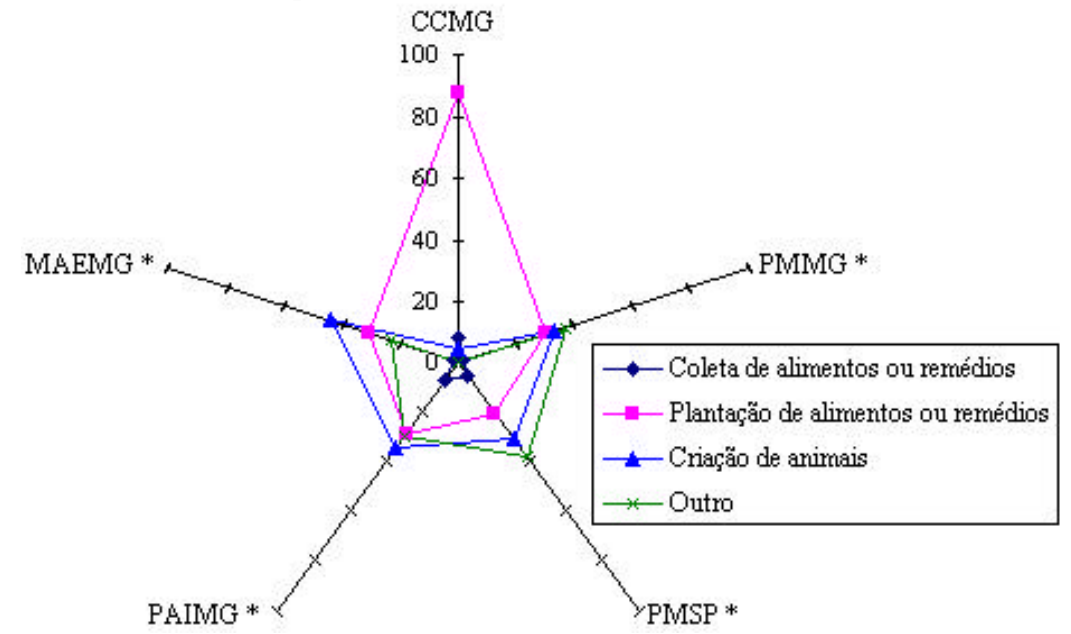

Figura 13- Distribuiçãodos pré-escolares quanto o tipo de uso de quintais. 


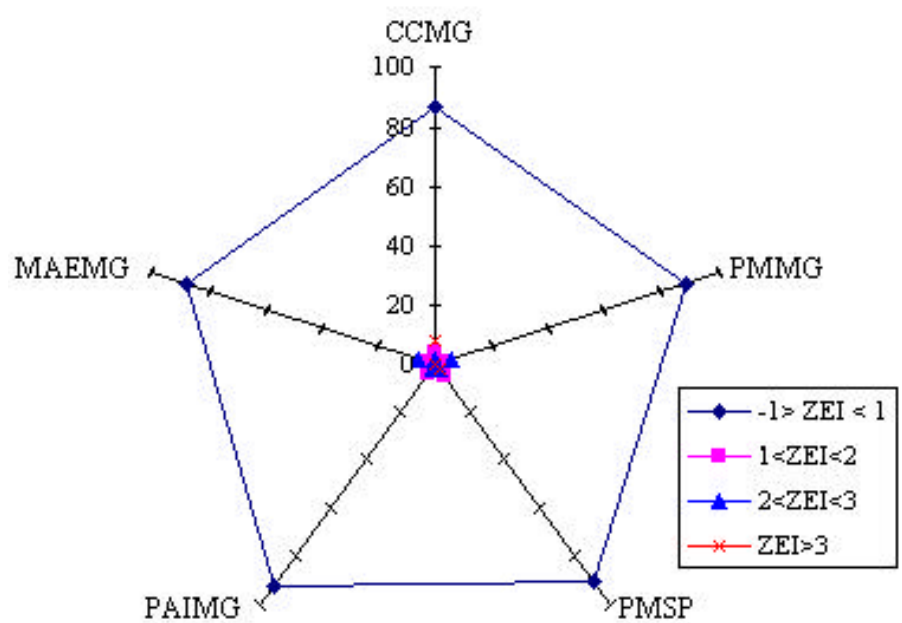

Figura 14 - Distribuição dos pré-escolares quanto ao escore z de estatura-pela-idade $(\mathrm{n}=2538)$

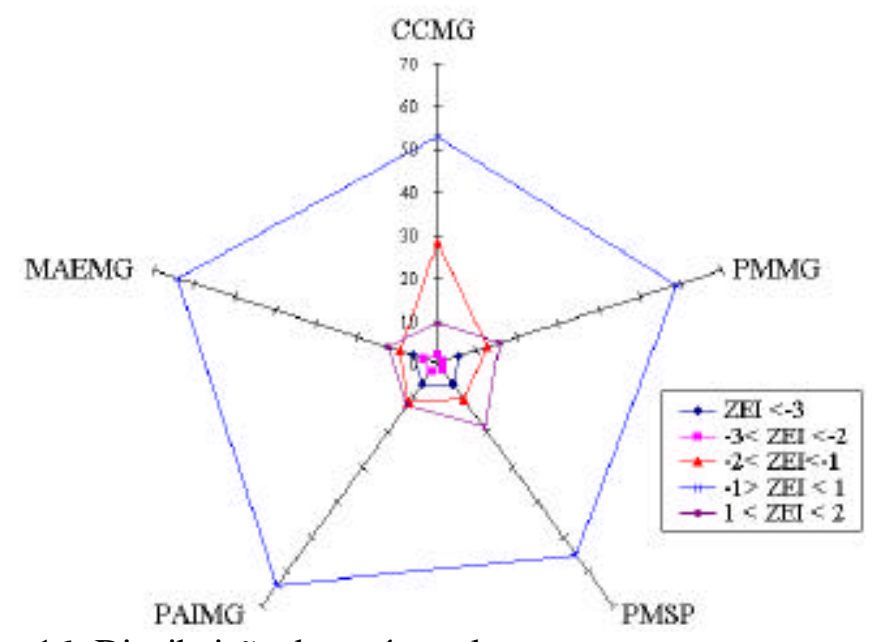

Figura 16- Distribuição dos pré-escolares quanto ao escore z de estatura-pela-idade (NCHS)

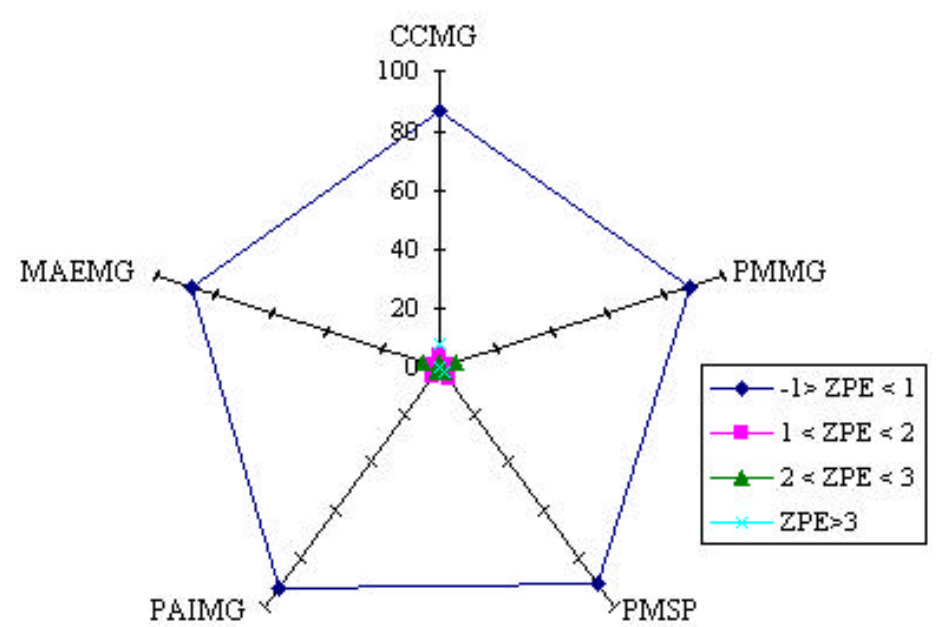

Figura 15- Distribuição dos pré-escolares quanto ao escore z de peso-pela -estatura $(n=2538)$

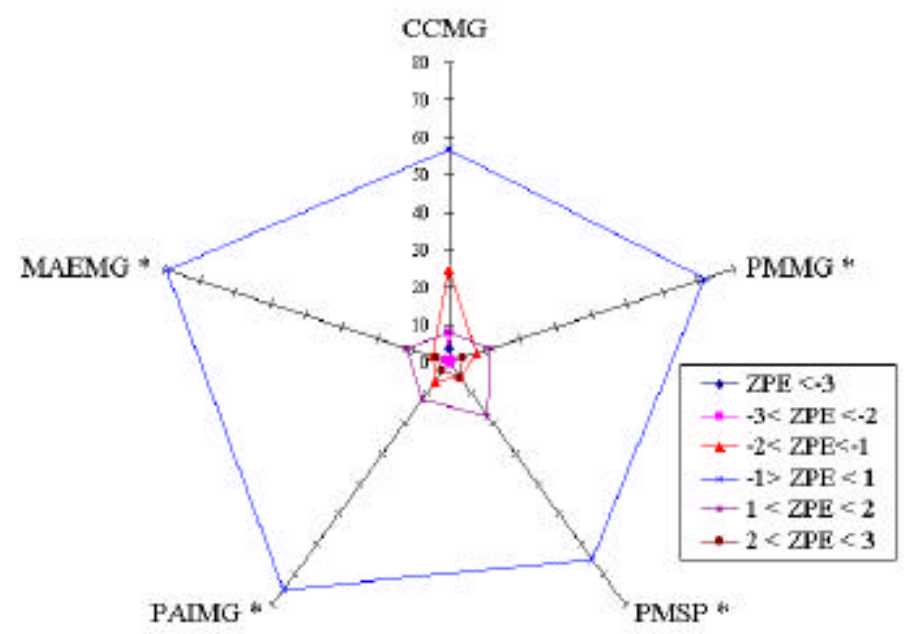

Figura 17- Distribuição dos pré-escolares quanto ao escore z de peso-pela -estatura (NCHS) 
Curva de ascimento dos estratos e do NCHS (sexo feminino)

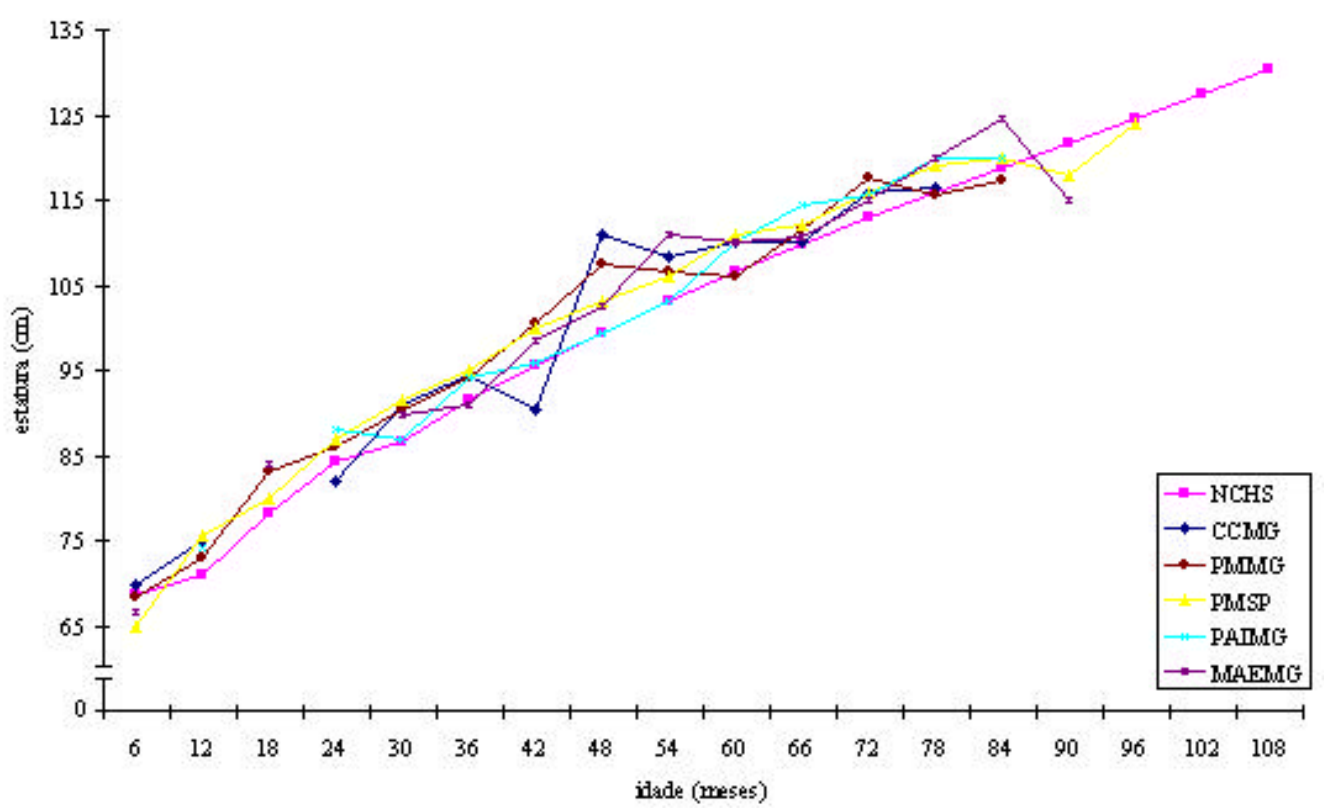

Figura 18- Comparação entre a curva padrão de referência do sexo feminino e os estratos estudados.

Curva de cresimento dos extratos e do NCHS (sexo masculino)

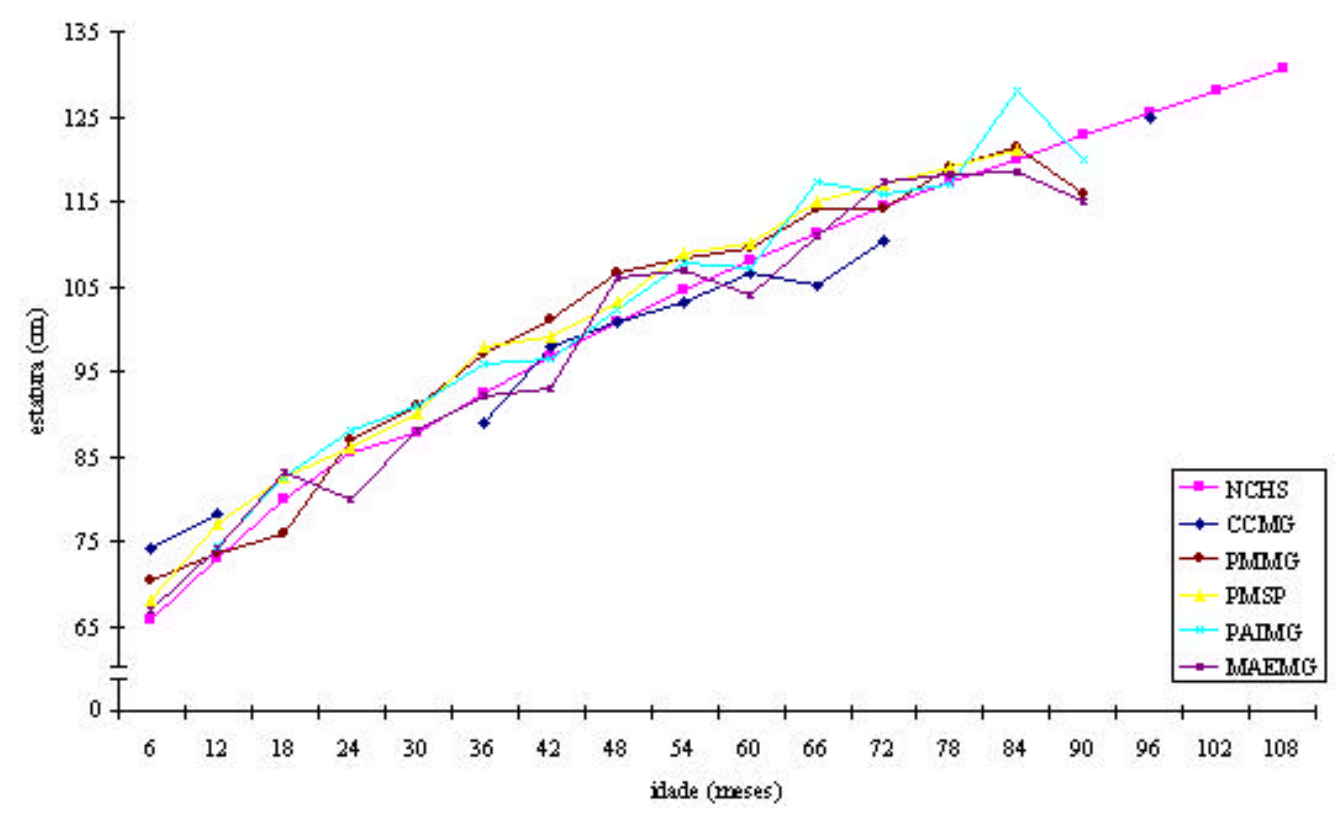

Figura 19- Comparação entre a curva padrão de referência do sexo masculino e os estratos estudados. 


\section{CONCLUSÕES}

Uma vez que a adaptação é um processo que sempre está sendo confrontado pelas condições do ambiente, que freqüentemente se modificam, as populações necessitam estar permanentemente se reajustando a essas novas condições ambientais. Entre as crianças filhas de migrantes, constatou que de acordo com o padrão NCHS, $91 \%$ e 86,9\% de indivíduos eutróficos respectivamente quanto à relação peso-pela-estatura e estatura-pela-idade. Desta forma, a migração da população de Novo Cruzeiro para Piracicaba, está sendo uma estratégia adaptativa bem sucedida;

> A predominância de melhores condições de infra-estrutura habitacional (água encanada, esgoto e eletricidade, habitações de alvenaria) como também a melhor renda familiar e a maior escolaridade materna, conferem melhor qualidade de vida ao habitantes do município de Piracicaba. Estes fatores também devem estar contribuindo para as altas taxas de eutrofia verificadas entre a população de crianças filhas de migrantes;

Casamentos entre indivíduos migrantes de MG e indivíduos não mineiros, contribuíram para aproximar as condições de vida desses casais daquelas superiores entre os estratos estudados, encontradas entre os casais constituídos por ambos os cônjuges nascidos em SP. Casais com ambos os cônjuges de MG, residentes em Piracicaba, encontram-se em condições melhores que as da 
população de origem, porém inferiores aos outros estratos residentes em Piracicaba.

As discrepâncias de casos de desnutrição entre as populações estudadas, conforme se empregou como referência para cada estrato o conjunto de crianças de todos os estratos (não indicando casos de desnutrição) ou a população NCSH (registrando casos de desnutrição), não comprometem a constatação de que todos os estratos avaliados encontram-se bem adaptados como população. Isto porque as frequiências esperadas de eutróficos em uma população saudável, são atingida em ambos os procedimentos. São necessárias, entretanto medidas junto às EMEI para se mitigar as ocorrências de desnutrição;

Existem casos de sobrepeso e obesidade nas crianças de famílias que residem em Piracicaba, não sendo registrados casos entre os pré-escolares de Novo Cruzeiro. Isto pode ser indicador das condições de vida mais modernizadas, em Piracicaba, freqüentemente associadas a supernutrição e sedentarismo. Estes hábitos podem ser caracterizados como fatores de risco aos quais estão expostos, as populações migrantes e seus descendentes.

Caso as motivações para migrar tenham sido condições de vida piores que a média da população do local de origem, constatamos que uma vez em Piracicaba, os descendendes dos migrantes atingiram condições nutricionais iguais às da maioria da população do local de origem.

Quanto à maioria dos outros indicadores estudados, as populações migrantes se encontram em condições mais favoráveis que as do local de origem, reforçando o fato de que na espécie humana a migração vem sendo uma das principais estratégias adaptativas, bem como o principal fator evolutivo para o homem moderno. 
ANEXOS 
ANEXO A. FICHA DE COLETA DE DADOS

\section{AVALIAÇÃo GENÉTICO-ANTROPOLÓGICA DE PRÉ - ESCOLARES}

Ficha ${ }^{\circ}$ : Data do preenchimento:

Escola ( ) creche ( ):

Escola ( ) creche ( ):
Data de ingres so na instituição: ______ Assiduidade (\%):
1. Dados da criança: classe:

Nome e sobrenomes:

Idade:

Sexo: M ( ) F ( )Data de nascimento:__________Local de nascimento:

Cor da pele: ( ) amarela ( ) branca ( ) negra ( ) mulata ( ) outra (qual ?):

Peso: ___ Estatura: ___ Data da medida:

2 . Dados dos pais: Nome e sobrenome do pai biológico:

Idade: ___ Local de nascimento (cidade e estado):

Nome e sobrenomes da mãe biológica:

Idade: L__ Local de nascimento (cidade e estado):

4. Perfil Sócio -econômico e Ecológico:

No mês passado, quanto ganharam as pessoas da família que trabalharam?

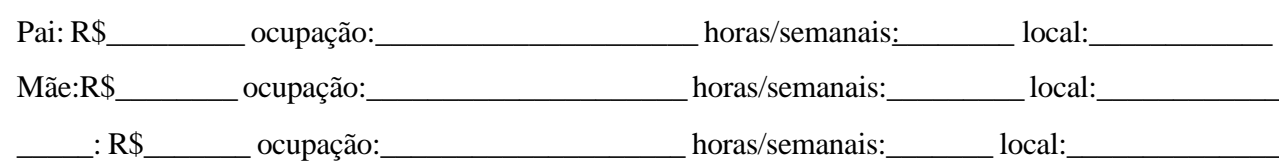

A família tem outra renda, além das já citadas ? R\$

Até que série estudou na escola?
Pai: série do grau
Mãe: série do grau por mês

Endereço da família:

\section{Bairro:}

Quais são as pessoas que moram na casa?

Pai: ( ) biológico ( ) adotivo ( ) não mora ( ) falecido

Mãe: (..) biológica ( ) adotiva ( ) não mora (..) falecida

Irmão(s): da criança: ___ $\left(\mathrm{n}^{\mathrm{o}}\right)$ Outros moradores: $\left(n^{\circ}\right)$

Número de cômodos:___ Número de moradores:

Tipo de casa: ( ) tijolos ( )papelão/lata
( ) madeira
( ) tijolo e madeira
( ) barro e madeira
( ) outro (Qual?)

De onde vem a água para beber?

( ) rede pública ( ) poço ( ) rio, córrego, lagoa ( ) outro

Há energia elétrica na casa? ( ) sim ( ) não Há esgoto? ( )sim ( ) não

Onde a família obtém seus alimentos, em quais locais?

Há quintal na residência? Qual seu tamanho?

Como o quintal é usado? (se preciso use o verso da folha)

( )fonte de coleta ou extração de alimentos ou remédios (quais?)

( )plantação de alimentos ou remédios (quais?)

( )criação de animais (quais?)

( )outra atividade (qual?)

Quem cuida do quintal ou trabalha nele?

5.Assinatura e cargo do responsável pelo preenchimento: 
ANEXO B. QUADRO DE CRECHES ESTUDADAS

\begin{tabular}{|c|c|c|c|}
\hline UNIDADE & Endereço & Bairro & TOTAL \\
\hline Piracicaba & & & 3996 \\
\hline Alvorada & R. Chiquinha Gonzaga, s/n & Alvorada I & 165 \\
\hline Balbo & R. Ipeúna, 40 & Parque Piracicaba & 187 \\
\hline Bartira & R. Adolfo Correia Dias, 41 & Jardim Bartira & 141 \\
\hline Borghesi & R. Pres. Washington Luis, 270 & Jardim Borghesi & 151 \\
\hline Caxambu & R. Paulo Brunns, 441 & Caxambu & 163 \\
\hline CECAP & R. Ibraim Nobre, 29 & CECAP II & 129 \\
\hline Dona Mimi & R. Campos Salles, 300 & Centro & 100 \\
\hline Eldorado & R. Candido Motta, 299 & Eldorado I & 145 \\
\hline Esplanada & R. José Pedro de Freitas, 132 & Esplanada & 167 \\
\hline Independência & R. Irmã Margarida Maria, 378 & Jardim Brasília & 115 \\
\hline Itapuã & R. Jacob Bergamin, 251 & Jardim Itapuã & 127 \\
\hline Jaragua & R. Prof. Mariano da Costa, 364 & Jardim Jaragua & 112 \\
\hline Jardim São Paulo & R. Felinto de Brito, s/n & Jardim São Paulo & 93 \\
\hline Joaninha Morgante & R. da Constituição, 151 & Paulicéia & 138 \\
\hline Jupia & R. João Eudóxio da Silva, s/n & Jupiá & 156 \\
\hline Kobayat & R. $\mathrm{N}^{\circ} 3,5$ & Kobayat Líbano & 111 \\
\hline Morada do Sol & R. Carolina Molon Neme, 100 & Morada do Sol & 110 \\
\hline Novo Horizonte & R. $\mathrm{N}^{\mathrm{o}} 1,233$ & Novo Horizonte & 140 \\
\hline Parque Orlanda & R. Jorge Anefolus, s/n & Parque Orlanda & 118 \\
\hline Paulicéia & R. D. Aurora, 369 & Paulicéia & 113 \\
\hline Petrópolis & R. Elvira Boyes, 358 & Petrópolis & 121 \\
\hline Planalto & R. Francisco Raia, s/n & Jardim Planalto & 138 \\
\hline Santa Terezinha & R. Nereu Ramos, 456 & Santa Terezinha & 50 \\
\hline São Francisco & R. Uchôa, 740 & São Francisco & 145 \\
\hline São José & Av. Presidente Wenceslau, 831 & São José & 114 \\
\hline São Miguel & R. Romeu de Carvalho, 200 & Castelinho & 60 \\
\hline Sol Nascente & R. José Tomazela, 80 & Jardim Itabirá & 127 \\
\hline Vila Cristina & R. Bom Pastor, 282 & Vila Cristina & 163 \\
\hline Vila Fátima & R. João Alves de Almeida, 357 & Vila Fátima & 165 \\
\hline Vila Sônia & R. Euclides Figueiredo, 79 & Vila Sônia & 192 \\
\hline Novo Cruzeiro & & & 60 \\
\hline Gente Miúda & S/ endereço & & 24 \\
\hline Novo Cruzeiro & $\mathrm{S} /$ endereço & & 36 \\
\hline TOTAL & & & 4056 \\
\hline
\end{tabular}




\section{REFERÊNCIAS BIBLIOGRÁFICAS}

ADAMS, C. Estratégias adaptativas de duas populações cablocas (Pará) aos ecossistemas de Várzea Estuarina e Estacional: uma análise comparativa. São Paulo, 2002. 373p. Tese (Doutorado) - Instituto de Biociências, Universidade de São Paulo.

AMBROSIO, 1.A., PERES, F.C., SALGADO, J.M. Diagnóstico dos produtos do quintal na alimentação das famílias rurais: Microbacia D' Água F, Vera Cruz. Informações Econômicas, v.26, n.7, p. 27-39, jul. 1996.

AMOROSO, M.C.M. Alimentação em um bairro pobre de Manaus, Amazonas. Acta Amazônica, v.11,n. 3, p. 1-43, set. 1981.

ANGELO, G.A. Produção de alimentos e manejo de quintais do distrito de Ferraz município de Rio Claro - SP. Rio Claro, 1999. 34p. Monografia (Graduação) Instituto de Biociências, Universidade Estadual Paulista "Júlio de Mesquita Filho".

ARAÚJO, K.C.; CARVALHO, C.M.R.G.; PAZ, S.M.R.S. Avaliação do consumo alimentar de vitamina A de crianças assistidas em creches comunitárias, Terezina (PI), Brasil. Revista da Sociedade Brasileira de Alimentação e Nutrição, v.22, p. 1-137 dez/2001.

BEGOSSI, A. Ecologia humana: um enfoque das relações homem - ambiente. Interciência, v.18, n.3, p. 121-132, maio-jun., 1993. 
BOGIN, B.; LOUCKY, J. Plasticity, political economy, and physical growth status of Guatemala Maya children living in the United States. American Journal of Physical Anthropology, v. 102, p. 17-32, 1997.

BRANDÃO, C.R. Plantar, colher e comer. Rio de Janeiro: Graal, 1981. 181p.

CAMARANO, A.A.; ABRAMOVAY, R. Êxodo rural, envelhecimento e masculinização no Brasil: panorama dos últimos 50 anos. Rio de Janeiro: IPEA (Textos para discussão n, 621), 1999. 23p.

CAMPBELL, M.L.; SANJUR, D. Single employed mothers and preschool child nutrition- na ecological analysis. Journal of Nutritional, v. 24, n. 2, p. 67-74, marabr., 1992.

CHADE, C.A.P. Avaliação da migração humana como estratégia adaptativa. Rio Claro, 2000. 64p. Monografia (Graduação) Faculdade de Ecologia, Universidade Estadual Paulista "Júlio de Mesquita Filho".

CHARNLEY, S. Environmentally- Displaced peoples and the cascade effect: lessons from Tanzania. Human Ecology, v. 25, n. 4, p. 593-618, 1997.

CLEVELAND, D.A.; SOLERI, D. Household gardens as a development strategy. Human Organization v. 46, n. 3, p. 259-270, 1987.

CORSO, A.C.; BOTELHO, L.J.; ZENI, L.A.Z.R.; MOREIRA, E.A.M. Sobrepeso em crianças menores de 6 anos de idade em Florianópolis, SC. Revista de Nutrição, v.16, n.1, p.21-28, jan./mar., 2003. 
CRUZ, G.F; SANTOS, R.S; CARVALHO, C.M.R.G.; MOITA, G.C. Avaliação dietética em creches municipais de Teresina, Piaú, Brasil. Revista de Nutrição, v.14, n.1, p. 21-32, jan./abr., 2001.

DEAN, A.G. Epi Info, version 6.04: a word processing, database, and statistics program for epidemiology on microcomputers (compact disc). Atlanta, Georgia: Centers for Disease Control and Prevention, 1994.

DURHAM, E. A caminho da cidade. São Paulo: Editora Perpectiva, 1984. 245p.

FERREIRA, J.P. (coord.) Municípios do Estado de Minas Gerais. Enciclopédia dos municípios brasileiros. v. 16, p.459. (Publicação comemorativa do $23^{\circ}$ aniversário do Instituto Brasileiro de Geografia e Estatística).

FRÉRE, N.; LUDOVINO, R.M.R.; MARTINS, P.F.S. Agricultura urbana em Belém/PA. Pará: APACC, 1999. 1v.

GARBANDELLA, A.M.D.; FRUTUOSO, M.F.P.; FRANCHI, C. Prática alimentar de adolescentes. Revista de Nutrição, v.12, n.1, p.55-63, jan./abr., 1999.

GUÉRIOS, R.F.M. Dicionário Etimológico de nomes e sobrenomes. São Paulo: Ed. Ave Maria, 1973. 231p.

FOLEY, R. Apenas mais uma espécie única - padrões de ecologia evolutiva humana. São Paulo: EDUSP, 1993. 363p.

GLANER, M.F.; NETO, C.S.P. Crescimento físico de moças rurais e urbanas. www.efdeportes.com/Revista Digital (28 nov. 2003). 
GUIMARÃES, R.G. A importância de quintais domésticos com relação à alimentação e renda familiar. Rio Claro, 1998. 40p. Monografia (Graduação) Instituto de Biociências, Universidade Estadual Paulista “Júlio de Mesquita Filho”.

HEALTH, R. Estudo associa idade materna ao risco de morte de bebês gêmeos. Revista Pediatrics. http://www.terra.com.br/saude/noticias/crianca/2002/12/htm (03 nov. 2003).

HOLLINGSHEAD, A.B. Migração e mobilidade. In: PIERSON, D. Estudos de Ecologia Humana. São Paulo: Martins, 1970. p. 219-236.

IGNEROVA, J.; BLAHA, P.; LHOTSKA, L. Physical growth of czech children and some socio-economic factors. Journal Human Ecology, v. 9, n.3, p. 227-231, 1998.

KASSOUF, A.L.A demanda as saúde pública no Brasil por região e setor. Pesquisa e Planejamento Econômico, v.24, n.2, p. 235-259, ago.1994.

KATER, M.G.L. Adaptação humana em populações de baixa renda. In: JORNADA BRASILEIRA DE ECOLOGIA HUMANA, 2., Campinas: s.ed., p. 49-53, 1981.

KIM, S.W. Physical growth of Aymara chidren in a herding community of the Bolivian Altiplano. Journal Human Ecology, v.20, p. 217-228, 1991.

KORMONDY, E.; BROWN, E. Fundamental of Human Ecology. New Jersey: Prentice Hall, 1998. 503p.

MACE, R. Evolutionary ecology of human life history. Animal Behaviour, v.59, p.110, 2000. 
MAESTRO, V. Padrão alimentar e estado nutricional: caracterização de escolares no município paulista. Piracicaba, 2002. 116p. Dissertação (Mestrado) - Escola Sperior de Agricultura “Luiz de Queiróz”, Universidade de São Paulo.

MAHAN, L.K.; ARLIN, M.T. Krause: alimentos, nutrição e dietoterapia. 8.ed. São Paulo: Rocca, 1994. 957p.

MALINA, R.B. Crescimento de crianças latino americanas: comparação entre os aspectos sócio-econômicos, urbano-rural, e tendência secular. Revista Brasileira de Ciência e Movimento, v.4, p. 46-75, 1990.

MALUF, A. Piracicaba - passado e presente. Piracicaba: Prefeitura de Piracicaba. 1988. 208p.

MARCONDES, E. Atividade física e crescimento. Clínica Pediátrica, v.7, p. 51-60, 1985.

MARTINE. G. O mito da explosão demográfica. Ciência hoje, v.9, n.51, p. 28-35, 1989.

MARTINS, I.S.; FISCHER, F.M.; OLIVEIRA, D.C. et al. Crescimento e trabalho de estudantes de ensino fundamental e médio em São Paulo, Brasil. Revista de Saúde Pública, v.36, n.1, p.19-25, 2002.

MIGLIANO, A.B. Amazônia: interações ecológicas e estratégias adaptativas dos cablocos do Médio Solimões. São Paulo, 2000. 183p. Dissertação - (Mestrado) Instituto de Biociências, Universidade de São Paulo. 
MOLINA, M.I.G. Migração rural-rural: análise sociológica da migração dos parceleiros do Projeto Iguatemi. Piracicaba, 1970. 188p. Tese (Doutorado)- Escola Superior de Agricultura "Luiz de Queiroz", Universidade de São Paulo.

MOLINA, S.M.G. Avaliação do desenvolvimento físico de pré-escolares e escolares de Piracicaba, SP. Campinas,1997. 247p. Tese (Doutorado) - Instituto de Biologia, Universidade Estadual de Campinas.

MONTEIRO, C.A.; CONDE, W.L. Tendência secular do crescimento pós-natal na cidade de São Paulo (1974-1996). Revista de Saúde Pública, v.34, n.36, p. 41-51, dez. 2000a

MONTEIRO, C.A.; CONDE, W.L. Tendência secular da desnutrição e da obesidade na infância na cidade de São Paulo (1974-1996). Revista de Saúde Pública v.34, n.36, p. 52-61, dez. 2000b

MORAN, E.F. A Ecologia humana das populações da Amazônia. Petrópolis: Vozes, 1990. 367p. (Coleção Ecologia \& Ecosofia).

MORAN, E.F. Adaptabilidade humana: uma introdução a antropologia ecológica. São Paulo: EDUSP,1994. 445p. (Coleção Ponta).

MOTA, E.L.A.; FRANCO, A.L.S.; MOTTA, M.C. Migração, estresse e fatores psicosssociais na determinação da saúde da criança. Revista de Psicologia: Reflexão e Crítica, v.12, n.1. p. 119-132, 1999.

NASCIMENTO, A.P.B.; PASINATO, R.; PONTILI, R.M.; MOLINA, S.M.G. Hábitos alimentares no meio urbano: análise comparativa de um grupo de adolescentes e adultos da cidade de Piracicaba, SP. (compact disc) IN: ENCONTRO DE PÓSGRADUAÇÃO DA UNIVAP, 3., São José dos Campos: s.ed., 2003a. 
NASCIMENTO, A.P.B.; MARTINS, J.S.; SILVA, M.R.; MOLINA, S.M.G. A importância do uso de quintais para as populações humanas (compact disc). IN: ENCONTRO DE PÓS-GRADUAÇÃO DA UNIVAP, 3., São José dos Campos: s.ed. 2003 b.

NATIONAL CENTER FOR HEALTH STATISTICS. Center for Disease Control and Prevention. Growth charts. http://www.cdc.gov (10 ago 2003)

NUNES, R. Migração: considerações teóricas e debates atuais. IN: ENCONTRO NACIONAL DE GEÓGRAFOS, 13.,. João Pessoa, 2002. Anais. João Pessoa:UFMG, 2002. 1v.

PERES, M.T.M. O colono de cana na modernização da Usina Monte Alegre: Piracicaba (1930-1950). São Paulo, 1990. 142p. Dissertação (Mestrado) - Faculdade de História, Pontífica Universidade Católica.

PERRRONI, C. Desnutrição em Piracicaba supera índice da OMS. Jornal de Piracicaba. Piracicaba, 28 set. 2003. p.5.

RAPOPORT, A.; PICCININI, C.A. O ingresso de bebês e crianças pequenas à creche: alguns aspectos críticos. Revista de Psicologia: Reflexão e Crítica, v.14, n.1, p.81$95,2001$.

RUFFO, P. Nutrição na adolescência. O mundo da Saúde, v.21, n.2, p.86-89, 1997.

SALDANHA, P.H. Efeito da migração sobre a estrutura genética de uma comunidade Paulista. São Paulo: FFCL-USP, 1968. 226p. 
SEPP, H; ABRAHAMSON, L.; LENNERNÄS JUNBERGER, M.; RISVIK, E. The contribution of groups to the nutrient intake and food pattern among pre-school children. Food Quality and Preference, v.13, p. 107-116, 2002.

SHIVA, V., DANKELMAN, I. As mulheres e a diversidade biológica: lições do Himalaia indiano In: GAIFAMI, A. (org). Cultivando a diversidade: recursos genéticos e segurança alimentar local. Rio de Janeiro: AS-PTA, 1994. p. 35-40.

SICHIERI, R.; MATHIAS, T.; MOURA, A.S. Estado nutricional de crianças e relações de trabalho da família em uma comunidade rural do Paraná. Cadernos de Saúde Pública, v.9, n.1, p.28-35, 1993.

SILVA, M.V.; OMETTO, A. M. H.; FURTUOSO, M. C. O.; PIPITONE, M. A. P.; STURION, G. L. Acesso a creche e estado nutricional das crianças brasileiras: diferenças regionais, por faixa etária e classes de renda. Revista de Nutrição, v.13, n.3, p.193-199, set./dez., 2000.

SOARES, N. T. Um novo referencial antopométrico de crescimento: significados e implicações. Revista de Nutrição, v.16, n.1, p.93-104, jan./mar., 2003.

SOARES, N. T.; GUIMARÃES, A. R. T.; SAMPAIO, H. A. C.; ALMEIDA, P. C.; COELHO, R. R. Estado nutricional de lactentes em áreas periféricas de Fortaleza. Revista de Nutrição, v.13, n.2, p. 99-106, maio/ago., 2000.

TOJO, R.; LEIS, R.; RECAREY, D.; PAVÓN, P. Dietary habits of preschool and schoolaged children: health risks and strategies for intervention. In: BALLABRIGA, A. Feeeding fom toddlers to adolescence. Philadelphia: Lippincott-Raven, 1996. cap.6, p.93-115. (Nestlé Nutrition Workshop Series, 37) 
VANNUCCHI, H. (Coord.); MENEZES, E. W.; CAMPANA, A. O.; LAJOLO, F. M. Aplicações das recomendações nutricionais adaptadas à população brasileira. Ribeirão Preto: SBAN, 1990. 156p. (Cadernos de Nutrição, 2)

WALKER, G.A. Common Statistical Methods for Clinical Research with SAS. Examples, Cary, NC: SAS Institute, 1997. 315p. 